\title{
Breast cancer related lymphedema
}

Citation for published version (APA):

Lopez Penha, T. (2016). Breast cancer related lymphedema: studies on prevalence, effect on quality of life, and microsurgical treatment options. [Doctoral Thesis, Maastricht University]. Maastricht University. https://doi.org/10.26481/dis.20160204tl

Document status and date:

Published: 01/01/2016

DOI:

10.26481/dis.20160204tl

Document Version:

Publisher's PDF, also known as Version of record

\section{Please check the document version of this publication:}

- A submitted manuscript is the version of the article upon submission and before peer-review. There can be important differences between the submitted version and the official published version of record.

People interested in the research are advised to contact the author for the final version of the publication, or visit the DOI to the publisher's website.

- The final author version and the galley proof are versions of the publication after peer review.

- The final published version features the final layout of the paper including the volume, issue and page numbers.

Link to publication

\footnotetext{
General rights rights.

- You may freely distribute the URL identifying the publication in the public portal. please follow below link for the End User Agreement:

www.umlib.nl/taverne-license

Take down policy

If you believe that this document breaches copyright please contact us at:

repository@maastrichtuniversity.nl

providing details and we will investigate your claim.
}

Copyright and moral rights for the publications made accessible in the public portal are retained by the authors and/or other copyright owners and it is a condition of accessing publications that users recognise and abide by the legal requirements associated with these

- Users may download and print one copy of any publication from the public portal for the purpose of private study or research.

- You may not further distribute the material or use it for any profit-making activity or commercial gain

If the publication is distributed under the terms of Article $25 \mathrm{fa}$ of the Dutch Copyright Act, indicated by the "Taverne" license above, 


\section{Breast Cancer Related Lymphedema}

Studies on prevalence, effect on quality of life, and microsurgical treatment options 
Cover art: Stark Artworks, www.stark-artworks.com Printing: CPI Koninklijke Wöhrmann ISBN: 978-94-6203-970-4

(C) Copyright: T. Lopez Penha, Maastricht 2015

The publication of this thesis was financially supported by: Maastricht University Medical Center, Nederlandse Vereniging voor Plastische Chirurgie, Junior Vereniging voor Plastische Chirurgie, Clinical Trial Center Maastricht B.V., and Allergan.

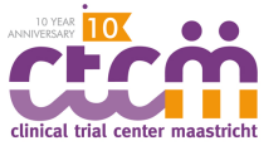

Their support is gratefully acknowledged. 


\title{
Breast Cancer Related Lymphedema
}

\section{Studies on prevalence, effect on quality of life, and microsurgical treatment options}

\begin{abstract}
Proefschrift
ter verkrijging van de graad van doctor aan de Universiteit Maastricht, op gezag van de Rector Magnificus, Prof. dr. L.L.G. Soete, volgens het besluit van het College van Decanen, in het openbaar te verdedigen op donderdag 4 februari 2016 om 16:00 uur
\end{abstract}

door

\section{Tiara Rebecca Lopez Penha}

Geboren op 11 maart 1986 te St.Maarten, Nederlandse Antillen 


\section{Promotores}

Prof. dr. M.F. von Meyenfeldt

Prof. dr. R.R.W.J. van der Hulst

\section{Co-promotores}

Dr. E.M. Heuts

Dr. A.C. Voogd

\section{Beoordelingscommissie}

Prof. dr. R.J.E.M Smeets (voorzitter)

Prof. dr. J.A. Roukema (Twee Steden ziekenhuis)

Prof. dr. V.C.G. Tjan-Heijnen

Prof. dr. D. Ulrich (UMC St. Radboud)

Dr. J.C.M. Veraart 


\section{For Brigitte}

"Don't be dismayed at good-byes.

A farewell is necessary before you can meet again.

And meeting again, after moments or lifetimes,

Is certain for those who are friends."

- Richard Bach 


\section{Contents}

Chapter 1 General introduction and thesis outline

Chapter 2 The prevalence of lymphedema minimally five years after breast cancer treatment.

Chapter 3 The quality of life in long long-term breast cancer survivors with breast cancer related lymphedema

Chapter 4 Biomechanical properties of the skin in breast cancer patients with upper-limb lymphedema compared to healthy individuals

Chapter 5 Reduced prevalence of breast cancer related lymphedema in patients with reconstructive breast surgery

Chapter 6 Quality of life of patients with breast cancer related lymphedema and breast reconstruction

Chapter 7 Microsurgical techniques for the treatment of breast cancer related lymphedema: a systematic review.

Chapter 8 The changing role of axillary treatment in breast cancer: who will remain at risk for developing arm morbidity in the future?

Chapter 9 General discussion

Summary

Summary (in Dutch)

Valorization

Acknowledgements (in Dutch)

Scientific output

About the author 


\section{List of abbreviations}

$\begin{array}{ll}\text { ADL } & \text { activity of daily living } \\ \text { ALND } & \text { axillary lymph node dissection } \\ \text { ARM } & \text { axillary reverse mapping } \\ \text { BCRL } & \text { breast cancer related lymphedema } \\ \text { BIS } & \text { bioimpedance spectroscopy } \\ \text { BMI } & \text { body mass index } \\ \text { BR } & \text { breast reconstruction } \\ \text { CDT } & \text { complex decongestive therapy } \\ \text { CG } & \text { compression garment } \\ \text { Chtx } & \text { chemotherapy } \\ \text { DIEP-flap } & \text { deep inferior epigastric perforator flap }\end{array}$

EORTCEuropean organization of research and treatment for cancer

HRQOL health related quality of life

Htx hormone therapy

IFP inguinal fat pad

IPC intermittent pneumatic compression

LDM-flap latissimus dorsi myocutaneous flap

LN lymph nodes

LYMPHA lymphatic microsurgical preventative healing approach

LVA lymphaticovenous anastomoses

MLD manual lymphatic drainage

MLVI microsurgical lymphaticovenous implantation

msTRAM-flap muscle sparing tranverse rectus abdominus myocutaneous flap

QOL quality of life

Rtx radiation therapy

SLNB sentinel lymph node biopsy

SOAC sum of arm circumference

TDC tissue dielectric constant

Ue skin extensibility

Uv delayed distension

Uf final deformation

Ur immediate retraction

Ua final retraction

WLSE wide local scar excision 


\section{Chapter 1}

\section{General introduction}


General introduction 


\section{General introduction}

Approximately one in eight women in the Netherlands will develop breast cancer during her lifetime. ${ }^{1}$ Fortunately, due to the increased awareness among women about the early signs of breast cancer, implementation of population based screening programs and advancements in treatment options, a large proportion of these women will survive the initial treatment phase. The fact that more women are successfully being treated for breast cancer has caused a shift of attention towards the period after active cancer treatment, also known as the period of survivorship. ${ }^{2}$ Survivorship refers to the period following active cancer therapy, the period in which the late effects of treatment occur. ${ }^{3}$ In saying this, the management of the late effects of breast cancer treatment is imperative for maintaining an acceptable long-term quality of life. Of the late effects of breast cancer treatment, lymphedema is one of the most underestimated and debilitating morbidities. ${ }^{4-6}$ Between $6 \%$ and $43 \%$ of breast cancer survivors develop breast cancer related lymphedema (BCRL). ${ }^{7,8}$ The large variability in the reported figures of BCRL is explained by differences in the definitions used and by differences in treatment and risk factors between populations. Adjuvant treatment for breast cancer, such as axillary surgery, radiation and chemotherapy can cause damage to the lymphatic system of the upper-limb resulting in lymph fluid stasis and an increased limb volume. 9, 10 This limb swelling may present with symptoms of heaviness, tightness and pain sensations. Furthermore, loss of normal upper-limb function and range of motion can be experienced. The negative psychological effects brought on by the impairments of activities of daily life and reduced limb aesthetics constitute an additional burden. ${ }^{5,11,12}$ An overview of the important aspects of BCRL such as the etiology, pathophysiology, diagnostic techniques and treatment options will be given in this chapter, as well as the aims of this thesis, following from this overview. The onset of BCRL can occur any time after primary cancer treatment, but in most cases develops in the first four years after treatment. ${ }^{13}$ The following risk factors are associated with the development of BCRL: the extent of breast/axillary surgery, adjuvant radiation, adjuvant chemotherapy, the 
number of positive lymph nodes, treatment on the side of the dominant limb, older age and obesity. ${ }^{14-16}$

\section{Pathophysiology}

Basic knowledge on the working mechanism of the lymphatic system is necessary in order to understand the pathophysiology of BCRL. The lymphatics of the upper extremity are divided into superficial and deep vessels, which form two communicating systems. The superficial (epifascial) vessels transport lymph fluid from the skin, subcutis and structures therein. Whereas the deep system (subfascial) transports lymph fluid from muscles, fascia, nerves, joints, ligaments and bones. ${ }^{17}$ Moreover, the axillary lymph nodes receive lymph fluid from the upper extremity, supra-umbilical anterolateral body wall and part of the breast. ${ }^{17}$ Lymph fluid transport is determined by interstitial pressure in extra cellular spaces, which in turn is influenced by three important factors: by the contraction of subjacent skeletal muscles, arterial pulsation near lymphatic vessels and by contraction of smooth muscle cells in the lymphatic wall stimulated by the sympathetic nervous system. ${ }^{18}$ Lymph vessels, like other vascular structures, are trilaminar and consist of ${ }^{19}$ :

- An internal membrane, containing endothelial cells;

- A medial membrane, containing varying proportions of smooth muscle cells;

- An outer membrane, extra cellular matrix containing fine bundles of collagen and elastin fibers.

The limb swelling that is seen in BCRL is the result of a combination of an accumulation of protein rich fluid in the interstitial tissues, tissue fibrosis, fat deposition and thickening of the skin. ${ }^{17}$ Its chronic and progressive nature makes BCRL an intricate disease. The International Society of Lymphology (ISL) has developed a widely used and accepted staging system based on clinical assessment. The ISL staging system consists of three stages each representing a phase in disease progression (Table 1). ${ }^{20}$ 
Table 1: International Society of Lymphology staging system

\begin{tabular}{ll}
\hline 0 & Subclinical stage; swelling not evident despite impaired lymph transport \\
I & $\begin{array}{l}\text { Early accumulation of fluid which subsides with limb elevation, pitting may } \\
\text { occur }\end{array}$ \\
II a & Limb elevation rarely reduces tissue swelling, pitting is manifest \\
II b & Excess fat and fibrosis supervene, the limb may or may not pit \\
III & Lymphostatic elephantiasis \\
\hline
\end{tabular}

Damage to the local (breast/axilla) lymphatic system causes obstruction of normal lymph flow, which leads to lymph stasis and an increase of pressure in the collecting lymphatics. ${ }^{21}$ The exact histopathological changes that occur as a result of the lymphatic outflow impairment are yet to be fully elucidated. However, the few studies available focusing on the ultra-structural aspects of edema, have given us some insight. ${ }^{18,21-26}$ As a reaction to tissue injury an inflammatory process is triggered, activating lymphocytes and leukocytes that release cytokines. Degeneration of media smooth muscle cells and the proliferation of collagen fibers further impair lymph fluid drainage. ${ }^{21,24-26}$ The excessive deposition of extracellular matrix, especially collagens, is the complex tissue response that is called fibrosis. ${ }^{22}$ In case of inadequate disease management, lymphedema progresses: arm-swelling transforming from a predominantly fluid encompassing entity to fibrosis and fat. ${ }^{24} \mathrm{BCRL}$ in its late chronic phase is irreversible and accompanied by more symptoms and physical impairments. The time-line in which disease progression takes place, remains unknown.

\section{Measurement techniques}

Part of the wide range in the reported incidence and prevalence rates of lymphedema is due to the lack of a uniform measurement protocol and criteria for diagnosis. ${ }^{27-44}$ Moreover, the different measurement techniques have considerable intra- and inter-rater variability. The affected limb is usually 
compared to the non-affected side, irrespective of the type of measurement technique. Measurement techniques most commonly used are the following:

Water displacement technique " $^{31}$ : this is considered the current "golden standard", in which limb volume is assessed using an inverse water displacement volumeter. The criteria for the diagnosis of BCRL using this technique is a difference in limb volume of $200 \mathrm{ml}$ or more between the affected and non-affected contralateral limb.

Circumferential limb measurement ${ }^{27,28}$ : here a tape measure is used to assess limb girth at predetermined intervals along the limb. A difference between the affected and non-affected contralateral arm of $2 \mathrm{~cm}$ or more at any measured point is considered clinically significant limb swelling.

Optoelectronic perometry ${ }^{35-37}$ : here infrared laser technology is used to assess limb volume. The contralateral unaffected limb as a comparison is also used for lymphedema diagnosis, a volume difference of $10 \%$ or $200 \mathrm{ml}$ or more.

However, the above-mentioned techniques used for assessing limb volume represent an indirect measurement of BCRL. These techniques do not take tissue composition into account, and thus make no distinction between extraand intracellular fluid when measuring limb volume. Furthermore, volume assessment does not give an indication of the severity of the BCRL.

Bioimpedance spectroscopy (BIS) is an alternative method for assessing $B C R L$ that uses skin electrodes to pass a small alternating current through a limb and measures the impedance to the flow of this current. ${ }^{36,38,39}$ The fluids in the body conduct electrical current and as fluid volume increases, impedance to current flow decreases. BIS therefore gives a measure that correlates with the amount of extracellular fluid.

Disease specific questionnaires can be used to diagnose BCRL and also measure the consequences of the symptoms on the quality of life. ${ }^{27,43,44}$ Patient reported signs and symptoms are often the first indication of clinically relevant lymphedema. ${ }^{27}$ The symptoms women with BCRL may present with include: tingling, pain heaviness, reports of poor clothing fit, or even as minimal as the limb "feels different". ${ }^{27,43}$ Examples of disease specific questionnaires are the Wesley Clinic Lymphedema Scale (WCLS) ${ }^{45}$, the Freiburg Life Quality Assessment (FLQA-1) ${ }^{46}$, the Upper Limb Lymphedema 27 (ULL-27) ${ }^{47}$ and the Lymphedema, Functioning, Disability and Health (Lymph-ICF) ${ }^{48}$. 


\section{Treatment}

The current standard of treatment for BCRL is a combination of different methods of conservative therapy, also known as complex decongestive therapy $(C D T)^{49} \mathrm{CDT}$ incorporates two stages of treatment. The first treatment phase entails: skincare, exercises aimed at improvement of mobility/range of motion in the shoulder, elbow or wrist joints, compression therapy through multi-layered bandaging and manual lymphatic drainage (MLD). Moreover, MLD is the manual stretching and pressure application to the skin in slow, rhythmic and circular motions to stimulate the activity in the lymphatic vessels to increase lymphatic fluid drainage. In the second treatment phase, CDT is aimed at maintenance of the achieved limb volume/ circumference reduction through compression therapy in the form of therapeutic elastic stockings for the arm. Skincare, mobility exercises and MLD is continued in this phase if needed. In addition to $\mathrm{CDT}$, other methods can be applied, including intermittent pneumatic compression (IPC) and kinesio taping.

IPC is a device with pneumatic cuffs connected to a pump that mimic the naturally occurring muscle pump effect of muscles contracting around peripheral lymphatics. ${ }^{49}$

Kinesio taping is a method used mostly by athletes, is used in some instances for BCRL with the hypothesis that it can help improve lymphatics and reroute lymph in superficial lymphatic vessels. ${ }^{50,51}$

These two additional therapeutic methods are applied dependent on the preference of the lymph therapist, as the literature contains no evidence on the most effective combination of treatments.

Conservative therapy is initially aimed at alleviating symptoms without curative intent, which for most patients means lifelong treatment. Dutch breast cancer treatment guidelines suggest a three-month treatment period with compression stockings in case of a 5-10\% limb volume increase. ${ }^{45}$ Adding compression therapy to complete decongestive therapy could induce significant limb volume reduction. When maximum limb volume reduction is achieved compression stockings should be worn for the rest of the patient's life. A systematic review evaluating the effects of conservative and dietary interventions for BCRL demonstrated compression garments or compression bandaging to reduce limb lymphedema volume, with a reported percentage reduction ranging from 17\% 
to $60 \% .{ }^{48}$ Furthermore, a statistically significant beneficial effect was found for the addition of MLD to compression therapy for reducing upper extremity lymphedema volume.

Surgical intervention to treat BCRL in the form of lymphatic microsurgery is mentioned in Dutch lymphedema guidelines, although the exact role of such interventions is not made clear as the current evidence base for the effectiveness of Lymphatic microsurgery as treatment for BCRL is ambiguous. ${ }^{53-61}$ More importantly, no prospective randomized trials have been published as of yet.

\section{Aim and outline of this thesis}

The main purpose of the studies described in this thesis is to gain more insight on $B C R L$ in order to substantiate the need for improvement of its management amongst breast cancer survivors.

Firstly, in Chapter 2 we investigated the prevalence of BCRL in a group of breast cancer survivors 5 years after initial treatment, using three different measuring methods. Knowledge on how lack of uniform criteria for the measurement of BCRL may affect its prevalence is essential for interpreting current literature on BCRL.

Next, in Chapter 3 the quality of life of women with BCRL was assessed in the same cohort of breast cancer survivors. All these women were treated in the sentinel lymph node biopsy era.

In Chapter 4 the biomechanical properties of the skin of the arm of women with BCRL were compared with the properties of the skin of their healthy arm. This was done to determine how BCRL affects the elasticity, visco-elasticity and level of hydration of the skin.

The role of breast reconstruction as a possible risk factor or protective factor for the development of BCRL in women after mastectomy is explored in Chapter 5.

In Chapter 6 we assessed if the improvement in quality of life, which is usually seen in breast cancer survivors after reconstructive breast surgery, was influenced by the presence of BCRL. 
Chapter 7 gives an overview of studies on the effectiveness of different microsurgical treatment options for BCRL.

In Chapter 8 an overview of the current changes taking place in axillary staging and treatment of breast cancer patients is given with the aim to identify patients with a high risk of developing morbidity in the arm and/or shoulder.

Chapter 9 describes a strategy to improve early detection and the treatment of BCRL.

Chapter 10 concludes this thesis with a general discussion, including conclusions and approvals for clinical practice and future research. 


\section{Reference}

1. RIVM; http://rivm.nl

2. Ganz PA, Hahn EE. Implementing a survivorship care plan for patients with breast cancer. J Clin Oncol 2008. 26(5):759- 67.

3. NCCS; http://canceradvocacy.org

4. Ahmed RL, Prizment A, Lazovich D, Schmitz KH, Folsom AR. Lymphedema and quality of life in breast cancer survivors: the lowa Women's Health Study. J Clin Oncol 2008; 26(35): 568996.

5. Oliveri JM, Day JM, Alfano CM, Herndon JE, 2nd, Katz ML, Bittoni MA, et al. Arm/hand swelling and perceived functioning among breast cancer survivors 12 years post-diagnosis: CALGB 79804. J Cancer Surviv. 2008; 2(4): 233-42.

6. Nesvold IL, Reinertsen KV, Fossa SD, Dahl AA. The relation between arm/shoulder problems and quality of life in breast cancer survivors: a cross-sectional and longitudinal study. J Cancer Surviv. 2011; 5(1): 62-72.

7. Petrek JA, Heelan MC. Incidence of breast carcinoma-related lymphedema. Cancer 1998;83(12 suppl): $2776-81$

8. Rietman JS, et al. Late morbidity after treatment of breast cancer in relation to daily activities and quality of life: a systematic review. Eur J Surg Oncol 2003; 29(3): 229-38.

9. Richtlijn mammacarcinoom 2012.

10. Ahmed RL, Schmitz KH, Prizment AE, Folsom AR. Risk factors for lymphedema in breast cancer survivors, the lowa Women's Health Study. Breast Cancer Res Treat 2011 Jul 15.

11. Cachaj A, Malyszczak K, Pyszel K, Lukas J, Tarkowski R, Pudelko M et al. Physical and psychological impairments of women with upper limb lymphedema following breast cancer treatment. Psychooncology. 2010;19(3): 299-305.

12. Voogd AC, Ververs JM, Vingerhoets AJ, Roumen RM, Coebergh JW, Crommelin MA. Lymphoedema and reduced shoulder function as indicators of quality of life after axillary lymph node dissection for invasive breast cancer. BR J Surg. 2003; 90(1):76-81.

13. Petrek JA, Heelan MC. Incidence of breast carcinoma-related lymphedema. Cancer. 1998;83(12 suppl): 2776-81.

14. Tsai RJ, Dennis LK, Lynch CF, Snetselaar LG, Zamba GK, Scott-Conner C. The risk of developing arm lymphedema among breast cancer survivors: a meta-analysis of treatment factors. Ann Surg Oncol.2009;16(7):1959-72.

15. Ashikaga T, Krag DN, Land SR, Julian TB, Anderson SJ, Brown AM et al. Morbidity results from the NSABP B-32 trial comparing sentinel lymph node dissection versus axillary dissection. J Surg Oncol 2010;102(2):111-8.

16. Giuliano AE, Hunt KK, Ballman KV, Beitsch PD, Whitworth PW, Blumencranz PW et al. Axillary dissection vs no axillary dissection in women with invasive breast cancer and sentinel node metastasis: a randomized clinical trial. JAMA 2011. 305(6): 569-75.

17. Stanton AWB, Modi S, Mellor RH, Levick JR, Mortimer PS. Recent advances in breast cancerrelated lymphedema of the arm: Lymphatic pump failure and predisposing factors. Lymphat Res Biol 2009;7:29-45.

18. Koshima I, Kawada S, Moriguchi T, Kajiwara Y. Ultrastructural observations of lymphatic vessels in lymphedema in human extremities. Plastic and reconstructive surgery 1996;97(2):397-405; discussion 6-7.

19. Arkill KP, Moger J, Winlove CP. The structure and mechanical properties of collecting lymphatics vessels: an investigation using multimodal nonlinear microscopy. J Anat 2010;216(5): 547-55.

20. International Society of Lymphology. The diagnosis and treatment of peripheral lymphedema. 2009 concensus document of the international society of lymphology. Lymphology 2009;42 
(2):51-60.

21. Mihara M, Hara H, Hayashi $\mathrm{Y}$, Narushima M, Yamamoto T, Todokoro T et al. Pathological steps of Breast- Cancer Related Lymphedema: Histological changes in the collecting lymphatic vessels after lymphadenctomy. PLoS ONE 2012; 7(7): e41126.

22. Trojanowska M, LeRoy EC, Eckes B, Krieg T. Pathogenesis of fibrosis: type 1 collagen and the skin. Journal of molecular medicine 1998;76(3-4):266-74.

23. Nagase T, Gonda K, Inoue K, Higashino T, Fukuda N, Gorai K, et al. Treatment of lymphedema with lymphaticovenular anastomoses. International journal of clinical oncology 2005;10(5):304-10.

24. Ji RC. Lymphatic endothelial cells, lymphedematous lymphangiogenesis, and molecular control of edema formation. Lymphatic research and biology 2008;6(3-4):123-37.

25. Mortimer PS. The pathophysiology of lymphedema. Cancer 1998;83(12 Suppl American):2798-2802.

26. Nagase T, Gonda K, Inoue K, Higashino T, Fukuda N, Gorai K et al. Treatment of lymphedema with lymphaticovenular anastomoses. International journal of clinical oncology 2005;10(5):304-310.

27. Armer JM, Radina ME, Porock D, Culbertson SD. Perdicting Breast cancer related lymphedema using self reported symptoms. Nurs Res. 2003;52 (6):370-9. Clinical practice guidelines for the care and treatment of breast cancer: 11. Lymphedema. CMAJ 2001;164(2):191-9.

28. Deltombe T, Jamart J, Recloux S, Legrand C, Vandenbroeck N, Theys S, et al. Reliability and limits of agreement of circumferential, water displacement, and optoelectronic volumetry in the measurement of upper limb lymphedema. Lymphology 2007;40(1):26-34.

29. Armer JM, Stewart BR. A comparison of four diagnostic criteria for lymphedema in a postbreast cancer population. Lymphat Res Biol 2005;3:208-217.

30. Damstra RJ, Glazenburg EJ, Hop WC. Validation of the inverse water volumetry method: A new gold standard for arm volume measurements. Breast Cancer Res Treat 2006;99:267273.

31. Sagen $\mathrm{A}, \mathrm{Ka}{ }^{\circ}$ resen $\mathrm{R}$, Skaane $\mathrm{P}$, Risberg MA. Validity for the simplified water displacement instrument to measure arm lymphedema as a result of breast cancer surgery. Arch Phys Med Rehabil 2009;90:803-809.

32. Hayes S, Cornish B, Newman B. Comparison of methods to diagnose lymphedema among breast cancer survivors: 6-month follow-up. Breast Cancer Res Treat 2005;89:221-226.

33. Stanton AW, Badger C, Sitzia J. Non-invasive assessment of the lymphedematous limb. Lymphology 2000;33:122-135.

34. Czerniec SA, Ward LC, Lee MJ, Refshuage KM, Beith J, Kilbreath SL. Segmental measurement of breast cancer-related arm lymphoedema using perometry and bioimpedance spectroscopy. Support Cancer Care 2011;19(5):703-10.

35. Czerniec SA, Ward LC, Refshuage KM, Beith J, Lee MJ, York S. Assessment of breast cancer-related arm lymphedema--comparison of physical measurement methods and selfreport. Cancer Invest. 2010;28(1):54-62.

36. Stanton AW, Northfield JW, Holroyd B, Mortimer PS, Levick JR. Validation of an optoelectronic limb volumeter (perometer). Lymphology 1997;30:77-97.

37. Cornish, B.H.; Bunce, I.H.; Ward, L.C.; Jones, L.C.; Thomas, B.J. Bioelectrical impedance for monitoring the efficacy of lymphedema treatment programmes. Breast Cancer Res Treat 1996,38(2), 169-176.

38. Warren, A.G.; Janz, B.A.; Slavin, A.S.; Borud, L.J. The use of bioimpedance analysis to evaluate lymphedema. Ann Plast Surg 2007, 58(5), 541-543.

39. Petrek, J. A., Pressman, P. I., \& Smith, R. A. (2000). Lymphedema: Current issues in research 
and management. CA A Cancer Journal for Clinicians, 50(5), 292-307.

40. Rockson, S. G., Miller, L. T., Senie, R., et al. (1998). American Cancer Society E Workshop. Workgroup III: Diagnosis and management of lymphedema. Cancer, 83 (12, Suppl American),2882-2885.

41. Devoogdt N, Van Kampen M, Geraerts I, Coremans T, Christiaens MR. Lymphoedema Functioning, Disability and Health Questionnaire (Lymph-ICF): Reliability and Validity. Phys Ther 2011; 91(6): 944-57.

42. Gartner R, Jensen MB, Kronborg L, Ewertz M, Kehlet H, Kroman N. Self-reported armlymphedema and functional impairment after breast cancer treatment--a nationwide study of prevalence and associated factors. Breast 2010;19(6):506-15.

43. CBO richtlijn 2006

44. Mirolo BR, Bunce IH, Chapman M, et al. Psychosocial benefits of postmastectomy lymphedema therapy. Cancer Nurs. 1995;18:197-205.

45. Augustin M, Bross F, Foldi E, et al. Development,validation and clinical use of the FLQA-I, a disease-specific quality of life questionnaire for patients with lymphedema.Vasa. 2005;34:3135 .

46. Viehoff PB, van Genderen FR, Wittink H.Upper Limb Lymphedema 27 (ULL-27): Dutch translation and validation of an illness-specific health-related quality of life questionnaire for patients with upper limb lymphedema. Lymphology. 2008; 41:131-138.

47. Devoogdt N, van Kampen M, Geraerts I, Coremans T, Christiaens M. Lymphoedema Functioning, Disability and Health Questionnaire (Lymph-ICF): reliability and validity. Phys Ther 2011:91(6); 944-57.

48. Tsai HJ, Hung HC, Yang JL, Huang CS, Tsauo JY. Could Kinesio tape replace the bandage in decongestive lymphatic therapy for breast cancer-related lymphedema? A pilot study. Support Care Cancer. 2009; 17(11): 1353-60.

49. Chou YH, Li SH, Liao SF, Tang HW. Case report: Manual lymphatic drainage and kinesio taping in the secondary malignant breast cancer-related lymphedema in an arm with arteriovenous (AV) fistula for hemodialysis. Am J Hosp Palliat Care. 2013;30(5):503-6.

50. McNeely ML, Peddle CJ, Yurick JL, Dayes IS, Mackey JR. Conservative and dietary interventions for cancer-related lymphedema: a systematic review and meta-analysis. Cancer 2011; 117(6): 1136-48.

51. Lin $\mathrm{CH}$, Ali R, Chen SC, Wallace C, Chang YC, Chen HC, et al. Vascularized groin lymph node transfer using the wrist as a recipient site for management of postmastectomy upper extremity lymphedema. Plast Reconstr Surg. 2009; 123(4): 1265-75.

52. Becker C, Pham DN, Assouad J, Badia A, Foucault C, Riquet M. Postmastectomy neuropathic pain: results of microsurgical lymph nodes transplantation. Breast. 2008;17(5): 472-6.

53. Becker C, Assouad J, Riquet M, Hidden G. Postmastectomy lymphedema: long-term results following microsurgical lymph node transplantation. Ann Surg. 2006; 243(3):313-5.

54. Saaristo AM, Niemi TS, Viitanen TP, Tervala TV, Hartiala P, Suominen EA. Microvascular Breast Reconstruction and Lymph Node Transfer for Postmastectomy Lymphedema Patients. Ann Surg. 2012 Jan 9.

55. Baumeister RG, Frick A. The microsurgical lymph vessel transplantation. Handchir Mikrochir Plast Chir 2003; 35(4): 202-9.

56. Weiss M, Baumeister RG, Hahn K. Post-therapeutic lymphedema: scintigraphy before and after autologous lymph vessel transplantation: 8 years of long-term follow-up. Clin Nucl Med. 2002; 27(11): 788-92.

57. Furukawa $\mathrm{H}$, Osawa M, Saito A, Hayashi T, Funayama E, Oyama A, et al. Microsurgical lymphaticovenous implantation targeting dermal lymphatic backflow using indocyanine green fluorescence lymphography in the treatment of postmastectomy lymphedema. Plast Reconstr 
Surg. 2011; 127(5): 1804-11.

58. Chang DW. Lymphaticovenular bypass for lymphedema management in breast cancer patients: a prospective study. Plast Reconstr Surg. 2010; 126(3): 752-8.

59. Damstra RJ, Voesten HG, van Schelven WD, van der Lei B. Lymphatic venous anastomosis (LVA) for treatment of secondary arm lymphedema. A prospective study of 11 LVA procedures in 10 patients with breast cancer related lymphedema and a critical review of the literature. Breast Cancer Res Treat. 2009; 113(2):199-206.

60. Yamamoto Y, Horiuchi K, Sasaki S, Sekido M, Furukawa H, Oyama A, et al. Follow-up study of upper limb lymphedema patients treated by microsurgical lymphaticovenous implantation (MLVI) combined with compression therapy. Microsurgery 2003; 23(1): 21-6. 
Chapter 1 


\section{Chapter 2}

The prevalence of lymphedema minimally five years after breast cancer treatment

Tiara R Lopez Penha Jules JG Slangen Esther M Heuts Adri C Voogd Maarten F Von Meyenfeldt

Adapted from: Eur J Surg Oncol. 2011 Dec; 37(12): 1059-6 


\section{Abstract}

Aim: The lack of consistency in the definition of breast cancer related lymphedema (BCRL) and of uniform measurement criteria contributes to the wide prevalence range found in current literature. This report aims to describe the long-term prevalence of $B C R L$ and secondly, to compare the long-term prevalence of BCRL when assessed by two objective measures and one subjective measure.

Methods: The upper limbs of 145 post-surgical breast cancer patients were evaluated for the presence of lymphedema using the water displacement method. Two circumference methods and patient perceived swelling were applied secondarily for comparison. Limb measurements were performed once, more than five years after surgery.

Results: The long-term prevalence of BCRL using water displacement was $8 \%$. Prevalence varied when the sum of arm circumference (SOAC), the arm circumference and the self-report methods were used: 16, 31 and $17 \%[P$ $<0.001]$, respectively. Of the women identified with BCRL using the water displacement technique, $82 \%$ were detected with the SOAC method, $82 \%$ with the arm circumference method and $91 \%$ by self-report. Using water displacement as the gold standard the methods with the highest specificities were the SOAC (90\%) and self-report method (89\%), arm circumference resulted in a low specificity of $73 \%$.

Conclusion: The prevalence of $B C R L$ more than five years after surgical treatment differs depending on the measuring method used. Our data underlines the necessity for consensus on the diagnostic criteria for BCRL. 


\section{Introduction}

Early breast cancer detection and concomitant advancements in treatment options have not only resulted in an increase in breast cancer survival rates, but also in that of disease related morbidities with upper limb lymphedema being one of the most debilitating. Swelling of the oedematous limb is brought on by obstruction of normal lymph flow, with known treatment risk factors which cause damage to the lymph vessels being axillary dissection, mastectomy and adjuvant radiation therapy. ${ }^{1-7}$

Breast cancer related lymphedema (BCRL) could present with pain, loss of sensibility, strength and mobility of the affected limb, reducing activity and causing physical and psychological impairments. ${ }^{8-12}$ Lack of consistency in the definition of BCRL and a lack of uniform measurement criteria have contributed to the wide prevalence range found in current literature. ${ }^{1-4}$ This is illustrated in a review on the late morbidity after treatment of breast cancer, in which the prevalence was reported to range between 6 and $43 \%{ }^{5}$ Moreover, few studies have described the long-term prevalence of $\mathrm{BCRL}^{13-16}$ and none, to our knowledge, have done so with the use of different measuring methods within the same patient group.

Therefore, the current study was conducted primarily with the aim of assessing the long-term prevalence of BCRL in women more than five years after breast cancer treatment. We also sought to assess the source of variation in BCRL prevalence by comparing prevalence outcomes of four different measuring methods (water displacement method, two arm circumference methods and self-reported limb swelling.

\section{Methods}

\section{Patients}

A database of patients treated at the Maastricht University Medical Centre (MUMC+) between January 2001 and December 2003 was queried to identify women operated for breast cancer five or more years prior to search $(n=386)$. Exclusion criteria were death $(n=96)$, migration $(n=8)$ and loco-regional recurrence $(n=34) .248$ eligible women were asked to take part in our study. 93 patients withheld written consent and ten patients ultimately did not take part 
due to personal circumstances or illness, resulting in a study population of 145 women. The hospital's medical ethics committee approved the study and the consent form.

\section{Lymphedema Measurements}

Four methods were used to assess the long-term prevalence of BCRL: the water displacement method, two arm circumference methods and the selfreport method. The water displacement method was regarded as the gold standard. In order to evaluate the type of measurement as a probable source of variance, we compared the prevalence of the two circumference methods and the self-report method with the gold standard. All limb measurements were performed at one moment in time, five or more years after breast cancer surgery. For each method the breast cancer treated side was compared to the untreated side. One researcher (JS) performed all limb measurements.

\section{Water displacement method}

For the assessment of upper-limb volume a home built volumeter was used according to J. Lette. ${ }^{17}$ This method carries a high reproducibility. ${ }^{18} \mathrm{~A}$ line was drawn at $80 \%$ of the arm length, measured from the tip of the third digit to the tip of the acromion. Subjects were instructed to lower the arm straight and slowly into the volumeter and to stop and keep it still when the $80 \%$-line reached the water surface. Both upper-limbs were measured twice. The overflowing water was collected in a bucket and weighed on a calibrated scale. (PR balance, Mettler-Toledo, Switzerland). The conversion value of $1 \mathrm{~kg}=1000$ $\mathrm{mL}$ was applied. Lymphedema was defined as a limb volume difference greater than $200 \mathrm{~mL}$ between the treated and untreated side.

\section{Circumference method}

The arm circumference was measured at ten sites on both limbs using a tape measure. The locations measured were: mid-metacarpal, the wrist and at 20 , 15,10 and $5 \mathrm{~cm}$ below and above the elbow fold. The sum of these circumferences was calculated per limb. Lymphedema was defined as a difference of the sum of arm circumferences (SOAC) of more than $5 \mathrm{~cm}$ between the treated and untreated side or as a difference of arm circumference of more than $2 \mathrm{~cm}$ between the treated and untreated side at any of the 10 measured locations on the limb. ${ }^{19}$ 


\section{Self-reported lymphedema}

Patients were asked to indicate the presence of (refractory) swelling during a standardized interview by answering the following question with a "yes" or "no": Have you experienced swelling of the upper-limb on the breast cancer treated side in the past year? Self-assessment was described as negative or positive for BCRL.

\section{Statistical Analysis}

Patient and clinical characteristics were described using descriptive statistics. Continuous variables were evaluated for normal distribution and expressed by providing the median and range. $\mathbf{X}^{2}$ was used to test the relationship between categorical variables. A P-value $<0.05$ was considered statistically significant. The sensitivity and specificity were measured for the SOAC, the circumference and the self-report methods, using the water displacement method as a reference. All data-analysis was conducted using SPSS for Windows 17.0 (SPSS Inc. Chicago, Illinois).

\section{Results}

\section{Patient Characteristics}

The 145 women included in this study were evaluated for BCRL after a median period [range] of 6.2 years since time of surgery [5.0 - 7.8]. At time of surgery, subjects' age ranged from 33-86 years with a median of 55.0 years. The median [range] body mass index (BMI), calculated using the patients weight and height at time of surgery, was 25.1 [17.1- 48.9]; a total of 28 patients were considered obese $(B M I \geq 30)$ at that time. The majority $(n=123)$ of the women underwent breast-conserving surgery; 22 women underwent ablative breast surgery. Of all patients, 69 had an axillary lymph node dissection (ALND) and 76 had a sentinel lymph node biopsy (SLNB). Radiation treatment either to the breast or chest wall and supraclavicular was given to 125 women. 


\section{Lymphedema measurements}

Using the gold standard, 11/145 women met the criteria of the water displacement method for the diagnosis of lymphedema. When patients were evaluated for lymphedema using the SOAC, the circumference and patient selfreport methods, prevalence differed: $23 / 145,45 / 145$ and 25/145, respectively. The difference between the four prevalence rates was significant $[P<0.001]$. Of the 28 obese women at baseline, 18 developed lymphedema according to at least one of the four measuring methods $[P=0.008]$. As for the 69 women who underwent ALND, almost half $(n=37)$ had either self-reported lymphedema and/or objectified limb swelling. In contrast, SLNB $(n=24)$ resulted in fewer patients with lymphedema $[\mathrm{P}=0.007]$.

\section{Sensitivity and specificity of lymphedema measurements}

Table 1 presents the sensitivity and specificity of the SOAC, the circumference and self-report methods using the water displacement method as reference measure. The self-report method displayed the highest sensitivity of the three. Comparatively, the circumference and the SOAC methods each identified fewer women presenting with lymphedema according to the water displacement method. The highest specificity was however measured by the SOAC method. Moreover, there were several cases in which patients had measured lymphedema according to criteria of the SOAC $(n=14)$ or the circumference method $(n=36)$ without having a difference in limb volume greater than $200 \mathrm{~mL}$ and vice versa $(n=3)$.

Table 1. The sensitivity and specificity

\begin{tabular}{lll} 
Measurement methods & Sensitivity, \% $(95 \% \mathrm{Cl})$ & Specificity, \% (95\% Cl) \\
\hline Circumference & $82(0.48-0.97)$ & $73(0.65-0.80)$ \\
SOAC & $82(0.48-0.97)$ & $90(0.83-0.94)$ \\
Self-report & $91(0.57-0.99)$ & $89(0.82-0.93)$ \\
\hline
\end{tabular}

$95 \% \mathrm{Cl} ; 95 \%$ confidence interval, SOAC; sum of arm circumference 
We were also interested in the prevalence of women with subjective lymphedema. In order to get a wider scope on the problem at hand, we combined self-reported complaints of swelling with objective (measured) swelling. Table 2 presents patients categorized as follows: no BCRL (no subjective complaints and no measured swelling), asymptomatic BCRL (no subjective complaints but measured swelling), symptomatic non-BCRL (subjective complaints but no measured swelling) and symptomatic BCRL (subjective complaints and measured swelling). Once again, the prevalence rates varied depending on the diagnostic method used. Interestingly, there were women with the perception of arm swelling but without clinical signs of lymphedema according to all three methods. However, there were also women with clinical signs of lymphedema who did not have self-perceived arm swelling.

Table 2. Patient's perception and measured lymphedema

\begin{tabular}{llll} 
BCRL category & $\begin{array}{l}\text { Water } \\
\text { displacement }\end{array}$ & SOAC & Circumference \\
\hline No BCRL, \% & 82 & 76 & 63 \\
Asymptomatic BCRL, \% & 1 & 6 & 20 \\
Symptomatic non-BCRL, \% & 10 & 8 & 6 \\
Symptomatic BCRL, \% & 7 & 10 & 11 \\
\hline
\end{tabular}

BCRL; breast cancer related lymphedema, SOAC; sum of arm circumference

\section{Discussion}

In the current study we assessed the prevalence of BCRL at a median time of 6.2 years after breast cancer surgery. To our knowledge this is the first study that used more than one measuring method for describing the long-term prevalence of BCRL. A wide point prevalence range of $8-31 \%$ was found in our data, with the circumference method at prevalence rate of $31 \%$ being the biggest outlier. In contrast, the water displacement, the SOAC and self-report methods yielded point prevalence estimates closer in range, 8-17\%. Of the scant long-term data that is available, Sagen et al reported a BCRL prevalence of $13 \%$ measured with the water displacement method five years after breast cancer treatment. ${ }^{20}$ 


\section{Lymphedema: more than just limb swelling?}

Lymphedema constitutes more than just limb volume increase; symptoms that patients experience as result of that volume change should therefore also be identified. Creating BCRL sub-categories, depicting subjective complaints against the different objective measurements, resulted in a better insight on this topic. $^{21,22}$ Symptomatic BCRL was identified in 7\% of the patients using the water displacement method; this was $10 \%$ for the arm circumference method and also $10 \%$ for the SOAC method. At a follow-up time of five years after breast cancer treatment McLaughlin et al reported a prevalence of $5 \%$ for symptomatic BCRL measured with the circumference method. ${ }^{14}$ We assessed a point prevalence double that after a median time of 6.2 years, which is likely explained by the fact that our cohort included more women who underwent axillary lymph node dissection ( 47 vs. $36 \%$ ). Not all patients with self-reported complaints of BCRL had clinical measurable signs of limb swelling (symptomatic non-BCRL). The discordance seen between patient perceptions and measured swelling is consistent with the results reported in other studies. ${ }^{14}$, ${ }^{23} \mathrm{~A}$ reason why not all of the subjective $\mathrm{BCRL}$ complaints might have shown a measured increase of limb volume or circumference could be due to the timing of the study. Many patients reported to have an increase in complaints after more than average exercise and with warm weather. The measurements in this study gave an impression of a patient's lymphedema status at one specific moment in time, and thus, cannot exclude the existence of refractory limb swelling. Furthermore, symptomatic non-BCRL could also be explained by sensory changes in the treated limb due to neurological damage caused by axillary surgery or radiation treatment. Vice versa, some women with measurable volume and or circumference difference had no subjective complaints of pain or swelling (asymptomatic BCRL). An important question is whether this BCRL category is clinically relevant; in other words if these patients will eventually go on to develop symptomatic BCRL.

\section{Method selection: a matter for consideration}

Volumetry is the most reliable method for the assessment of lymphedema, with the classic water and the novel optoelectronic (perometer) volumeter forming the two methods of choice. Both methods have comparable reliability ${ }^{24-27}$; therefore, our selection of the water displacement method was based on costefficiency, the most applied method and readily available device. Even though we have used the water displacement method as our gold standard, we believe 
it to have its shortcomings in cases where minor swelling is accompanied by muscle atrophy. This can develop over time when normal use of the affected limb is avoided due to lymphedema related symptoms, such as pain and heaviness. Minor volume increase in the form of extracellular lymph accumulation can be compensated by a volume decrease in muscle mass, in which case lymphedema will go undetected. Bioelectrical impedance spectroscopy (BIS) on the other hand can accurately differentiate extracellular fluid from other tissues and thus solely assess lymph volume by measuring the impedance of a spectrum of low frequency electric current passed through a body region. ${ }^{28-30}$ It could therefore be argued as to why BIS was not used in the current study as the gold standard for BCRL assessment instead of the water displacement method. Hayes et al described the short-term prevalence at six months after breast cancer treatment using the BIS method as the gold standard and the sum of arm circumference and the patient self-report method for comparison. ${ }^{31}$ Importantly, in the early stages of lymphedema swelling is refractory and predominately constitutes of extracellular lymph fluid, thereby making BIS a suitable tool for diagnosis. ${ }^{32-35}$ However, as disease progression ensues, limb swelling becomes a more permanent entity with the occurrence of fibrosis and fat deposition. ${ }^{36}$ As the aim of our study was to assess the longterm prevalence of $B C R L$ five or more years after breast cancer treatment, some lymphedema cases might have already progressed into the chronic phase during this period. Thus, the use of BIS instead of the water displacement method as the gold standard for the identification of BCRL in this study's setting is not justified. For lack of a more reliable assessment method we have accepted the possible limitations of the water displacement method.

\section{Study limitation}

A weakness of this study is the fact that it was performed without preoperative or direct postoperative baseline measurements; these could have produced a more accurate identification of changes in limb volume and circumference. Instead, the contra-lateral upper-extremity was used as comparison to determine the presence of lymphedema. Differences in circumference or arm volume may exist between a woman's dominant and non-dominant arm. In most women these differences are less than $2 \mathrm{~cm}$ and therefore not significant. ${ }^{6,7}$ However, slight pre-operative limb volume or circumference differences might mask the presence of minor lymphedema in the smaller extremity. 


\section{Conclusion}

The prevalence of BCRL more than five years after surgical treatment differs depending on the measuring method used. The range of prevalence rates observed in this one group of women measured at a single point in time by four different methods, underlines the necessity for consensus on the diagnostic criteria for BCRL. Currently, there is no single measuring method that can identify lymphedema error-free, this is in part due to the changing nature of lymphedema. We advise screening breast cancer patients by using a combination of subjective complaints and preoperative and sequential postoperative limb volume measurements (water displacement method), eliminating the chance of missing minor cases of limb swelling. This approach will result in more knowledge on the true prevalence of BCRL. Furthermore, the efficacy of therapeutic regimens and the design of optimal therapeutic approaches can be assessed creating the beginning of an accepted evidence based systemic approach of the problem of BCRL. Finally, the implementation of a lymphedema screening program will clarify the clinical relevance of the asymptomatic $B C R L$ and symptomatic non-BCRL categories. 


\section{References}

1. Tsai RJ, et al. The risk of developing arm lymphedema among breast cancer survivors: a metaanalysis of treatment factors. Ann Surg Oncol 2009; 16:1959-72.

2. Herd-Smith A, Russo A, Muraca MG, Del Turco MR, Cardona G. Prognostic factors for lymphedema after primary treatment of breast carcinoma. Cancer 2001; 92(7): 1783-7.

3. Johansson K, Ohlsson K, Ingvar C, Albertsson M, Ekdahl C. Factors associated with the development of arm lymphedema following breast cancer treatment: a match pair case-control study. Lymphology 2002; 35(2): 59-71.

4. Erickson VS, Pearson ML, Ganz PA, Adams J, Kahn KL. Arm edema in breast cancer patients. J Natl Cancer Inst 2001; 93(2): 96-11.

5. Rietman JS, et al. Late morbidity after treatment of breast cancer in relation to daily activities and quality of life: a systematic review. Eur J Surg Oncol 2003; 29(3): 229-38.

6. Sakorafas GH, Peros G, Cataliotti L, Vlastos G. Lymphedema following axillary lymph node dissection for breast cancer. Surg Oncol 2006; 15 (3): 153-65.

7. Kissin MW, Querci della Rovere G, Easton D, Westbury G. Risk of lymphoedema following the treatment of breast cancer. Br J Surg 1986; 73(7): 580-4.

8. Chachaj A, Malyszczak K, Pyszel K, et al. Physical and psychological impairments of women with upper limb lymphedema following breast cancer treatment. Psychooncology 2010; 19(3): 299-305.

9. Smoot B, Wong J, Cooper B, et al. Upper extremity impairments in women with or without lymphedema following breast cancer treatment. J Cancer Surviv 2010; 4(2): 167-78.

10. Hayes SC, Rye S, Battistutta D, DiSipio T, Newman B. Upper-body morbidity following breast cancer treatment is common, may persist longer-term and adversely influences quality of life. Health Qual Life Outcomes 2010; 8: 92.

11. Beaulac SM, McNair LA, Scott TE, LaMorte WW, Kavanah MT. Lymphedema and quality of life in survivors of early-stage breast cancer. Arch Surg 2002; 137(11): 1253-7.

12. Karki A, Simonen R, Malkia E, Selfe J. Impairments, activity limitations and participation restrictions 6 and 12 months after breast cancer operation. J Rehabil Med 2005; 37(3): 180-8.

13. Petrek JA, Senie RT, Peters M, Rosen PP. Lymphedema in a cohort of breast carcinoma survivors 20 years after diagnosis. Cancer 2001; 92:1368-77.

14. McLaughlin SA, et al. Prevalence of lymphedema in women with breast cancer 5 years after sentinel lymph node biopsy or axillary dissection: Patient perceptions and precautionary behaviors. J Clin Oncol 2008; 26:5220-26.

15. Kornblith $A B$,et al. Long-term adjustment of survivors of early- stage breast carcinoma, 20 years after adjuvant chemotherapy. Cancer 2003; 98: 679-89.

16. Engel J, Kerr J, Schlesinger-Raab A, Sauzer $\mathrm{H}$, Holzel $\mathrm{O}$. Axilla surgery severly affects quality of life: results of a 5-year prospective study in breast cancer patients. Breast Cancer Res Treat 2003; 79(1): 47-57.

17. Lette J. A simple and innovative device to measure arm volume at home for patients with lymphedema after breast cancer. J Clin Oncol 2006; 24(34): 5434-40.

18. Sagen A, Karesen R, Skaane P, Risberg MA. Validity for the simplified water displacement instrument to measure arm lymphedema as a result of breast cancer surgery. Arch Phys Med Rehabil 2009; 90(5): 803-9.

19. Harris SR, Hugi MR, Olivotto IA, Levine M. Clinical practice guidelines for the care and treatment of breast cancer: 11. Lymphedema. CMAJ 2001; 164(2): 191-9.

20. Sagen A, Karesen R, Sandvik L, Risberg MA. Changes in arm morbidities and health-related quality of life after breast cancer surgery - a five-year follow-up study. Acta Oncol 2009; 48(8): 1111-8. 


\section{Prevalence of lymphedema}

21. Gartner R, Jensen MB, Kronborg L, Ewertz M, Kehlet H, Kroman N. Self-reported arm-lymphedema and functional impairment after breast cancer treatment--a nationwide study of prevalence and associated factors. Breast 2010; 19(6): 506-15.

22. Piller N, Carati C. The diagnosis and treatment of peripheral lymphedema. Lymphology $2009 ; 42(3)$ : 146-7.

23. Voogd AC, Ververs JMMA, Vingerhoets AJJM, Roumen RMH, Coebergh JWW, Crommelin MA. Lymphoedema and reduced shoulder function as indicators of quality of life after axillary lymph node dissection for invasive breast cancer. BJS 2003; 90: 76-81.

24. Lee MJ, Boland RA, Czerniec S, Kilbreath SL. Reliability and concurrent validity of the perometer for measuring hand volume in women with and without lymphedema. Lymphat Res Biol 2011; 9(1): 138.

25. Tierney S, Aslam M, Rennie K, Grace P. Infrared optoelectronic volumetry, the ideal way to measure limb volume. Eur J Vasc Endovasc Surg 1996; 12(4): 412-7.

26. Auvert JF, Vayssairat M. Volumetrics: an indispensable complementary test in lymphology. Rev Med Interne 2002; 23 Suppl 3: 388s-90s.

27. Man IO, Markland KL, Morrissey MC. The validity and reliability of the Perometer in evaluating human knee volume. Clin Physiol Funct Imaging 2004; 24(6): 352-8.

28. Jaffrin MY, Morel H. Body fluid volumes measurements by impedance: A review of bioimpedance spectroscopy (BIS) and bioimpedance analysis (BIA) methods. Med Eng Phys 2008; 30(10): 125769.

29. Cornish B. Bioimpedance analysis: scientific background. Lymphat Res Biol 2006; 4(1): 47-50.

30. Warren AG, Janz BA, Slavin SA, Borud LJ. The use of bioimpedance analysis to evaluate lymphedema. Ann Plast Surg 2007; 58(5): 541-3.

31. Hayes S, Cornish B, Newman B. Comparison of methods to diagnose lymphoedema among breast cancer survivors: 6-month follow-up. Breast Cancer Res Treat 2005; 89(3): 221-6.

32. Ward LC, Czerniec S, Kilbreath SL. Quantitative bioimpedance spectroscopy for the assessment of lymphoedema. Breast Cancer Res Treat 2009; 117(3): 541-7.

33. Ward LC, Dylke E, Czerniec S, Isenring E, Kilbreath SL. Confirmation of the reference impedance ratios used for assessment of breast cancer-related lymphedema by bioelectrical impedance spectroscopy. Lymphat Res Biol 2011; 9(1): 47-51.

34. Cornish BH, Chapman M, Thomas BJ, Ward LC, Bunce IH, Hirst C. Early diagnosis of lymphedema in postsurgery breast cancer patients. Ann N Y Acad Sci 2000; 904:571-5.

35. Cornish BH, Ward LC, Thomas BJ, Bunce IH. Quantification of lymphoedema using multi-frequency bioimpedance. Appl Radiat Isot 1998; 49(5-6): 651-2.

36. The diagnosis and treatment of peripheral lymphedema. 2009 Consensus Document of the International Society of Lymphology. Lymphology 2009; 42(2): 51. 


\section{Chapter 3}

The quality of life in long-term breast cancer survivors with breast cancer related lymphedema

Tiara R Lopez Penha Jolanda Bodegraven Bjorn Winkens Esther M Heuts, Adri C Voogd Maarten F Von Meyenfeldt

Adapted from: Acta Chir Belg 2014; 114(4): 239-44 


\section{Abstract}

Aim: To compare the health related quality of life (HRQOL) of long-term breast cancer survivors with and without breast cancer related lymphedema (BCRL) treated in the sentinel lymph node biopsy (SLNB) era.

Methods: HRQOL was assessed as subject of a secondary analysis of data gathered for a study evaluating the prevalence of BCRL in long-term breast cancer survivors. The 145 women in this study cohort had undergone SLNB and or axillary lymph node dissection (ALND) according to Dutch breast cancer treatment guidelines. HRQOL was assessed using two quality of life questionnaires: the European Organization for Research and Treatment of Cancer Quality (QLQ-C30) and the Breast Cancer-specific Quality of Life (QLQBR23).

Results: Twenty-six women, of whom 5 only underwent SLNB, were identified with objectively measured lymphedema and/or self-perceived arm swelling. Patients with BCRL scored significantly lower on the social $(p=0.000)$ functioning scale after adjustments for BMl and age compared to women without BCRL. Compared to normative data, women with BCRL scored significantly lower on social- $(p<0.001)$ and role $(p=0.001)$ functioning scales.

Conclusion: $H R Q O L$ in long-term breast cancer survivors with $B C R L$ is structurally lower than of those without BCRL, even in this small cohort of cancer survivors treated in the SLNB-era. 


\section{Introduction}

As a concomitant effect of the increase of the survival rate after breast cancer treatment ${ }^{1}$, attention is being shifted towards treatment-related complications and their effect on the quality of cancer survivorship. ${ }^{2-5}$ One of the most frequent and burdensome complications of breast cancer treatment is lymphedema. Breast cancer related lymphedema (BCRL) can develop as a result of damage to the lymphatic system brought on by (axillary) surgery and adjuvant therapy. BCRL is characterized by an accumulation of fluid in the interstitial tissue that causes limb swelling, functional disability, recurrent pain and infections and increased psychological distress. ${ }^{6-9}$

Both patients undergoing sentinel lymph node biopsy (SLNB) alone and SLNB followed by an axillary lymph node dissection (ALND) are at risk for developing upper-limb lymphedema. Despite the efforts of reducing upper-body morbidities by the introduction of the SLNB, BCRL rates are still significant. One of the largest RCT's comparing morbidity rates between SLNB and ALND reported a fairly high BCRL incidence rate of $7 \%$ and a subclinical BCRL rate of $13 \%$ after three years in patients having undergone SLNB. ${ }^{10}$

The studies published up till now on the health-related quality of life (HRQOL) in long-term breast cancer survivors ( $\geq 5$ years) with $B C R L$ are derived from patient cohorts in the pre-SLNB era. ${ }^{7,11-13}$ A HRQOL assessment of contemporary patients, in which less invasive axillary surgery is being performed more often, is of added value to the available body of evidence. Therefore, the aim of this study is to compare the HRQOL of long-term breast cancer survivors with and without BCRL in a cohort of women treated in the SLNB-era. Furthermore, we will compare the HRQOL of this cohort with normative data computed from individuals drawn from the general Dutch population.

\section{Patients and Methods}

\section{Patients}

The HRQOL was assessed as subject of a secondary analysis of data gathered for a study evaluating the prevalence of BCRL more than five years after breast cancer treatment. ${ }^{14}$ We evaluated the HRQOL of 145 women treated for primary unilateral breast cancer at the Maastricht University Medical Centre 
(MUMC+) between January 2001 and December 2008. Patients were excluded in case of disease recurrence, metastases, death and withheld written informed consent. Study participants visited the MUMC+ five or more years after breast cancer treatment for a one-time clinical assessment. The quality of life questionnaires were filled in by the patients themselves. Oncologic and treatment-related characteristics of each patient were abstracted from hospital records. The hospital's medical ethics committee approved this study and the consent form.

\section{Lymphedema measurements}

Arm swelling was assessed using the water displacement method, the current gold standard. A home built volumeter was applied according to J. Lette ${ }^{15}$ for volume measurements. Both limbs were measured twice, comparing the treated side to the untreated side. An arm volume difference greater than $200 \mathrm{ml}$ was defined as objective lymphedema. A detailed description of the arm volume measurement has been previously published. ${ }^{14}$

Furthermore, participants were asked to indicate the presence of (refractory) swelling during a standardized interview by answering the following question with a "yes" or "no": Have you experienced swelling of the upper-limb on the breast cancer treated side in the past year? Self-reported lymphedema was described as positive if the question was answered with a yes.

Study participants were divided into two groups: 1) patients with self-reported and/or objectively measured arm swelling, 2) patients without arm swelling.

\section{Quality of life measurements}

The HRQOL was assessed using the Dutch version of two validated questionnaires developed by the European Organization of Research and Treatment for Cancer (EORTC): QLQ-C30 version 3.0 and QLQ-BR23 breast cancer supplementary module. ${ }^{16}$ Authors received permission from the EORTC to use the questionnaires for research purposes.

From the QLQ-C30 questionnaire, the Global Health (self-perceived quality of life and health) scale and function scales including physical- (activity in everyday life), role- (leisure time \& work life), social- (family \& social life), emotional- (feelings of worry, depression \& irritability) and cognitive (concentration \& memory) function were used. As for the QLQ-BR23 questionnaire, we only analyzed the seven questions pertaining to arm and 
breast symptoms (questions about the presence of symptoms of pain and/or swelling in the treated arm and/or breast and the presence of reduced shoulder mobility). All of the raw scores were standardized by linear transformation so that scores ranged from $0-100$, as indicated by the EORTC. A higher score on the functioning scale and Global Health scale corresponds with a more healthy level of functioning and health.

The QLQ-C30 scores acquired from this study were compared to normative values computed from individuals drawn from the general Dutch population. ${ }^{17}$ This population was designed to be representative of the Dutch-speaking population in the Netherlands. While the cohort consisted of men and women, we only used the data acquired from the 796 women (mean age of 50.8 years) for this study.

\section{Statistical analyses}

Statistical analysis was conducted using SPSS for MAC 17.0 (SPSS Inc. Chicago, Illinois). Continuous variables were presented as mean and standard deviation with mean difference and $95 \%$ confidence interval $(95 \% \mathrm{Cl})$. Categorical variables were presented in numbers and percentages. The differences between groups (BCRL versus no BCRL) were tested using the independent-samples t-test for continuous variable and Chi-square test for categorical variables. A multivariate analysis was conducted using a model containing $\mathrm{BCRL}$ and two variables, $\mathrm{BMI}$ and age. The analysis was restricted to three variables because of the small number of patients in the BCRL group. A two-sided $p$-value $\leq 0.05$ was considered statistically significant.

\section{Results}

\section{BCRL prevalence}

Of the 145 women, $11(7.6 \%)$ were identified to have an arm volume difference greater than $200 \mathrm{ml}$. As for the rate of women with self-perceived arm swelling, $25(17.2 \%)$ reported to have had swelling in the past year. Almost all $(n=10)$ of the participants with objective BCRL also reported self-perceived arm swelling, bringing the total of women in the lymphedema group to $26(17.9 \%)$.

Baseline characteristics of the women with BCRL $(n=26)$ and those without $B C R L(n=119)$ are presented in Table 1. Women with BCRL were more likely to 
have a higher BMI at surgery and at follow-up (both $p<0.001$ ), have undergone adjuvant chemotherapy $(p=0.003)$ and hormonal treatment $(p=0.009)$ compared to women without BCRL. Furthermore, they were also more likely to have undergone total axillary lymph node dissection $(p<0.001)$, have more positive lymph nodes $(p=0.024)$ and more total lymph nodes excised $(p=$ $0.001)$. Of the 76 women who only underwent a SLNB, 5 (6.6\%) met de criteria for BCRL versus 21/69 (30.4\%) women after ALND.

\section{EORTC QLQ-C30 and QLQ-Br23 scores}

Compared to women without BCRL, those with $B C R L$ scored significantly lower on the physical functioning $(p=0.003)$, role functioning $(p=0.008)$, social functioning $(p<0.001)$, breast symptoms $(p=0.034)$ and arm symptoms $(p=$ 0.001 ) scales (Table 2). We also compared normative QLQ-C30 scores of women in the general Dutch population with the scores of the two groups in our study. Both the BCRL and no BCRL group scored significantly lower on QLQC30 function scales when compared to the normative scores, but only the BCRL group scored statistically lower on the role $(p=0.001)$ and social functioning $(p=0.000)$ scales (Table 2). Furthermore, women without BCRL had a significantly higher Global Health score $(p=0.003)$ compared to data from the normative Dutch population (Table 2).

\section{Multivariate analysis}

The statistically significant lower scores for the physical-, role- and social functioning scales seen in the BCRL group were further assessed by multivariate analysis in order to control for confounding factors. BCRL and BMI were independently associated with a decrease in the social functioning scale. Standardized coefficients showed a small impact of both BCRL and BMI, $\beta=$ $.20, p<0.05$ and $\beta=-.23, p=0.01$ respectively. As for the other two functioning scales, after multivariate correction for BMl and age, BCRL was not significantly associated with the physical functioning $(p=0.070)$ nor with the role functioning scales $(p=0.17)$. 
Table 1. Patient characteristics of those with and without BCRL

\begin{tabular}{|c|c|c|c|c|}
\hline Clinical-factors & $\begin{array}{l}\text { BCRL } \\
N=26\end{array}$ & $\begin{array}{l}\text { No BCRL } \\
\mathrm{N}=119\end{array}$ & $\begin{array}{l}\text { Difference between } \\
\text { means }(95 \% \mathrm{Cl})\end{array}$ & P-value \\
\hline Age at surgery, mean (SD), in years & $55.4(11.1)$ & $56.5(11.3)$ & $-1.1(-3.7-6.0)$ & 0.644 \\
\hline Age at FU, mean (SD), in years & $61.6(11.2)$ & $62.7(11.2)$ & $-1.1(-3.7-5.9)$ & 0.655 \\
\hline $\begin{array}{l}\text { Time from surgery to } F U \text {, mean } \\
(S D) \text {, in months }\end{array}$ & $77.0(10.0)$ & $75.6(9.6)$ & $1.4(-5.5-2.8)$ & 0.523 \\
\hline$B M I\left(\mathrm{~kg} / \mathrm{m}^{2}\right)$ at surgery, mean $(S D)$ & $30.3(6.2)$ & $25.1(4.0)$ & $5.2(-7.2--4.7)$ & $<0.001$ \\
\hline$B M I\left(k g / m^{2}\right)$ at $F U$, mean $(S D)$ & $31.6(6.8)$ & $25.4(4.1)$ & $6.2(-8.1--4.1)$ & $<0.001$ \\
\hline \multicolumn{5}{|l|}{ Tumor status, no (\%) } \\
\hline Tis $-\mathrm{TI}$ & $18(69.2)$ & $99(83.2)$ & & \multirow[t]{2}{*}{0.109} \\
\hline TII - TIV & $8(30.8)$ & $20(16.8)$ & & \\
\hline \multicolumn{5}{|l|}{ Breast surgery, no (\%) } \\
\hline Mastectomy & 9 (34.6) & $25(21.0)$ & & \multirow[t]{2}{*}{0.199} \\
\hline Lumpectomy & $17(65.4)$ & $94(79.0)$ & & \\
\hline \multicolumn{5}{|l|}{ Axillary surgery, no (\%) } \\
\hline SLNB & $5(19.2)$ & $71(59.7)$ & & \multirow[t]{2}{*}{$<0.001$} \\
\hline ALND & $21(80.8)$ & $48(40.3)$ & & \\
\hline Total nodes excised, mean (SD) & $12.3(7.6)$ & $7.0(7.2)$ & $5.3(-8.4--2.2)$ & 0.001 \\
\hline $\begin{array}{l}\text { Total positive nodes excised, mean } \\
\text { (SD) }\end{array}$ & $2.1(2.7)$ & $0.8(2.5)$ & $1.3(-2.3--0.2)$ & 0.024 \\
\hline Dominant arm is affected, no (\%) & $12(46.2)$ & $59(49.6)$ & & 0.752 \\
\hline Post-menopausal, no (\%) & $18(69.2)$ & $77(64.7)$ & & 0.660 \\
\hline \multicolumn{5}{|l|}{ Adjuvant Therapy, no (\%) } \\
\hline Rtx (Breast / loco regional) & $19(73.1)$ & $90(75.5)$ & & 0.785 \\
\hline $\mathrm{CHtx}$ & $18(69.2)$ & $44(37.0)$ & & 0.003 \\
\hline $\mathrm{Htx}$ & $20(76.9)$ & $58(48.7)$ & & 0.009 \\
\hline
\end{tabular}

SD; standard deviation, no; number, FU; follow-up, BMI; body mass index, SLNB; sentinel lymph node biopsy, ALND; axillary lymph node dissection, RT; radiotherapy, CHtx; chemotherapy, Htx; hormone therapy 
Table 2. QLQ-C30 \& QLQ-BR23 scores of patients with BCRL, without BCRL and in the general Dutch population

\begin{tabular}{|c|c|c|c|c|c|c|}
\hline EORTC & $\begin{array}{l}\text { BCRL } \\
(n=26)\end{array}$ & $\begin{array}{l}\text { No BCRL } \\
(n=119)\end{array}$ & $\begin{array}{l}\text { Normative data } \\
(\mathrm{n}=796)\end{array}$ & BCRL VS no BCRL & $\begin{array}{l}\text { BCRL VS normative } \\
\text { data }\end{array}$ & $\begin{array}{l}\text { no BCRL VS normative } \\
\text { data }\end{array}$ \\
\hline QLQ-C30, mean (SD) & & & & $\begin{array}{l}\text { Difference between } \\
\text { means }(95 \% \mathrm{Cl})\end{array}$ & $\begin{array}{l}\text { Difference between } \\
\text { means }(95 \% \mathrm{Cl})\end{array}$ & $\begin{array}{l}\text { Difference between } \\
\text { means }(95 \% \mathrm{Cl})\end{array}$ \\
\hline Global Health status & $78(18)$ & $83(16)$ & $78(17)$ & $-5(-12-2)$ & $0(-7-7)$ & $5(2-8)^{\star *}$ \\
\hline Physical function & $73(17)$ & $84(18)$ & $90(15)$ & $-11(-19--4)^{\star \star}$ & $-17(-23--11)^{\star \star \star}$ & $-6(-9--3)^{\star \star \star}$ \\
\hline Role function & $75(28)$ & $88(21)$ & $89(21)$ & $-13(-22--3)^{\star *}$ & $-14(-22--6)^{\star \star *}$ & $-1(-5-3)$ \\
\hline Emotional function & $79(20)$ & $80(19)$ & $89(16)$ & $-1(-9-7)$ & $-10(-16--4)^{\star * *}$ & $-9(-13--6)^{\star \star *}$ \\
\hline Cognitive function & $78(24)$ & $82(19)$ & $92(15)$ & $-4(-13-5)$ & $-14(-20--8)^{\star \star *}$ & $10(-13--7)^{\star \star *}$ \\
\hline Social function & $81(23)$ & $94(14)$ & $94(16)$ & $-13(-20--16)^{* * *}$ & $-13(-19--7)^{\star * *}$ & $0(-3-3)$ \\
\hline \multicolumn{7}{|l|}{ QLQ-BR23, mean (SD) } \\
\hline Breast symptoms & $18(17)$ & $11(15)$ & & $7(-13--1)^{*}$ & & \\
\hline Arm symptoms & $36(28)$ & $14(18)$ & & $22(-31--13)^{\star \star *}$ & & \\
\hline
\end{tabular}

\footnotetext{
${ }^{*} p<0.05,{ }^{* *} p<0.01,{ }^{* * *} p \leq 0.001,95 \% \mathrm{Cl} ; 95 \%$ confidence interval, BCRL; breast cancer related lymphedema
} 


\section{Discussion}

The aim of this study was to assess the HRQOL of long-term breast cancer survivors with BCRL using the EORTC QLQ-C30 and BR23 questionnaires. After adjustment for BMI and age, the women with BCRL scored lower on the social functioning scale when compared to the women without BCRL. Moreover, the presented cohort as a whole scored lower on a majority of the functioning scales compared to that of the general Dutch population, but it was only the BCRL group that scored significantly lower on role- and social functioning.

Our findings are in line with other studies reporting on the impact of BCRL on the HRQOL in long-term breast cancer survivors ( $\geq 5$ years). The available studies are few, but all to some degree show functional impairment (Table 3 ). An important point to address is the fact that the patients in these long-term studies were largely included prior to the implementation of the SLNB. Almost all of the women in these studies underwent ALND. To our knowledge, this is the first study reporting on the HRQOL of long-term breast cancer survivors with BCRL depicted in the SLNB-era. It is known that ALND is associated with a higher risk of objective and subjective upper-limb morbidities compared to SLNB, resulting in a higher risk of impaired HRQOL. ${ }^{18-22}$ In the current study we simply assessed the influence of $B C R L$ on the HRQOL, not regarding the possible effect of other upper-limb morbidities such as pain, decreased range of motion etc. Half of the women in this cohort underwent a SLNB (76/145). Of these 76 women, five were in the $B C R L$ group, which equals to a $6.6 \%$ rate in the SLNB patients. This incident rate fits well into the 3\%-23\% BCRL incident range reported after SLNB in a review of procedure specific incidence rates of BCRL by Shah et al. ${ }^{23}$

The cohort of breast cancer survivors presented with a statistically significant higher Global Health score as compared to the normative population, meaning that breast cancer survivors were more satisfied with their general health and quality of life than healthy women. This observation, also known as the "response-shift phenomenon", has been described in previous publications reporting on the quality of life in long-term breast cancer survivors. ${ }^{3}$ The history of illness could have caused the patient to redefine her concept of quality of life and therefore being more satisfied. ${ }^{24}$ That said, women with BCRL in this study nevertheless suffered from an impaired functioning, with respect to social and role functioning. 
In light of the recent publication of the ACOSOG-Z0011 trial, the role of ALND performed currently with the aim of maintaining regional nodal control is being questioned. Results of this trial demonstrated no survival benefit in sentinel node positive (1-2 nodes) patients undergoing breast-conserving surgery in combination with radiation therapy randomized to undergo additional ALND as compared to those randomized not to. ${ }^{25}$ It is expected that the next generation of trials will provide more insight on the matter, which as a consequence might eventually lead to fewer indications for ALND in the future. The authors of the present study are of the opinion that regardless of this, BCRL will remain a clinically relevant morbidity of the upper-limb as demonstrated by the BCRL incident rates after SLNB. ${ }^{6,23}$

Several limitations should be considered in this study. Firstly, not all potential sociodemographic and psychological confounders were recorded. We were not able to control for the potential confounding effects of anxiety/ depression ${ }^{21}$, lack of social support ${ }^{26}$ and coping mechanisms ${ }^{27}$ to name a few, as they have shown to play an important role in predicting the HRQOL. Secondly, the power was low due to a small number of subjects in the lymphedema group, this causing us the limit the use of variables to three for the multivariate analysis.

\section{Conclusion}

In conclusion, our findings indicate that the HRQOL in breast cancer survivors with BCRL is structurally lower than of those patients without BCRL, even in this small cohort of cancer survivors treated in the SLNB-era. 
Table 3. Overview of HRQOL assessment studies in long-term breast cancer survivors with and without BCRL

\begin{tabular}{|c|c|c|c|c|}
\hline Ref. & Population & $\begin{array}{l}\text { Time since } \\
\text { surgery }\end{array}$ & BCRL definition & HRQOL assessment \\
\hline 7 & $\begin{array}{l}\mathrm{N}=245 \text {, cross-sectional study. } \\
\text { Inclusion: } 1985-1991 \text {. } \\
\text { Axillary surgery: } 100 \% \text { underwent } \\
\text { ALND }\end{array}$ & $\begin{array}{l}\text { Ranging } 9.4- \\
16.5 \text { years }\end{array}$ & Self-report of swelling & $\begin{array}{l}\text { BCRL ( } n=75) \text { VS no BCRL } \\
\text { SF-36: Severe swelling \& activity limiting swelling } \\
\text { each significantly associated with worse physical } \\
\text { function. }\end{array}$ \\
\hline 11 & $\begin{array}{l}\mathrm{N}=1287 \text {, population based study. } \\
\text { Inclusion: } 1986-2003 \text {. } \\
\text { Axillary surgery: not provided }\end{array}$ & $\begin{array}{l}\text { Mean } 8.1 \text { SD } \\
0.2 \text { years }\end{array}$ & $\begin{array}{l}\text { Self-report of BCRL } \\
\text { diagnosis }\end{array}$ & $\begin{array}{l}\text { BCRL }(n=104) \text { VS no BCRL or arm symptoms } \\
\text { SF-36: significantly } \downarrow \text { scores for all scales except } \\
\text { mental health \& role limitations emotional } \\
\text { subscale. }\end{array}$ \\
\hline 12 & $\begin{array}{l}\mathrm{N}=990 \text {, prospective study. } \\
\text { Inclusion: } 1996-1998 \text {. } \\
\text { Axillary surgery: } 93 \% \text { underwent } \\
\text { ALND }\end{array}$ & 5 years & $\begin{array}{l}\text { Self-report of swelling } \\
\text { and/ or limitations in } \\
\text { arm movement (arm } \\
\text { problems) }\end{array}$ & $\begin{array}{l}\text { Arm problems ( } \mathrm{n}=\text { not provided) VS none } \\
\text { EORTC QLQ-C30: arm problems scored } \\
\text { significantly lower on Global Health \& all } \\
\text { functioning domains. }\end{array}$ \\
\hline $13^{\prime}$ & $\begin{array}{l}\mathrm{N}=151 \text {, retrospective cohort study. } \\
\text { Inclusion: } 1986-2000 \text {. } \\
\text { Axillary surgery: } 100 \% \text { underwent } \\
\text { ALND }\end{array}$ & $\begin{array}{l}\text { Mean } 4.8 \mathrm{SD} \\
0.2 \text { years }\end{array}$ & $\begin{array}{l}\text { Volume difference } \geq \\
200 \mathrm{~cm}^{3} \text { between } \\
\text { operated and non- } \\
\text { operated limb }\end{array}$ & $\begin{array}{l}\text { BCRL }(n=42) \text { VS no BCRL } \\
\text { FACT-B: BCRL significantly associated with } \\
\text { decreased emotional-, functional-, physical-, and } \\
\text { breast well-being. }\end{array}$ \\
\hline $\begin{array}{l}\text { Current } \\
\text { study }\end{array}$ & $\begin{array}{l}\mathrm{N}=145 \text {, cross-sectional study. } \\
\text { Inclusion: } 2001-2008 \\
\text { Axillary surgery: } 48 \% \text { underwent } \\
\text { ALND }\end{array}$ & $\begin{array}{l}\text { Mean } 6.2 \text { SD } \\
0.81 \text { years }\end{array}$ & $\begin{array}{l}\text { Self-report of swelling } \\
\text { and/or volume } \\
\text { difference } \geq 200 \mathrm{~cm}^{3} \\
\text { between operated and } \\
\text { non-operated limb }\end{array}$ & $\begin{array}{l}\text { BCRL }(n=26) \text { VS no BCRL } \\
\text { EORTC QLQ-C30: BCRL significantly associated } \\
\text { with decreased social functioning. }\end{array}$ \\
\hline
\end{tabular}




\section{References}

1.Research/CancerFactsFigures/BreastCancerFactsFigures/breast-cancer-facts-and-figures-20112012. Available from: www.cancer.org.

2. Montazeri A, Health-related quality of life in breast cancer patients: a bibliographic review of the literature from 1974 to 2007. J Exp Clin Cancer Res 2008; 27: 32.

3. Mols F, Vingerhoets AJ, Coebergh JW, van de Poll-Franse LV, Quality of life among long-term breast cancer survivors: A systematic review. European Journal of Cancer 2005; 41(17): 26132619.

4. Taira N, Shimozuma K, Shiroiwa T et al, Associations among baseline variables, treatmentrelated factors and health-related quality of life 2 years after breast cancer surgery. Breast Cancer Res Treat 2011; 128(3): 735-47.

5. Shimozuma K, Ganz PA, Petersen L, Hirji K, Quality of life in the first year after breast cancer surgery: rehabilitation needs and patterns of recovery. Breast Cancer Res Treat 1999; 56(1): 45-57.

6. Voogd AC, Ververs JM, Vingerhoets AJ, Roumen RM, Coebergh JW, Crommelin MA, Lymphoedema and reduced shoulder function as indicators of quality of life after axillary lymph node dissection for invasive breast cancer. Br J Surg 2003; 90(1): 76-81.

7. Oliveri JM et al. Arm/hand swelling and perceived functioning among breast cancer survivors 12 years post-diagnosis: CALGB 79804. J Cancer Surviv. 2008;2(4):233-42.

8. Cachaj $A$ et al. Physical and psychological impairments of women with upper limb lymphedema following breast cancer treatment. Psychooncology. 2010;19(3): 299-305.

9. Ververs JM, Roumen RM, Vingerhoets AJ et al, Risk, severity and predictors of physical and psychological morbidity after axillary lymph node dissection for breast cancer. Eur J Cancer 2001; 37(8): 991-9. Ververs JM

10. Ashikaga T, Krag DN, Land SR et al. Morbidity results from the NSABP B-32 trial comparing sentinel lymph node dissection versus axillary dissection.J Surg Oncol.2010;102(2):111-8.

11. Ahmed RL, Prizment A, LAzovich D, Schmitz K, Folsom AR, Lymphedema and quality of life in breast cancer survivors: the lowa Women's Health Study. J Clin Oncol 2008; 26(35): 5689-96.

12. Engel J, Kerr J, Schlesinger-Raab A, Sauer H, Hölzel D, Axilla surgery severely affects quality of life: results of a 5 -year prospective study in breast cancer patients. Breast Cancer Res Treat 2003; 79(1): 47-57.

13. Beaulac SM, McNair LA, Scott TE, LaMorte WW, Kavanah MT, Lymphedema and quality of life in survivors of early-stage breast cancer. Arch Surg 2002; 137(11): 1253-7.

14. Lopez Penha TR, Slangen JJ, Heuts EM, Voogd AC, Von Meyenfeldt MF, Prevalence of lymphoedema more than five years after breast cancer treatment. Eur J Surg Oncol 2011; 37(12): 1059-63.

15. Lette J, A simple and innovative device to measure arm volume at home for patients with lymphedema after breast cancer. J Clin Oncol 2006; 24(34): 5434-40.

16. Aaronson NK, Ahmedzai S, Bergman B et al, The European Organization for Research and Treatment of Cancer QLQ-C30: a quality-of-life instrument for use in international clinical trials in oncology. J Natl Cancer Inst 1993; 85(5): 365-76.

17. van de Poll-Franse LV, Mols F, Gundy CM et al. Normative data for the EORTC QLQ-C30 and EORTC-sexuality items in the general Dutch population. Eur J Cancer 2011; 47(5): 67-675.

18. Rietman JS, Dijkstra PU, Hoekstra HJ et al, Late morbidity after treatment of breast cancer in relation to daily activities and quality of life: a systematic review. Eur J Surg Oncol 2003; 29(3): 22938. 
19. Mansel RE, Fallowfield L, Kissin M et al, Randomized multicenter trial of sentinel node biopsy versus standard axillary treatment in operable breast cancer: the ALMANAC Trial. J Natl Cancer Inst 2006; 98(9): 599-609.

20. Fleissig A, Fallowfield L, Langridge $\mathrm{Cl}$ et al, Post-operative arm morbidity and quality of life. Results of the ALMANAC randomised trial comparing sentinel node biopsy with standard axillary treatment in the management of patients with early breast cancer. Breast Cancer Res Treat 2006; 95(3): 279-93.

21. Aerts PD, de Vries J, van der Steeg AF, Roukema JA, The relationship between morbidity after axillary surgery and long-term quality of life in breast cancer patients: the role of anxiety. Eur $\mathrm{J}$ Surg Oncol 2011; 37(4): 344-9.

22. Nesvold IL, Reinertsen KV, Fosså SD, Dahl AA, The relation between arm/shoulder problems and quality of life in breast cancer survivors: a cross-sectional and longitudinal study. $J$ Cancer Surviv 2011; 5(1): 62-72.

23. Shah C, Arthur D, Riutta J, Whitworth P, Vicini FA, Breast -Cancer related lymphedema: A review of procedure specific incidence rates, clinical assessment aids, treatment paradigms, and risk reduction. Breast $\mathrm{J} 2012$; 18(4): 357-61.

24. Mols F, Vingerhoets AJ, Coebergh JW, van de Poll-Franse LV, Well-being, posttraumatic growth and benefit finding in long-term breast cancer survivors. Psychol Health 2009; 24(5): 583 595.

25. Giuliano AE, Hunt KK, Ballman KV et al, Axillary dissection vs no axillary dissection in women with invasive breast cancer and sentinel node metastasis: a randomized clinical trial. JAMA 2011; 305(6): 569-75.

26. Chachaj A, Malyszczak K, Pyszel K et al, Physical and psychological impairments of women with upper limb lymphedema following breast cancer treatment. Psychooncology 2010; 19(3): 299305.

27. Hårtl K, Engel J, Herschbach P, Reinecker H, Sommer H, Friese K, Personality traits and psychosocial stress: quality of life over 2 years following breast cancer diagnosis and psychological impact factors. Psychooncology 2010; 19(2): 160-9. 
Biomechanical properties of the skin in BCRL 


\section{Chapter 4}

Biomechanical properties of the skin in patients with breast cancer related lymphedema compared to healthy individuals



Adapted from: Lymphat Res Biol 2015. Sep;13 (3):215-21 


\section{Abstract}

Background: Biomechanical skin changes in breast cancer related lymphedema (BRCL) have barely been described and objectively tested. This study aims to compare the skin of upper-limb lymphedema with skin of the healthy contralateral arm, in order to demonstrate changes of elasticity, viscoelasticity and level of hydration of the skin in BCRL. The secondary aim is to investigate the correlation between biomechanical skin changes and measurements that are currently used in clinical practice, such as volume measurement and Lymph-ICF score.

Methods and Results: Eighteen patients with BCRL and 18 healthy individuals were included in the study. A Cutometer ${ }^{\circledR}$ was used for measurements for skinelasticity and visco-elasticity, a Corneometer ${ }^{\circledR}$ was used for measurements of skin-hydration. Measurements of both test groups were compared. In BCRL patients, there was a significant difference $(p=<0,028)$ between the elasticity of the skin of the lymphedema arm compared to the healthy contralateral arm. There were no significant differences for level of skin-hydration or viscoelasticity in lymphedema patients between the measurements on the skin of the lymphedematous and healthy arm. In healthy individuals, there were no significant differences for all measurements between skin of both arms. Spearman's correlation was significant $(p=<0,01)$ for difference in volume and difference in elasticity in BCRL patients.

Conclusion: This study shows an impaired elasticity for the skin of the lower arm in patients with lymphedema compared to the contralateral healthy arm. Promising evidence is suggested for the use of the Cutometer device in the diagnostic evaluation of BCRL. 


\section{Introduction}

One of the most underestimated and debilitating morbidities breast cancer survivors may experience is breast cancer related lymphedema (BRCL). BCRL may present with symptoms of heaviness, tightness and pain. It is a result of the accumulation of lymphatic fluid in the interstitial tissues and is characterized by swelling of the arm, hand, breast and/or trunk. In the initial stage of lymphedema, the edema may be soft and pitting. If left untreated, the reaction to tissue injury induces the accumulation of inflammatory cells, which is a hallmark of pathophysiological events in the skin. Activation of lymphocytes, leukocytes and release of cytokines induce connective tissue synthesis in fibroblasts. The excessive deposition of extracellular matrix, especially collagens, is the complex tissue response which is called fibrosis. ${ }^{3}$ Ultrastructural research has shown that this process is accompanied by the degeneration of smooth muscle cells in the lymphedematous tissue. ${ }^{4}$ The contraction of these smooth muscle cells, together with the compression of skeletal muscles, determine the interstitial pressure that stimulates lymphatic drainage. The above-described pathological changes of the lymphedematous tissue can be regarded as a key step for the progressing pathological status of lymphedema. ${ }^{5,6}$

Tissue resistance in post-surgical lymphedema has previously been measured and evaluated with the use of tonometry. ${ }^{7}$ Indentation measurement on lymphedema patients has shown increased tissue resistance in lymphedematous skin. ${ }^{8,9}$ Both the pathogenesis of BCRL and the previous findings of increased tissue indentation in lymphedatous tissue, implicate a role of biomechanical skin changes within development of BCRL.

The Cutometer device is seen as an attractive and suitable option for testing and monitoring changes in biomechanical properties of the $\operatorname{skin}^{10,11}$. This device has been used in previous research for the evaluation of skin properties in facial wrinkles, wounds and scar healing. ${ }^{12-14}$ Furthermore, it has been used for measuring elasticity of the skin after radiotherapy. ${ }^{15}$ Besides the biomechanical skin properties in the evaluation of BCRL, fluid accumulation is an initial component in edematous and lymphedematous conditions. Tissue fluid water and proteins accumulate in the interstitial space, ${ }^{16,17}$ this makes it both of fundamental and clinical interest to know what relationship exists between tissue water and tissue resistance. 
Local tissue water in lymphedema has already been quantified using the tissue's dielectric constant (TDC), showing significantly greater values in lymphedematous legs compared to healthy legs. ${ }^{9}$ These outcomes gained our interest for determining skin hydration in lymphedematous conditions. In the past, measurements of skin hydration have particularly been used in dermatologic testing of products and for the evaluation of skin development. ${ }^{18-20}$ Measurements are mostly performed by use of a Corneometer, which is a validated tool for measuring hydration of the stratum corneum of the skin. ${ }^{20}$

The primary aim of this study is to compare the lymphedematous skin to that of the healthy contralateral arm in breast cancer survivors, in order to demonstrate the biomechanical changes (elasticity, visco-elasticity) and level of hydration of the skin. The secondary aim is to correlate biomechanical skin changes with current clinical assessment measurements of lymphedema, such as objective volume measurement as well as subjective functional impairments measured with the Lymph-ICF score.

\section{Materials and Methods}

\section{Subjects}

A total of 34 women with BCRL were asked to participate in the study, of which 24 were willing to participate. All subjects were over 18 years and were treated for unilateral early stage breast cancer in Maastricht University Medical Centre+ (MUMC+) between May, $14^{\text {th }} 2004$ and December 21 ${ }^{\text {st }}, 2010$. During routine follow-up visit after primary breast cancer surgery, upper-limb volume of the affected side was measured with the water-displacement method and compared to that of the healthy contralateral arm. Patients were enrolled in the study if they had more than $\mathbf{2 0 0}$ milliliters $(\mathrm{ml})$ volume difference and had subjective complaints or if they were currently being treated by a lymphedema therapist. Patients were excluded from participation if they had, recurrent breast cancer, bilateral breast cancer, distant breast cancer metastases, or if they had a medical history of cancer other than breast cancer. A total of 22 patients met the inclusion criteria. Subjects were instructed not to wear elastic arm garments on the test day so that volume measurements were not influenced. Written consent was obtained from each subject prior to inclusion of this study. 
Eighteen healthy participants, all women, without BCRL or open lesions on their upper extremity were asked to participate. Three subjects with unilateral BCRL wore an elastic arm garment on the test day (against the given instructions). One patient exceeded the maximum arm volume measurable by the water displacement method. These four BCRL patients were excluded from the study before calculations were made.

Ultimately 36 subjects completed the study, 18 subjects with unilateral BCRL and 18 healthy individuals. Baseline characteristics of all subjects were collected before testing.

\section{Study design}

All subjects were invited for a single consultation in the outpatient clinic of MUMC+. Measurements were done in the same room with specified conditions; a temperature of $20-22^{\circ} \mathrm{C}$ and $40-60 \%$ humidity as instructed in the measuring principles of the Cutometer® MPA 580 (Courage and Khazaka, Köln, Germany). Patients were seated with their arm on the surface of the table with their hand and fingers relaxed during Cutometer measurements. The angle of the elbow was approximately $120^{\circ}$, the angle between the upper arm and the supporting surface was approximately $40^{\circ}$, and the angle between the upper arm and the shoulder was approximately $90^{\circ}$. Measurements for elasticity, visco-elasticity and hydration were performed on each subject on both arms.

Elasticity measurements were taken of the skin of both lower arms, at the volar midpoint between the tip of the ulnar styloid process and medial epicondyle of the humerus (F-MP). This is one of the predetermined sites of the lower arm where extra lymphatic fluid of the upper-limb can accumulate. ${ }^{21}$ The volar site of the arm was taken so that measurements were not influenced by body hair on the dorsal site of the arm. Cutometer measurements were repeated after ten minutes, as advised by the device manufacturer. The suction and release time of the Cutometer could cause the skin to be strained and might distort the results of the next measurement. The average of both measurements was taken and used for analysis.

All study procedures were in accordance with the ethical standards of the Medical Ethical Committee Maastricht and with the Helsinki Declaration of 1975 , as revised in 2008. 


\section{Elasticity and visco-elasticity of the skin}

Vertical extensibility of the skin was measured using a Cutometer MPA 580 system with a Cutometer $Q$ probe; a non-invasive suction device that measures the vertical deformation of the skin surface. A constant negative pressure of 450 mbar during 6 seconds was applied, to draw the skin up into the circular aperture $(6 \mathrm{~mm}$ diameter) of the probe, followed by normalization of the pressure and returning of the skin in original shape. ${ }^{22}$ The Cutometer device generates a graph showing skin extensibility (Ue), delayed distension (Uv), final deformation (Uf), immediate retraction (Ur) and final retraction (Ua). (Figure 2) The Cutometer software MPA 580 was used to automatically generate $R$ parameters ( $\mathrm{R} 0$ to $\mathrm{R} 9$ ). These parameters are relative parameters which are thought to be independent on skin thickness, which varies in age, sex and anatomical region. ${ }^{11}$ Skin elasticity is reflected by R2, R5 and R7. ${ }^{23}$ These values were generated as follows (figure 2): R2 (Ua/Uf) (gross elasticity), R5 (Ur/Ue) (net elasticity) and R7 (Ur/Uf) (biological elasticity). Value R6 (Uv/Ue) represents the viscoelasticity ratio.

\section{Hydration of the skin}

An additional Corneometer CM 825 probe was used to assess the level of hydration of the stratum corneum in the lymphedema and healthy contralateral arm. The probe contains a grid of electrodes, which are used for measuring the capacitance of the electrodes and epidermal skin to calculate total skin capacitance. The values of capacitance of the skin are converted in the instrument in arbitrary units of skin hydration ranging from 0 to $120 .^{18}$ Calibration was performed using a cellulose filer paper saturated with a $15 \%$ $\mathrm{NaCl}$ aqueous solution, giving a maximal hydration value of 120 . To increase reliability, measurements at F-MP on both arms were taken three times from which the average was taken.

\section{Determining severity of lymphedema}

The degree of lymphedema is determined by different measurements and values, including volume difference of the upper-limb and experienced disabilities as a result of the lymphedematous limb. ${ }^{24,25}$ All lymphedema patients in the study underwent an objective measurement of volume of both arms, and had to fill-out the Lymphedema Functioning, Disability and Health" ("Lymph-ICF") questionnaire for evaluation of the current functional impairments they were experiencing from the lymphedema. 
The Lymph-ICF is a validated questionnaire that assesses the impairments in function, activity limitations and participation restrictions in patients with upper limb lymphedema, based on 29 questions corresponding with a score between 0-100. A higher score indicates more problems with functioning related to upper-limb lymphedema. ${ }^{26}$

Inter-limb volume difference measured using the water displacement method, the golden standard for measuring arm volume. ${ }^{25}$ A Volumeter (Varitex, Haarlem, The Netherlands) was filled with tap water with a temperature of 25 ${ }^{\circ} \mathrm{C}$ and $32{ }^{\circ} \mathrm{C}$. Water temperatures across the range of 20 to 32 degrees Celsius were not found to affect the volume measured. ${ }^{27,}{ }^{28} \mathrm{~A}$ circumference line was drawn at $80 \%$ of the arm length, measured from the tip of the third digit to the tip of the acromion. Subjects were instructed to lower the arm into the Volumeter until the water reached the circumference line. The Volumeter weighed the overflowing water with an integrated calibrated scale with an accuracy of $1 \mathrm{cc}$. All water displacement measurements were done after hydration measurements with the Corneometer CM 825 probe, so that the hydration state of the stratum corneum of the skin could not be influenced by the water exposure of the arm in the Volumeter.

\section{Data analysis}

Patients and clinical characteristics were described using descriptive statistics. Reliability analysis was used to calculate intraclass correlation coefficient (ICC) to determine the intra-rater reliability of the Cutometer measurements in the lymphedematous arm. The Intraclass Correlation Coeffeicient (ICC) was used to determine the intra-rater reliability of all elasticity measurements in healthy and lymphedema skin. Intra-rater reliability was determined from two repeated measurements with the Cutometer done by the same investigator. To assess differences between biomechanical skin properties in both arms, a Paired Samples t-test was used. A p-value of $<0,05$ was considered statistically significant.

The measurement parameters (elasticity or hydration) that were significantly different in the BCRL arm and the healthy contralateral arm, were correlated to clinical assessment points (difference in limb volume and lymph-ICF score). These correlations were calculated with Spearman's correlation coefficient. Data were analyzed using statistical software (SPSS 20.0 Inc Chicago, III). 


\section{Results}

\section{Participants}

All 36 subjects were able to complete the study. BCRL patients had a median age of 63 years [SD 9,2]. Ten patients had left-sided lymphedema, 8 patients had right-sided lymphedema. Healthy individuals had a mean age 23 [SD 12,4] of and a mean BMI of 22 [2,7]. All 18 individuals were female. Patient characteristics of both groups are described in Table 1.

Table 1. Patient characteristics

\begin{tabular}{|c|c|c|c|c|}
\hline \multirow[b]{2}{*}{ Patient Characteristics } & \multicolumn{2}{|c|}{ Healthy individuals $(\mathrm{N}=18)$} & \multicolumn{2}{|c|}{ BCRL Patients ( $\mathrm{N}=18$ ) } \\
\hline & Mean [SD] & $\mathrm{n}=18(100 \%)$ & Mean [SD] & $\mathrm{n}=18(100 \%)$ \\
\hline Age (years) & $23[12,4]$ & & $63[9,2]$ & \\
\hline $\mathrm{BMI}\left(\mathrm{kg} / \mathrm{m}^{2}\right)$ & $22[2,7]$ & & $27[5,1]$ & \\
\hline Right-handed N (\%) & & $17(94,4 \%)$ & & $16(88 \%)$ \\
\hline Smoking N (\%) & & $2(11,1 \%)$ & & $2(11,1 \%)$ \\
\hline Lymphedema & & $0(0 \%)$ & & $21(100 \%)$ \\
\hline Arm volume difference (cc) & - & & $385[369,1]$ & \\
\hline Lymph-ICF score & - & & $36[19,5]$ & \\
\hline Right- sided lymph edema N (\%) & & - & & $10(55,5 \%)$ \\
\hline Dominant-hand lymph edema N (\%) & & - & & $8(44,4 \%)$ \\
\hline
\end{tabular}

\section{Reliability of measurements}

Intraclass correlation coefficients (ICC) for all elasticity parameters were high, namely: 0,707 for biological elasticity (R7), 0,715 for net elasticity (R5) and 0,882 for gross elasticity (R2). ICC for viscoelasticity (R6) was 0,753 .

\section{Interlimb difference - elasticity and viscoelasticity}

Patients with BCRL had an impaired elasticity of the skin in the lower lymphedematous arm, compared to their healthy contralateral arm. All values for elasticity showed a significant difference. (R2: $p=0,028$; $R 5$ : $p=0,019 ; R 7$ : $p=0,013$ ). The mean elasticity difference between both arms ranged from 0,127 (R5) to 0,08 (R7). There was no significant difference between viscoelasticity of the lymphedematous arm and contralateral healthy arm $(R 6:-p=0,409)$. Healthy individuals showed no difference for values of elasticity and visco-elasticity 
between the skin of both lower arms (R2: $p=0,782 ; R 5: p=0,339 ; R 7: p=0,147$ and R6: $p=0,632$ ). (Table 2)

\section{Interlimb difference - hydration}

The hydration of the skin between both arms was not significantly different in $B C R L$ patients $(p=0,218)$. In healthy individuals, the difference was also not significant $(p=0,488)$ (Table 2$)$.

Table 2. Difference in skin properties in healthy individuals and BCRL patients

\begin{tabular}{|c|c|c|c|c|c|c|c|c|c|c|}
\hline \multirow{3}{*}{ Arm difference } & \multicolumn{5}{|c|}{ Healthy individuals $(\mathrm{N}=18)$} & \multicolumn{5}{|c|}{ BCRL patients $(\mathrm{N}=18)$} \\
\hline & \multirow[t]{2}{*}{ Mean } & \multicolumn{2}{|c|}{$\begin{array}{l}95 \% \text { confidence } \\
\text { interval }\end{array}$} & \multirow[t]{2}{*}{$\mathrm{T}$} & \multirow[t]{2}{*}{$\begin{array}{c}\text { Sign } \\
\text { (2-tailed) }\end{array}$} & \multirow[t]{2}{*}{ Mean } & \multicolumn{2}{|c|}{$\begin{array}{l}95 \% \text { confidence } \\
\text { interval }\end{array}$} & \multirow[t]{2}{*}{$\mathrm{T}$} & \multirow[t]{2}{*}{$\begin{array}{c}\text { Sign } \\
\text { (2-tailed) }\end{array}$} \\
\hline & & Lower & Upper & & & & Lower & Upper & & \\
\hline Hydration & 0.611 & -1.207 & 2.429 & 0.709 & 0.488 & 2.596 & -1.685 & 6.877 & 1.28 & 0.218 \\
\hline \multicolumn{11}{|l|}{ Elasticity } \\
\hline R2 - gross elasticity & 0.002 & -0.015 & 0.020 & 0.281 & 0.782 & 0.085 & 0.010 & 0.159 & 2.404 & $0,028^{*}$ \\
\hline R5 - net elasticity & 0.023 & 0.023 & 0.026 & -0.983 & 0.339 & 0.128 & 0.024 & 0.238 & 2.591 & $0,019 *$ \\
\hline R7 - biological elasticity & 0.006 & -0.031 & 0.019 & -0.488 & 0.632 & 0.082 & 0.020 & 0.144 & 2.779 & $0,013^{*}$ \\
\hline \multicolumn{11}{|l|}{ Viscoelasticity } \\
\hline R6 - visco-elasticity & 0.030 & -0.071 & 0.012 & -0.519 & 0.147 & -0.026 & -0.091 & 0.039 & -0.846 & 0.409 \\
\hline
\end{tabular}

Paired sample t-Test, * significance level $<0.05$

\section{Interlimb difference - volume}

Mean difference for volume between both arms in BCRL patients was $385 \mathrm{cc}$ [SD 369].

Lymph - ICF score

Mean Lymph-ICF score for BCRL patients were 36 [SD 19,5]. 
Correlations (between biomechanical skin changes and volume difference or Lymph ICF score)

Spearman correlations for inter-limb differences in elasticity (R2, R5 and R7) and inter-limb volume difference were significant for $R 2: r=0,591(p=0,010)$; $R 5: r=0,618(p=0,006)$ and $R 7: r=0,649(p=0,004)$ (Figures 1,2,3).

Correlation coefficients for elasticity and Lymph-ICF score were low and not significant, ranging from $r=0,031$ (R7) to $r=0,088(R 2)$.

Figure 1. Correlation between elasticity difference (R2) and volume difference (cc) between both arms.

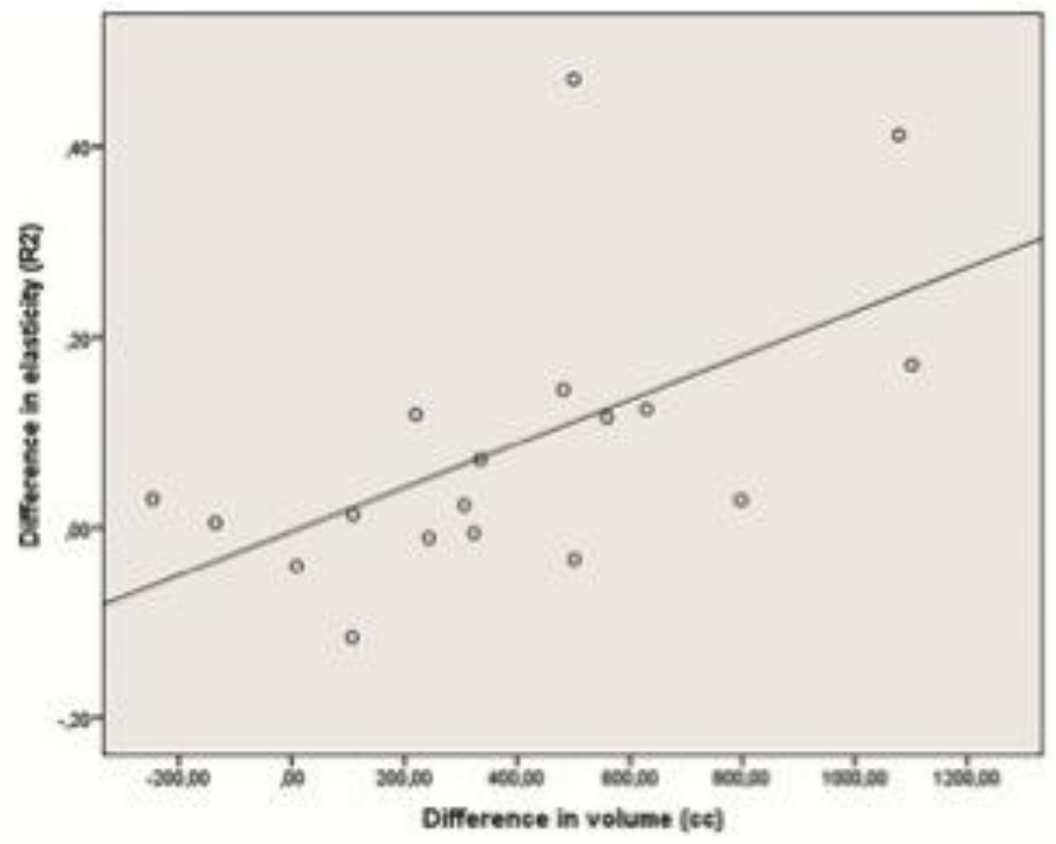


Figure 2. Correlation between elasticity difference (R5) and volume difference (cc) between both arms.



\section{Discussion}

The results of this study show a significantly lower elasticity of the skin in upperlimb lymphedema. This finding is supported by the theory that there is an increase in volume of the subcutaneous tissue which affects the skin by increasing its tension at rest. ${ }^{24}$ The proportional changes within the tissue result in modification of the intermolecular bridging and thickening of the collagen bundle. ${ }^{30}$

The Cutometer device revealed to be a reliable method for the evaluation of skin elasticity in lymphedematous skin using the suction method. Values for extensibility and elasticity were reliable with a reproducibility ranging from 0,707 to 0,882 . Other studies using a Cutometer for measuring skin properties found small coefficients of variation between measurements ranging from $0,7 \%$ $6,2 \% .^{10,31}$ Inter-relation parameters for elasticity measurements show high correlations. (R: $0.7->0,9){ }^{32}$ The advantage of measurements with the Cutometer is that the outcome for elasticity is corrected for the depth of deformation applied with the instrument. The small size of the measuring probe 
makes it very applicable in clinical practice. In addition, the minimal measuring diameter decreases the chance of bias due to topographical irregularities.

Figure 3. Correlation between elasticity difference (R7) and volume difference (cc) between both arms.

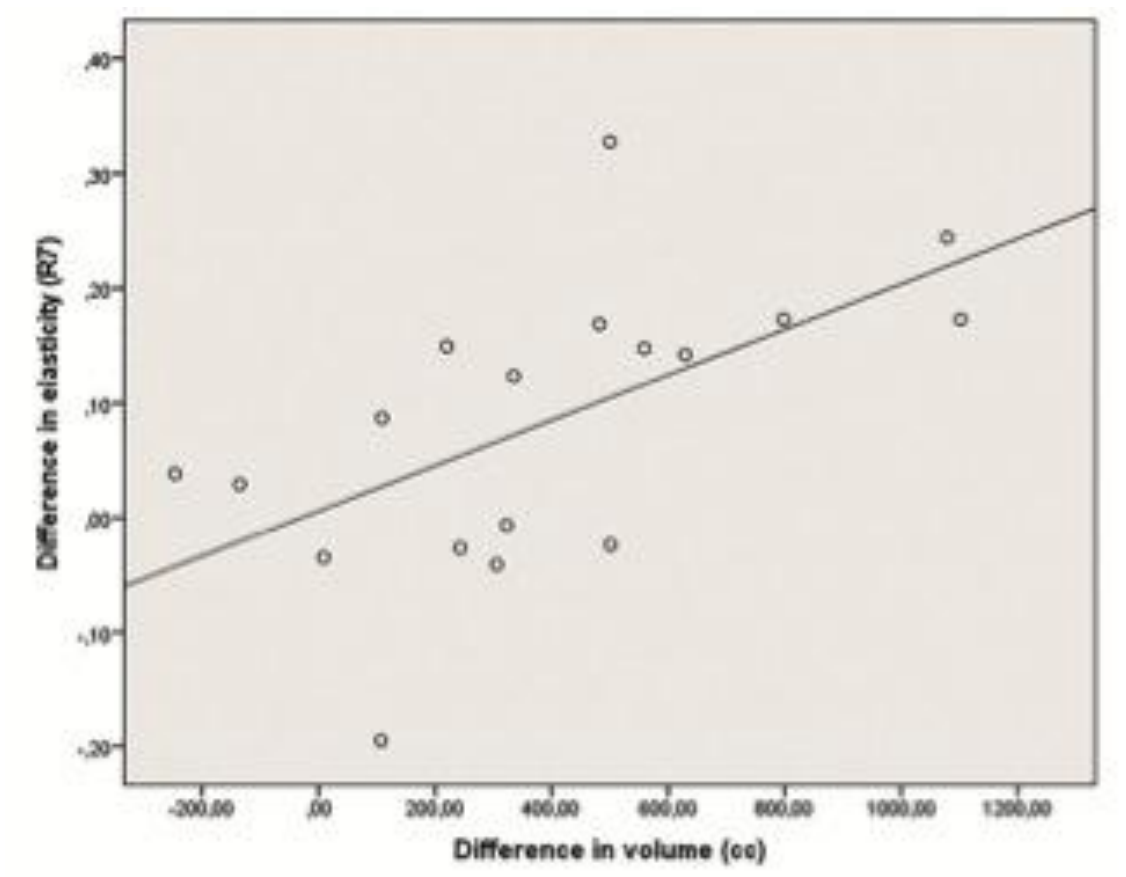

Tools that have previously been used for the measurement of biomechanical properties of the skin are a Tonometer or a caliper. A tonometer can be applied to the skin and measures the depth of the mass that is descended. Results of measuring with the tonometer highly relied on the correct positioning and amount of pressure applied when placing the tool on the skin. 7,33 A caliper, which is used to measure skin creases of the arm, appeared to be a reliable measuring method, but edema of the deeper tissues is not taken into account. 34 Tissue indentation measurements for the assessment of lymphedema have previously been developed to evaluate tissue resistance. Tissue resistance is not only dependent on the biomechanical properties of the skin, but also influenced by the underlying accumulated interstitial water. ${ }^{9}$ The amount of 
interstitial water can be easily influenced by therapy such as manual lymphatic drainage. Indentation measuring is therefore not suitable for quantifying the biomechanical properties of the skin alone. Measurements with the Cutometer are less dependent on the amount of interstitial water, as it measures only the skin extensibility with use of the suction method. This can make the measurement very suitable for diagnostic of follow-up measurement in clinical practice to investigate the pathological changes of the skin in BCRL.

There are a few other studies that use a Cutometer for measuring skin extensibility and elasticity in lymphedematous skin. Auriol et al. showed a $20 \%$ reduction of skin extensibility (Ue) and elasticity (R5) in the lymphedema lowerlimb in comparison to its healthy contralateral limb. ${ }^{34}$ These results are consistent with our findings of an impaired elasticity in the skin of upper-limb lymphedema. In addition, the current study shows a significant correlation between elasticity- and volume difference of both arms. This suggests a clinical relevance for the elasticity parameter. In other words: a continued decrement in the elasticity parameters may be an indication for further progression of lymphedema.

Lymphedema evaluation in clinical practice tends to focus on volume change. Although volume is important and is the most objective current clinical measure, using only volume may overlook important tissue texture changes, as well as latent stage lymphedema disease. ${ }^{29}$ Hacard et al. set up a study with patients undergoing therapy for lymphedema, and used values of elasticity measured with a Cutometer to evaluate the changes in skin properties before and after therapy. ${ }^{23}$ Correlations were calculated for elasticity parameters and decrease of volume after therapy. A correlation was not found. This could be explained by the fact that in severe stages of lymphedema, where skin fibrosis and accumulation of extracellular matrix occurs ${ }^{3}$, elastic fibers might be destroyed. The elasticity parameter is therefore probably not applicable for a solitary follow-up measurement after treatment. However, elasticity parameters might be very useful in the late stages of lymphedema where fibrosis of the skin occurs despite a constant volume of the limb.

Considering that a relatively small population group is used in this study, individual patients might have had a big influence on results and significance. If elasticity parameters are to be used as a follow-up or diagnostic tool in clinical practice, research should be further carried out in a prospective setting with 
more patients in different stages of lymphedema and measurements taken before and after lymphedema treatment. Subgroup analyses can then be performed to investigate for which purposes in clinical practice the Cutometer measurements are most relevant.

Our Corneometer measurements showed no significant differences for levels of hydration in the lymphedematous arm compared to the contralateral healthy arm. This is explained by the fact that the Corneometer mainly measures the hydration state of the stratum corneum of the skin. ${ }^{35}$

Fluid in lymphedema usually accumulates in the subcutaneous tissue of the arm, which cannot be measured on the skin surface. Measurements with use of tissue's dielectric constant (TDC) have shown a significantly higher amount of local tissue water in lymphedematous arms when compared to healthy arms or arms of breast cancer patients prior to surgery. ${ }^{36,37} \mathrm{TDC}$ measurement might therefore be more suitable for assessing local tissue water in BCRL then the Corneometer measurement.

\section{Conclusion}

In this article a new method for measuring skin-elasticity of upper-limb lymphedema is proposed. This study showed an impaired elasticity of the skin of the lower arm in lymphedema compared to the contralateral healthy arm. There is no significant difference in elasticity in skin of both arms in healthy individuals. This study reports promising evidence for the use of Cutometer device in the evaluation of BRCL. Further research is planned which includes a larger population in a prospective setting in subgroups for different stages of lymphedema, so subgroup analyses can be performed. The use of the Cutometer as a diagnostic or follow-up tool in clinical practice can then be more extensively evaluated. 


\section{References}

1. Ahmed RL, Prizment A, Lazovich D, Schmitz KH, Folsom AR. Lymphedema and quality of life in breast cancer survivors: the lowa Women's Health Study. Journal of clinical oncology : official journal of the American Society of Clinical Oncology. 2008;26(35):5689-96.

2. Hormes JM, Bryan C, Lytle LA, Gross CR, Ahmed RL, Troxel AB, et al. Impact of lymphedema and arm symptoms on quality of life in breast cancer survivors. Lymphology. 2010;43(1):1-13. 3. Trojanowska M, LeRoy EC, Eckes B, Krieg T. Pathogenesis of fibrosis: type 1 collagen and the skin. Journal of molecular medicine. 1998;76(3-4):266-74.

4. Koshima I, Kawada S, Moriguchi T, Kajiwara Y. Ultrastructural observations of lymphatic vessels in lymphedema in human extremities. Plastic and reconstructive surgery. 1996;97(2):397-405; discussion 6-7.

5. Nagase T, Gonda K, Inoue K, Higashino T, Fukuda N, Gorai K, et al. Treatment of lymphedema with lymphaticovenular anastomoses. International journal of clinical oncology. 2005;10(5):304-10. 6. Ji RC. Lymphatic endothelial cells, lymphedematous lymphangiogenesis, and molecular control of edema formation. Lymphatic research and biology. 2008;6(3-4):123-37.

7. Chen YW, Tsai HJ, Hung HC, Tsauo JY. Reliability study of measurements for lymphedema in breast cancer patients. American journal of physical medicine \& rehabilitation / Association of Academic Physiatrists. 2008;87(1):33-8.

8. Mayrovitz HN, Davey S. Changes in tissue water and indentation resistance of lymphedematous limbs accompanying low level laser therapy (LLLT) of fibrotic skin. Lymphology. 2011;44(4):168-77. 9. Mayrovitz HN. Assessing lymphedema by tissue indentation force and local tissue water. Lymphology. 2009;42(2):88-98.

10. Sandford E, Chen Y, Hunter I, Hillebrand G, Jones L. Capturing skin properties from dynamic mechanical analyses. Skin research and technology : official journal of International Society for Bioengineering and the Skin. 2013;19(1):e339-48.

11. Dobrev HP. A study of human skin mechanical properties by means of Cutometer. Folia Med (Plovdiv). 2002;44(3):5-10.

12. Draaijers LJ, Botman YA, Tempelman FR, Kreis RW, Middelkoop E, van Zuijlen PP. Skin elasticity meter or subjective evaluation in scars: a reliability assessment. Burns. 2004;30(2):10914.

13. Luebberding S, Krueger N, Kerscher M. Mechanical properties of human skin in vivo: a comparative evaluation in 300 men and women. Skin research and technology : official journal of International Society for Bioengineering and the Skin. 2013.

14. Yoo J, Chandarana S, Fung K, Franklin JH, Nichols AC, Doyle PC. The use of autologous platelet and plasma products in salvage neck dissections: a prospective clinical study evaluating early and late wound healing. J Biol Regul Homeost Agents. 2012;26(2 Suppl 1):63S-9S.

15. Marcenaro M, Sacco S, Pentimalli S, Berretta L, Andretta V, Grasso R, et al. Measures of late effects in conservative treatment of breast cancer with standard or hypofractionated radiotherapy. Tumori. 2004;90(6):586-91.

16. Olszewski WL. The pathophysiology of lymphedema - 2012. Handchirurgie, Mikrochirurgie, plastische Chirurgie : Organ der Deutschsprachigen Arbeitsgemeinschaft fur Handchirurgie : Organ der Deutschsprachigen Arbeitsgemeinschaft fur Mikrochirurgie der Peripheren Nerven und Gefasse 2012;44(6):322-8.

17. Olszewski WL, Ambujam PJ, Zaleska M, Cakala M. Where do lymph and tissue fluid accumulate in lymphedema of the lower limbs caused by obliteration of lymphatic collectors? Lymphology. 2009;42(3):105-11. 
18. Barel A, Clarys P. In vitro calibration of the capacitance method (Corneometer CM 825) and conductance method (Skicon-200) for the evaluation of the hydration state of the skin. . Skin Research Technology. 1997;3:107-13.

19. Fluhr JW, Gloor M, Lazzerini S, Kleesz P, Grieshaber R, Berardesca E. Comparative study of five instruments measuring stratum corneum hydration (Corneometer CM 820 and 825, Skicon 200, Nova DPM 9003). Skin research and technology : official journal of International Society for Bioengineering and the Skin. 1999;5:161-70.

20. Lee Y, Je YJ, Lee SS, Li ZJ, Choi DK, Kwon YB, et al. Changes in transepidermal water loss and skin hydration according to expression of aquaporin-3 in psoriasis. Ann Dermatol. 2012;24(2):168-74.

21. Starritt EC, Joseph D, McKinnon JG, Lo SK, de Wilt JH, Thompson JF. Lymphedema after complete axillary node dissection for melanoma: assessment using a new, objective definition. Ann Surg. 2004;240(5):866-74.

22. Courage W KG. Instruction manual for Cutometer Q MPA 580. Courage \& Khazaka, Köln. 2013. 23. Hacard F, Machet L, Caille A, Tauveron V, Georgescou G, Rapeneau I, et al. Measurement of skin thickness and skin elasticity to evaluate the effectiveness of intensive decongestive treatment in patients with lymphoedema: a prospective study. Skin research and technology : official journal of International Society for Bioengineering and the Skin. 2013.

24. Sakorafas GH, Peros G, Cataliotti L, Vlastos G. Lymphedema following axillary lymph node dissection for breast cancer. Surgical oncology. 2006;15(3):153-65.

25. International Society of $L$. The diagnosis and treatment of peripheral lymphedema: 2013 Consensus Document of the International Society of Lymphology. Lymphology. 2013;46(1):1-11.

26. Devoogdt N, Van Kampen M, Geraerts I, Coremans T, Christiaens MR. Lymphoedema Functioning, Disability and Health questionnaire (Lymph-ICF): reliability and validity. Physical therapy. 2011;91(6):944-57.

27. Pellecchia GL. Figure-of-eight method of measuring hand size: reliability and concurrent validity. Journal of hand therapy : official journal of the American Society of Hand Therapists. 2003;16(4):300-4.

28. Boland R, Adams R. Development and evaluation of a precision forearm and hand volumeter and measuring cylinder. Journal of hand therapy : official journal of the American Society of Hand Therapists. 1996;9(4):349-58.

29. Johnson KC, Kennedy AG, Henry SM. Clinical measurements of lymphedema. Lymphatic research and biology. 2014;12(4):216-21.

30. Manschot JF, Brakkee AJ. The measurement and modelling of the mechanical properties of human skin in vivo--II. The model. Journal of biomechanics. 1986;19(7):517-21.

31. Hashmi F, Malone-Lee J. Measurement of skin elasticity on the foot. Skin research and technology : official journal of International Society for Bioengineering and the Skin. 2007;13(3):252-

8.

32. Neto $P$, Ferreira M, Bahia F, Costa P. Improvement of the methods for skin mechanical properties evaluation through correlation between different techniques and factor analysis. Skin research and technology : official journal of International Society for Bioengineering and the Skin. 2013;19(4):405-16.

33. Liu NF, Olszewski W. Use of tonometry to assess lower extremity lymphedema. Lymphology. 1992;25(4):155-8.

34. Auriol F, Vaillant L, Pelucio-Lopes C, Machet L, Diridollou S, Berson M, et al. Study of cutaneous extensibility in lymphoedema of the lower limbs. The British journal of dermatology. 1994;131(2):265-9. 
35. O'Goshi K, Serup J. Inter-instrumental variation of skin capacitance measured with the Corneometer. Skin research and technology : official journal of International Society for Bioengineering and the Skin. 2005;11(2):107-9.

36. Mayrovitz HN, Weingrad DN, Davey S. Tissue dielectric constant (TDC) measurements as a means of characterizing localized tissue water in arms of women with and without breast cancer treatment related lymphedema. Lymphology. 2014;47(3):142-50.

37. Mayrovitz HN. Assessing local tissue edema in postmastectomy lymphedema. Lymphology. 2007;40(2):87-94. 
Biomechanical properties of the skin in BCRL 


\section{Chapter 5}

Reduced prevalence of lymphedema in patients with reconstructive breast surgery

Tiara R Lopez Penha Adri C Voogd Esther M Heuts Charlotte ljsbrandy Nicole AM Hendrix Maarten $\mathrm{F}$ von Meyenfeldt René RWJ van der Hulst

Adapted from: Breast J 2014 Nov;20 (6):671-3 


\section{Abstract}

Aim: To determine if breast reconstruction has an influence, either protective or risk increasing, on the prevalence of breast cancer related lymphedema (BCRL).

Methods: Women who underwent unilateral mastectomy and axillary lymph node dissection (ALND) with or without immediate or delayed breast reconstruction between January 2006 and December 2010 were included. BCRL was defined as subjective complaints of arm swelling accompanied by an inter-limb volume difference of $>200 \mathrm{ml}$ or receiving treatment for arm lymphedema.

Results: A total of 130 women were included. Breast reconstruction $(n=59)$ was performed with a tissue expander or implant in 26 cases, with an autologous free flap in 29 cases and with a combination of an implant and latissimus dorsi myocutaneous flap in 4 cases. The prevalence of BCRL was $45 \%(32 / 71)$ in the mastectomy only group and $19 \%(11 / 59)$ in the reconstruction group $(\mathrm{p}=0.001)$. After multivariable adjustment breast reconstruction was associated with a significantly lower $B C R L$ risk $(O R=0.30$; $95 \% \mathrm{Cl} 0.13-0.72)$.

Conclusion: $B C R L$ was less frequently observed in patients undergoing breast reconstruction after mastectomy and ALND. Further studies are needed to confirm this association of breast reconstruction with BCRL. This information is of interest for the surgical decision making process. 


\section{Introduction}

Breast reconstruction, either with an implant or tissue flap, has become an indispensible addition to breast cancer management. Not only do modern reconstructive techniques provide good aesthetic results, they also have been demonstrated beneficial with regards to quality of life and body image ${ }^{1,2}$ without interfering with cancer management. ${ }^{3,4}$ The wide application of reconstructive breast surgery has raised the question whether it should be considered as a risk factor or protective factor for the development of breast cancer related lymphedema (BCRL). The current literature provides some evidence for a protective effect of breast reconstruction, autologous and implant based, on the development of BCRL. ${ }^{5-7}$

Breast reconstruction is an important component of rehabilitation after ablative breast surgery. In cases where breast-conserving surgery is impossible due to tumour size, mastectomy followed by an immediate or delayed reconstruction is optional. These procedures do not only provide good aesthetic results, but have also been demonstrated beneficial with regards to quality of life and body image ${ }^{1-4}$ without interfering with cancer management. ${ }^{5,6}$ Hence, it is evident why breast reconstructions have become an indispensible addition to breast cancer management.

Arm lymphedema is one of the most burdensome breast cancer treatment related complications. ${ }^{7,8}$ Breast cancer related lymphedema (BCRL) can occur when local lymphatic vessels are damaged, causing fluid stasis that manifests as arm swelling and structural tissue changes. ${ }^{9,10}$ Some treatment modalities are notorious lymphedema risk factors, namely chemotherapy, radiation therapy and axillary surgery. ${ }^{11-13}$ The question whether reconstructive breast surgery should be added to the list of risk factors has lead to an increased interest in the role of this commonly performed surgery within the context of breast cancer treatment. The current literature bears some data on the role of breast reconstruction, autologous and implant based, on the development of BCRL. ${ }^{14-18}$

The aim of this study was to determine the impact of reconstructive breast surgery on the development of BCRL by comparing the prevalence rate of $B C R L$ in breast cancer survivors who only underwent mastectomy and of those with an additional breast reconstruction. 


\section{Methods}

\section{Patients}

We retrospectively identified all women who underwent a unilateral mastectomy with or without breast reconstruction for primary breast cancer between January $1^{\text {st }} 2006$ and December $31^{\text {st }} 2010$ in one university hospital, Maastricht University Medical Centre+, and two neighbouring community hospitals, Orbis Medical Centre in Sittard and VieCuri Medical Centre in Venlo. Approval for the study was obtained from the Medical Ethics committee of the Maastricht University Medical Centre+. Information on the surgical procedures (oncological and reconstructive), tumour characteristics and adjuvant medical treatment was extracted from hospital medical records. Patients who had died or who were alive with recurrent/metastatic disease or contralateral breast involvement were excluded. The remaining 692 women were contacted via mail and were asked to take part in a one-time medical examination and standardized interview. Two hundred ninety two (42\%) agreed to participate. However, 9 were excluded secondarily, 5 because recurrent disease had developed and 4 because bilateral disease had been treated, resulting in a study population of 283 women. For this study, only those 130 patients were selected who had undergone a full axillary lymph node dissection, as this is known to be the most important risk factor for developing BCRL. The 153 women who either had no axillary surgery $(n=7)$ or only underwent sentinel lymph node biopsy (SLNB) $(n=146)$ were excluded from analyses.

\section{Study procedures}

The participants were interviewed and examined by the chief investigator (TLP) with assistance of two dedicated researchers $(\mathrm{NH}, \mathrm{Cl})$.

\section{Standardized interview}

A standardized interview was conducted using a lymphedema risk assessment questionnaire, which was specifically developed for the purpose of the study. This questionnaire includes questions on post-operative seroma formation, history of an episode(s) of erysipelas in the affected arm since surgery and history of injury (bone fracture and/or distortions) of the affected arm since mastectomy. Furthermore, each patient was asked to indicate the presence of subjective swelling by answering the following question with a "yes" or "no": 
Have you experienced swelling of the upper-limb on the breast cancer treated side in the past year?

\section{Clinical examination}

The patients' bodyweight and height were measured in order to determine the body mass index $\left(\mathrm{BMl} \mathrm{kg} / \mathrm{m}^{2}\right)$. This was followed by a clinical examination of the chest wall and upper limbs, in which information on limb symmetry, skin texture/ thickness/tension and the aspect of surgical scar(s) was documented. Lastly, bilateral limb volume was assessed using the water displacement technique. $^{19} \quad$ BCRL was defined as subjective complaints of arm swelling accompanied by an inter-limb volume difference of $>200 \mathrm{ml}$ or if the patient was undergoing treatment for arm lymphedema (compression garment/bandages, manual lymphatic drainage, or kinesiotape applications).

\section{Statistical analysis}

Statistical analysis was performed using SPSS 20.0 (Chicago, Illinois). Data are presented as numbers with percentages for categorical variables and means with standard deviation or medians with range for continuous variables. Summary statistics were obtained using Chi square tests and Fisher's exact tests for categorical data and student's t-test and Mann-Whitney $U$ test (non normal distribution) for continuous variables. Univariable and multivariable logistic regression analyses were performed to determine the association between BCRL and clinical characteristics, specifically the association of BCRL with breast reconstruction. The odds ratio $(\mathrm{OR})$ and $95 \%$ confidence interval $(95 \% \mathrm{Cl})$ are provided. A p-value of $<0.05$ was considered statistically significant.

\section{Results}

\section{Patient characteristics}

130 patients underwent mastectomy with (55\%) and without (45\%) breast reconstruction. These women were examined and interviewed after a mean follow-up of 42.86 (SD 19.92) months after mastectomy. The patients in the breast reconstruction group were significantly younger $(p<0.001)$ and had fewer lymph nodes removed $(p=0.04)$ than their counterparts in the mastectomy only group. The majority of the reconstructive surgeries were done immediately 
Lymphedema prevalence and reconstructive breast surgery

Table 1. Characteristics of the women with and without BCRL

\begin{tabular}{|c|c|c|c|}
\hline Variables & No BCRL (n=87) & BCRL $(n=43)$ & p-value \\
\hline Age at mastectomy, mean (SD), years & $53.92(10.36)$ & $54.61(11.37)$ & 0.73 \\
\hline Age at FU, mean (SD), years & $57.65(10.11)$ & $57.82(11.12)$ & 0.93 \\
\hline $\mathrm{BMI}\left(\mathrm{kg} / \mathrm{m}^{2}\right)$ at $\mathrm{FU}$, mean $(\mathrm{SD})$ & $26.17(5.36)$ & $27.22(4.94)$ & 0.07 \\
\hline $\begin{array}{l}\text { Time since mastectomy, mean (SD), } \\
\text { months }\end{array}$ & $44.78(19.21)$ & $37.75(18.27)$ & 0.08 \\
\hline $\begin{array}{l}\text { Time since reconstruction, mean (SD), } \\
\text { months }\end{array}$ & $35.68(17.03)$ & $31.45(16.67)$ & 0.44 \\
\hline Lymph nodes removed, mean (SD) & $15.80(4.62)$ & $17.60(5.88)$ & 0.06 \\
\hline $\begin{array}{l}\text { Positive lymph nodes removed, median } \\
\text { [range] }\end{array}$ & $2[0-18]$ & $2[0-20]$ & 0.93 \\
\hline Side of surgery is dominant, no (\%) & $45(51)$ & $22(51)$ & 0.95 \\
\hline Neo-adjuvant chemotherapy, no (\%) & $19(22)$ & $11(26)$ & 0.63 \\
\hline \multicolumn{4}{|l|}{ Adjuvant Therapy, no (\%) } \\
\hline Chemotherapy & $50(57)$ & $27(64)$ & 0.42 \\
\hline Trastuzumab & $21(24)$ & $7(17)$ & 0.35 \\
\hline Radiation therapy & $41(46)$ & $24(56)$ & 0.35 \\
\hline Hormone therapy & $63(72)$ & $33(77)$ & 0.60 \\
\hline Seroma, no (\%) & $23(26)$ & $16(38)$ & 0.21 \\
\hline History of erysipelas in arm, no (\%) & $4(5)$ & $9(21)$ & 0.01 \\
\hline History of injury in arm, no (\%) & $1(1)$ & $6(14)$ & 0.005 \\
\hline Difference in arm volume, mean (SD), $\mathrm{ml}$ & $40.58(115.25)$ & $221.18(220.30)$ & $<0.001$ \\
\hline Breast reconstruction, no (\%) & & & 0.001 \\
\hline Autologous & $23(26)$ & $6(14)$ & \\
\hline TE /implant & $22(25)$ & $4(10)$ & \\
\hline LDM flap \& implant & $3(3)$ & $1(2)$ & \\
\hline
\end{tabular}

Abbreviations: SD; standard deviation, no; number, FU; follow-up, BMI; body mass index, SLNB; sentinel lymph node biopsy, ALND; axillary lymph node dissection, TE; tissue expander, LDM; latissimus dorsi myocutaneous.

following mastectomy in the same surgical session (54\%). Of the total number of breast reconstructions performed, 29 were autologous-based, 26 were with a tissue expander- or an implant and 4 were with a combination of a latissimus 
dorsi myocutaneous flap and an implant. The deep inferior epigastric perforator (DIEP) flap was the most performed autologous-based breast reconstruction (83\%).

\section{Prevalence of BCRL}

A total of 56 (43\%) women had complaints of subjective arm swelling. The prevalence was $49 \%(n=35)$ in the mastectomy only group and $36 \%(n=21)$ in the reconstruction group $(\mathrm{p}=0.12)$. As for an inter-limb volume difference of $>200 \mathrm{ml}$, this concerned $28(21 \%)$ women, of which $30 \%(n=21)$ were in de mastectomy only group and $12 \%(n=7)$ in the reconstruction group $(p=0.01)$. Furthermore, $36(28 \%)$ women were undergoing treatment for arm lymphedema, $38 \%(n=27)$ in the mastectomy only group and $15 \%(n=9)$ in the reconstruction group $(p=0.004)$. Ultimately, $43(33 \%)$ patients met the criteria for BCRL at the time of follow up (Table 1). When looking at the BCRL prevalence of each group individually, a rate of $45 \%(n=32)$ was observed in the mastectomy only group and $19 \%(n=11)$ in the reconstruction group $(p=0.001)$.

\section{Predictors of BCRL}

Table 2 presents univariable \& multivariable logistic regression analyses of factors associated with the development of BCRL. On univariable logistic regression analyses, patients with a history of injury of the affected arm since mastectomy $(\mathrm{OR}=14.50)$ or a history of an episode of erysipelas $(\mathrm{OR}=5.73)$ in the affected arm since mastectomy were associated with BCRL. A multivariable logistic regression analysis was performed using the following three variables: history of erysipelas, history of injury, and breast reconstruction (Table 3). In this model, breast reconstruction was associated with a significantly lower risk of having $\mathrm{BCRL}(\mathrm{OR}=0.30 ; 95 \% \mathrm{Cl} 0.13-0.72)$. Furthermore, history of injury and history of erysipelas in the affected arm were significantly associated with an increased likelihood of having BCRL, with an OR of $12.55(95 \% \mathrm{Cl} 1.32$ 112.09), 5.07 (95\% Cl 1.36 - 18.83), respectively. A distinction could not be made between the different types of reconstructive breast surgeries due to the small number of patients in these subgroups.

Table 2. Univariable \& multivariable logistic regression analyses of factors associated with the development of BCRL 


\begin{tabular}{lllllll} 
Prognostic factor & OR & $\mathbf{9 5 \%} \mathbf{C l}$ & $\boldsymbol{p}$-value & OR & $\mathbf{9 5 \%} \mathbf{C l}$ & $\boldsymbol{p}$-value \\
\hline Age & 1.01 & $0.97-1.04$ & 0.61 & --- & --- & --- \\
LN's removed & 1.07 & $0.99-1.15$ & 0.07 & --- & --- & -- \\
Erysipelas (yes/no) & 5.73 & $1.65-19.88$ & 0.006 & 5.07 & $1.36-18.83$ & 0.015 \\
Injury (yes/no) & 14.50 & $1.68-124.77$ & 0.015 & 12.55 & $1.32-112.09$ & 0.028 \\
BR (yes/no) & 0.25 & $0.11-0.57$ & $<0.001$ & 0.30 & $0.13-0.72$ & 0.007 \\
\hline
\end{tabular}

Abbreviations: OR; odds ratio, 95\% Cl; 95\% confidence interval, LN's; lymph nodes, BR; breast reconstruction

\section{Discussion}

In this study, breast cancer survivors who underwent mastectomy with ALND followed by breast reconstruction had a significantly lower risk of developing BCRL compared to their counterparts who only underwent mastectomy with ALND. This finding is in line with the current body of evidence; reports from comparative studies show a possible protective effect of breast reconstruction on the risk of developing BCRL. ${ }^{14-16}$ Moreover, when looking at the incidence of BCRL in a cohort of women after delayed autologous reconstruction ${ }^{17}$ and after a combination of immediate autologous or implant-based reconstructions ${ }^{18}$, rates were found to be low. We were not able to determine if the difference amongst the reconstructive methods influenced the prevalence of $B C R L$ in our population, due to the small number of patients in each group and the low prevalence of BCRL in the study cohort. Although the method of reconstruction is not likely to have an influence on the development of $B C R L$, choosing the internal mammary vessels as recipient instead of the axillary vessels in free autologous reconstructions seems to be associated with a lower BCRL risk. ${ }^{18}$ All free flap reconstructions in our study were anastomosed to internal mammary vessels or their perforator vessels.

Besides the patients undergoing compression therapy for BCRL, we diagnosed BCRL using subjective and objective measurements. Volumetric limb analysis by means of water displacement is currently considered to be "the gold standard" for diagnosing BCRL. ${ }^{19}$ However, we included patient perception of arm swelling as a criterion for defining BCRL with the intention to reduce false positive diagnoses and ensure that the measured inter-limb volume difference was due to lymphedema and not pre-existing non pathologic volume 
differences (muscle, fat). ${ }^{20,21}$ We also identified women reporting subjective arm swelling without a limb volume increase, which could be the result of sensory changes interpreted by the patient as a feeling of swelling. In saying this, the method of limb measurement strongly influences outcome (BCRL) ${ }^{20}$ In a previous publication we demonstrated the need for uniformity of the diagnostic criteria for BCRL, as using different measuring methods resulted in variable prevalence rates in a single cohort. ${ }^{20}$ Many authors do not elaborate on their criteria used to define BCRL. Of the five studies published on the association of $B C R L$ with breast reconstruction, only Avraham et $a l^{16}$ provided a clear definition for their criteria for BCRL, while the other four authors ${ }^{14,15,17,18}$ disregarded this important factor.

In the literature several physiological mechanisms have been mentioned through which breast reconstruction might protect against the development of BCRL. Firstly, it is suggested that an autologous flap reconstruction serves as a lymphatic bridge $\mathrm{e}^{22}$ or even constitutes regenerative properties due to the newly transposed lymphatic tissue accompanied in the flap. ${ }^{23}$ Moreover, in the case of an implant-based reconstruction, Blanchard et al propose a hypothesis of a "vacuum pump" effect for the lymphatic system. ${ }^{24}$ We assume that the increased circulation in the highly vascularized capsule, which forms around the implant, induces a concomitant increase in lymphatic flow. Future investigations with flow imaging lymphoscintigraphy are needed to confirm this hypothesis. Some authors have established the positive impact of autologous breast reconstruction on patients with already existing BCRL, reporting a decrease in limb volume post-operatively. ${ }^{24-26}$ In addition, simultaneous breast and lymphatic reconstruction as a treatment for upper-limb BCRL showed promising short-term results. ${ }^{27}$ If confirmed in further studies these findings would significantly influence the current management of post-mastectomy patients.

The strength of our study is the use of a combination of clearly defined subjective and objective measurements to define BCRL and the fact that assessment was done by the same dedicated investigators for all patients in this study cohort, thus reducing the risk of inter-observer variability of the measured outcomes. In addition, by describing the prevalence instead of the incidence of BCRL at 3.5 years after mastectomy we believe to have filtered out the cases with acute lymphedema that develop in the direct post-operative stage but disappear, thus only identifying the chronic BCRL cases during follow-up. Even though BCRL can develop any time after breast surgery, with a follow-up of almost 4 years after mastectomy we expect to have included a 
representative group. ${ }^{28}$ On the other hand, the lack of a preoperative assessment of the limb volume might be considered as a limitation of our study. Another potential weakness is its non-randomized design and thus the risk of confounding by indication. A statistically significant difference in the mean age and the number of lymph nodes removed was found between the mastectomy and reconstruction group. As for age, the literature shows inconsistent results about the relationship between this variable and the risk of BCRL. Most studies report no association between age and $B C R L$, while some found a decreased risk among older patients. ${ }^{31}$ These reports make younger age in the reconstruction group an unlikely explanation for our observation of a lower prevalence of $B C R L$ in this group. When looking in the literature reporting on the association of the number of lymph nodes removed and $B C R L$, a decreasing trend in the odds for BCRL is seen as the difference in removed lymph nodes between the compared groups becomes smaller. Ahmed et al. report a 3.52 higher odds of having BCRL in women with $>20$ lymph nodes removed versus those with no lymph nodes removed. ${ }^{29}$ Meeske et al. describe a 2.16 higher odds of having BCRL in women with $\geq 10$ lymph nodes removed versus those with no lymph nodes removed. ${ }^{30}$ The most recent study, by Dominick et al., reports a 1.65 higher odds of BCRL in women with $\geq 16$ lymph nodes removed as compared to those with $\leq 10$ lymph nodes removed. ${ }^{31}$ The mean number of lymph nodes removed in our study was only 1.8 nodes higher in the mastectomy only group than in the reconstruction group. Taking the above evidence into account, it is unlikely that such a small difference would lead to a clinically relevant increase of the BCRL risk in the mastectomy group. Unfortunately, it is most unlikely that a randomized study will ever be performed with the aim to determine the effect of reconstructive breast surgery on the $\mathrm{BCRL}$ risk. Being aware of that, the best evidence we can acquire is evidence from studies like ours in which sufficient measures have been taken to rule out the impact of potential confounders.

\section{Conclusion}

In summary, BCRL was less frequently observed in patients undergoing breast reconstruction after mastectomy. Further studies are needed to confirm the association of breast reconstruction with BCRL. This information is of interest for the surgical decision making process. 


\section{References}

1. Dean C, Chetty U, Forrest AP. Effects of immediate breast reconstruction on psychosocial morbidity after mastectomy. Lancet 1983; 1(8322): 459-62.

2. Elder EE, Brandberg Y, Bjorklund T, Rylander R, Lagergren J, Jurell G, et al. Quality of life and patient satisfaction in breast cancer patients after immediate breast reconstruction: a prospective study. Breast 2005; 14(3): 201-8.

3. Reavey $\mathrm{P}, \mathrm{McC}$ arthy $\mathrm{CM}$. Update on breast reconstruction in breast cancer. Curr Opin Obstet Gynecol 2008; 20(1): 61-7.

4. Avraham T, Clavin N, Mehrara BJ. Microsurgical breast reconstruction. Cancer J 2008; 14(4): 241 7.

5. McCarthy CM, Pusic AL, Sclafani L, Buchanan C, Fey JV, Disa JJ, et al. Breast cancer recurrence following prosthetic, postmastectomy reconstruction: incidence, detection, and treatment. Plast Reconstr Surg 2008; 121(2): 381-8.

6. Vandeweyer E, Hertens D, Nogaret JM, Deraemaecker R. Immediate breast reconstruction with saline-filled implants: no interference with the oncologic outcome? Plast Reconstr Surg 2001; 107(6): 1409-12.

7. Hayes SC, Johansson K, Stout NL, Prosnitz R, Armer JM, Gabram S, Schmitz KH. Upper-body morbidity after breast cancer: incidence and evidence for evaluation, prevention, and management within a prospective surveillance model of care. Cancer 2012; 118(suppl 8): 2237-49.

8. Paskett ED, Dean JA, Oliveri JM, Harrop JP. Cancer-related lymphedema risk factors, diagnosis, treatment, and impact: a review. J Clin Oncol 2012; (Epub ahead of print).

9. The diagnosis and treatment of peripheral lymphedema. 2009 Concensus Document of the International Society of Lymphology. Lymphology. 2009; 42(2): 51-60.

10. Ji RC. Lymphatic endothelial cells, lymphedematous lymphangiogenesis, and molecular control of edema formation. Lymphat Res Biol. 2008; 6(3-4): 123-37.

11. Shah C, Arthur D, Riutta J, Whithworth P, Vicini FA. Breast-cancer related lymphedema: a review of procedure-specific incidence rates, clinical assessment aids, treatment paradigms, and risk reduction. Breast J 2012; 18(4): 357- 61.

12. Ahmed RL, Schmitz KH, Prizment AE, Folsom AR. Risk factors for lymphedema for breast cancer survivors, the lowa Women's Health Study. Breast Cancer Res Treat 2011; 130(3): 981- 91.

13. Tsai RJ, Dennis LK, Lynch CF, Snetselaar LG, Zamba GK, Scott-Conner C. The risk of developing arm lymphedema among breast cancer survivors: a meta-analysis of treatment factors. Ann Surg Oncol 2009; 16(7): 1959- 72.

14. Card A, Crosby MA, Liu J, Lindstrom WA, Lucci A, Chang DW. Reduced incidence of breast cancer- related lymphedema following mastectomy and breast reconstruction versus mastectomy alone. Plast Reconstr Surg 2012; (Epub ahead of print).

15. Lee KT, Mun GH, Lim SY, Pyon JK, Oh KS, Bang SI. The impact of immediate breast reconstruction on post-mastectomy lymphedema in patients undergoing modified radical mastectomy. Breast 2012; (Epub ahead of print).

16. Avraham T, Daluvoy SV, Riedel ER, Cordeiro PG, Van Zee KJ, Mehrara BJ. Tissue expander breast reconstruction is not associated with an increased risk of lymphedema. Ann Surg Oncol 2010; 17(11): 2926-32.

17. Chang DW, Kim S. Breast reconstruction and lymphedema. Plast Reconstr Surg 2010; 125(1): 1923.

18. Crosby MA, Card A, Lindstrom WA, Chang DW. Immediate breast reconstruction and lymphedema incidence. Plast Reconstrc Surg 2012; 129(5): 789e-95e.

19. Lette J. A simple and innovative device to measure arm volume at home for patients with lymphedema after breast cancer. J Clin Oncol 2006; 24(34): 5434-40. 


\section{Lymphedema prevalence and reconstructive breast surgery}

20. Lopez Penha TR, Slangen JJ, Heuts EM, Voogd AC, von Meyenfeldt MF. Prevalence of lymphedema more than five years after breast cancer treatment. Eur J Surg Oncol 2011; 37(12): 1059-63.

21. Mclaughlin SA, Wright MJ, Morris KT, Sampson MR, Brockway JP, Hurley KE, Riedel ER, Van Zee $\mathrm{KJ}$. Prevalence of lymphedema in women with breast cancer 5 years after sentinel lymph node biopsy or axillary dissection: patient perceptions and precautionary behaviors. J Clin Oncol 2008; 26(32): 5220-6.

22. Classen DA, Irvine L. Free muscle flap transfer as a lymphatic bridge for upper extremity lymphedema. J Reconstr Microsurg 2005; 21(2): 93-9.

23. Slavin SA, Upton J, Kaplan WD, Van den Abbeele AD. An investigation of lymphatic function following free-tissue transfer. Plast Reconstr Surg 1997; 99(3): 730-41; discussion 42-3.

24. Blanchard M, Arrault M, Vignes S. Positive impact of delayed breast reconstruction on breastcancer treatment-related arm lymphoedema. J Plast Reconstr Aesthet Surg 2012; 65(8): 1060-3.

25. Abbas Khan MA, Mohan $A$, Hardewicke $J$ et al. Objective improvement in upper-limb lymphoedema following ipsilateral latissimus dorsi pedicled flap breast reconstruction -a case series and review of literature. J Plast Reconstr Aesthet Surg 2011; 64(5): 680-4.

26. Lee KT, Lim SY, Pyun JK, Mun GH, oh KS, Bang SI. Improvement of upper extremity lymphedema after delayed breast reconstruction with an extended latissimus dorsi myocutaneous flap. Arch Plast Surg 2012; 39(2): 154-7.

27. Saaristo AM, Niemi TS, Viitanen TP, Tervala TV, Hartiala P, Suominen EA. Microvascular breast reconstruction and lymph node transfer for post mastectomy lymphedema patients. Ann Surg 2012; 255(3): 468-73.

28. Petrek JA, Senie RT, Peters M, Rosen PP. Lymphedema in a cohort of breast carcinoma survivors 20 years after diagnosis. Cancer 2001; 92(6): 1368-77.

29. Ahmed RL, Schmitz KH, Prizment AE, Folsom AR. Risk factors for lymphedema in breast cancer survivors, The lowa women's health study. Breast Cancer Rest Treat 2011; 130(3): 981- 91.

30. Meeske KA, Sullivan-Halley J, Smith AW, McTiernan A, Baumgartner KB, Harlan LC, Bernstein L. Risk factors for arm lymphedema following breast cancer diagnosis in black women and white women. Breast Cancer Res Treat 2009; 113(2): 383- 91.

31. Dominick SA, Madlensky L, Natarajan L, Pierce JP. Risk factors associated with breast-cancer related lymphedema in the WHEL-study. J Cancer Surviv 2013; 7(1): 115-23. 


\section{Chapter 6}

\section{Quality of life in patients with breast cancer related lymphedema and reconstructive breast surgery}

Tiara R Lopez Penha Bente Botter Esther M Heuts Adri C Voogd Maarten F von Meyenfeldt René RWJ van der Hulst 


\section{Abstract}

Aim: To evaluate the quality of life (QOL) of breast cancer survivors who have undergone breast reconstruction and have breast cancer related lymphedema (BCRL).

Methods: Patients with a unilateral mastectomy with or without breast reconstruction were evaluated for BCRL and their QOL. Patients were divided into a non-BCRL and a BCRL group. Patients with subjective complaints of arm swelling and/or an inter-limb volume difference of $>200 \mathrm{ml}$, or undergoing treatment for arm lymphedema were defined as having BCRL. QOL was assessed using cancer-specific (EORTC QLQC30 and EORTC QLQ-B23) and disease specific (Lymph-ICF) questionnaires.

Results: 253 patients with a mean follow-up time of $51.7( \pm 18.5)$ months since mastectomy completed the QOL questionnaires. Of these patients, 116 (46\%) underwent mastectomy alone and 137 (54\%) had additional breast reconstruction. A comparison of the QOL scores of 180 patients in the non$B C R L$ group showed a significantly better physical function $(p=0.004)$ for patients with reconstructive surgery compared to mastectomy patients. In the 73 patients with BCRL, a comparison of the QOL scores showed no significant differences between patients with mastectomy and reconstructive surgery. After adjusting for potential confounders, multivariate analysis showed a significant impact of $B C R L$ on physical function $(\beta=-7.46 ; p=0.009)$, role function $(\beta=-15.75 ; p=0.003)$, cognitive function $(\beta=-11.56 ; p=0.005)$, body vision $(\beta=-11.62 ; p=0.007)$, arm symptoms $(\beta=20.78 ; p=0.000)$ and all domains of the Lymf-ICF questionnaire.

Conclusions: This study implies that BCRL has a negative effect on the $\mathrm{QOL}$ of breast cancer survivors, negating the positive effects on $\mathrm{QOL}$ reconstructive breast surgery has. 


\section{Introduction}

Survival rates of breast cancer have increased over the past years. ${ }^{1}$ With a long-term survival rate of $>80 \%$, a growing number of women are living with the side effects of breast cancer treatment. ${ }^{2}$ It is therefore logical that the quality of life (QOL) has become an important outcome measure in many breast cancer studies.

One of the most debilitating side effects of breast cancer treatment is upper-limb lymphedema, also known as breast cancer related lymphedema (BCRL). The lymphatic system of the upper-limb can be damaged due to axillary surgery, radiation and/or chemotherapy, resulting in stasis of lymph fluid and an increased limb volume. BCRL can develop directly after surgery or, in most cases, in the first four years after breast cancer treatment. ${ }^{5}$ Patients may develop symptoms of heaviness, tightness, pain sensations, loss of normal upper-limb function and range of motion. ${ }^{6}$ Breast cancer survivors with $B C R L$ have a significantly lower QOL than patients without arm morbidity. ${ }^{5-11}$

There is evidence that breast reconstruction has a positive effect on the QOL of breast cancer patients. ${ }^{12}$ However, is this positive effect also present in patients with BCRL? As of yet, no attention has been given to the assessment of the QOL in patients with BCRL who have also undergone breast reconstruction. With this study we hope to obtain a better understanding of the impact of BCRL on the QOL of breast cancer survivors with reconstructive breast surgery. Therefore, our aim is to explore the QOL in patients with or without BCRL who have undergone mastectomy alone or mastectomy followed by reconstructive breast surgery.

\section{Methods}

\section{Patients}

This study is part of a secondary analysis of a multicenter study analyzing the influence of breast reconstruction on the development of BCRL. ${ }^{13} \mathrm{~A}$ total of 283 patients, who underwent a unilateral mastectomy with or without a breast reconstruction between January 2006 and December 2010, were analyzed for the development of BCRL. Information on the surgical procedures (oncological and reconstructive), tumor characteristics and adjuvant medical treatment were obtained from hospital medical records. The Medical Research Ethics 
Committee of the Maastricht University Hospital approved this secondary analysis.

A total of $274(97 \%)$ patients gave written approval to be contacted for a secondary study. All patients were asked to participate in a standardized QOL interview. 21 patients were excluded because they could not be reached, had deceased, or refused to participate, resulting in a study population of 253 patients. In order to investigate the QOL in patients with BCRL, patients were divided into two groups: a non-BCRL group and a BCRL group.

The BCRL group consisted of patients with subjective complaints of arm swelling and/or an inter-limb volume difference of $>200 \mathrm{ml}$, or undergoing treatment for arm lymphedema. Subjective complaints of arm swelling were positive when patients said to have experienced swelling in the upper-limb on the breast cancer treated side in the past year. The inter-limb volume difference was measured using the water displacement method, which currently is considered as the gold standard. ${ }^{14}$

\section{Quality of life questionnaires}

Standardized interviews were conducted by telephone by one researcher (BB). Patients were surveyed using three validated QOL questionnaires: the Dutch version of the European Organization of Research and Treatment for Cancer (EORTC) QLQ-C30 version 3.0 with the EORTC QLQ-BR23 breast cancer supplementary module ${ }^{15-17}$ and The Lymphedema Functioning, Disability and Health questionnaire (Lymph-ICF). ${ }^{18}$ Permission to use the questionnaires for research purposes was granted.

\section{EORTC QLQ-C30}

The EORTC QLQ-C30 measures the QOL of cancer patients. As indicated by the EORTC answers were converted in to a 0-100 score on five functional scales: physical, role, emotional, cognitive and social functioning, a global health status scale and several symptom scales including: fatigue, nausea/vomiting, pain, dyspnea, insomnia, appetite loss, constipation, diarrhea and financial difficulties. Due to the mean follow-up time of this study (51.7 \pm 18.5 months since mastectomy), the symptoms scales were not included in the analyses as they mostly relate to systemic therapy and their side effects. A lower score on the functional scales and the global health status scale correlates with a lower QOL. 


\section{EORTC QLQ-BR23}

The breast cancer specific EORTC QLQ-BR23 consists of 23-items, divided into four functional scales - body image, sexual functioning, sexual pleasure and future perspective - and four symptom scales - arm symptoms, breast symptoms, systemic therapy side effects and upset by hair loss. Scoring is identical to the EORTC QLQ C-30 questionnaire. Systemic therapy side effects and upset by hair loss were not included in the analyses due to the mean follow-up time. The sexual functioning and the sexual pleasure domain were also excluded from analyses, as almost half of the population (44\%) chose not to fill in the question or indicated not to be sexually active.

\section{Lymph-ICF}

The Lymphedema Functioning, Disability and Health questionnaire (LymphICF) is a condition specific instrument, consisting of seven questions related to arm symptoms and twenty-two questions pertaining to impairments in function of activity of daily living (ADL). Per subscale patients were asked to score their level of complaints, on a scale of 0 to 10 centimeters, where 0 was comparable to no complaints and 10 to a lot of complaints to that specific question. Answers were converted in to a 0-100 score, where $1 \mathrm{~cm}$ corresponds with 10 points on the $0-100$ score.

\section{QOL measurements}

The QOL was assessed in all patients using the three questionnaires. We compared the QOL scores at four different levels. The first comparison was made to assess the impact of BCRL on QOL in this cohort; the QOL scores in the non-BCRL group were compared to the QOL scores in the BCRL group. Furthermore, in order to obtain an understanding of the impact of $B C R L$ on the $Q O L$ in breast cancer survivors who have undergone breast reconstruction, the following three comparisons were made: the $\mathrm{QOL}$ scores of reconstructive patients with mastectomy patients in the non-BCRL group, the QOL scores of reconstructive patients with mastectomy patients in the BCRL group and lastly, the QOL scores of reconstructive patients in the non-BCRL group with reconstructive patients in the BCRL group. 


\section{Statistics}

SPSS for Windows 20.0 (SPSS Inc. Chicago, Illinois) was used for statistical analysis. For describing patient and clinical characteristics, descriptive statistics were used. Mean and standard deviation were reported in case of continuous variables, using the independent-samples ttest. Non-normal distributions were reported as median and ranges, the Mann-Whitney-Wilcoxon test was used for testing significance. Categorical variables were reported as number and percentages, for testing significance the chi-square test was used. Multiple linear regression analysis was used to adjust for potential confounders in the group of patients with reconstructive surgery, using a model containing each QOL domain as a separate outcome. The following confounders were used in the model: total number of lymph nodes removed during sentinel node biopsy and/ or full axillary clearance, BCRL, radiation treatment and chemotherapy. A P-value of $<0.05$ was considered statistically significant for all tests.

\section{Results}

\section{Patient characteristics}

Of the 253 patients, $116(46 \%)$ underwent mastectomy alone and 137 (54\%) had additional breast reconstruction. Patients with breast reconstruction were significantly younger $(p<0.001)$, had a lower $B M I$ at follow-up $(p=0.02)$ and less frequently underwent axillary lymph node dissection $(p=0.00)$. Mastectomy patients had a significantly higher level of history of seroma $(p=0.01)$ and trauma to the arm $(p=0.03)$. Interviews were performed after a mean follow-up of $51.7( \pm 18.5)$ months post-mastectomy (table 1). Reconstructive surgery was performed in the same surgical session in $66 \%$ and secondarily in $34 \%$ of the total breast reconstructions. Tissue expander/implant reconstruction was done in $56 \%$, autologous reconstruction in $39 \%$ and $5 \%$ of the patients had a combination of an implant and a latissimus dorsi flap. 
Table 1. Patient characteristics

\begin{tabular}{|c|c|c|c|c|}
\hline Variables & $\begin{array}{l}\text { Total } \\
(n=253)\end{array}$ & $\begin{array}{l}\text { Mastectomy } \\
(n=116)\end{array}$ & $\begin{array}{l}\text { Reconstruction } \\
\quad(n=137)\end{array}$ & p-value \\
\hline Age at mastectomy, mean (SD) & $54.6(10.1)$ & $59.6(10)$ & $50.4(8.1)$ & 0.00 \\
\hline Age at FU, mean (SD) & $58.1(10.2)$ & $63.2(10.1)$ & $53.8(8.0)$ & 0.00 \\
\hline $\mathrm{BMI}\left(\mathrm{kg} / \mathrm{m}^{2}\right)$ at $\mathrm{FU}$, mean (SD) & $27.0(5.4)$ & $27.8(5.8)$ & $26.2(4.9)$ & 0.02 \\
\hline $\begin{array}{l}\text { Time since mastectomy, mean } \\
\text { (SD), mo }\end{array}$ & $51.7(18.5)$ & $52.8(19.7)$ & $50.9(17.4)$ & 0.28 \\
\hline Tumor stage, no (\%) & & & & 0.16 \\
\hline pT0 - pT1 & $119(48)$ & $47(40)$ & $72(54)$ & \\
\hline pT2 - pT3 & $100(39)$ & $54(47)$ & $46(33)$ & \\
\hline урт0 - урТ4 & $34(13)$ & $15(13)$ & $19(13)$ & \\
\hline Axillary surgery, no (\%) & & & & 0.00 \\
\hline SNLB & $131(52)$ & $55(47)$ & $75(55)$ & \\
\hline SNLB/ALND & $117(46)$ & $61(53)$ & $56(41)$ & \\
\hline LN's removed, median [range] & $5[0-29]$ & $10[1-29]$ & $3[0-29]$ & 0.02 \\
\hline $\begin{array}{l}\text { Positive LN's removed, median } \\
\text { [range] }\end{array}$ & $0[0-20]$ & $0[0-20]$ & $0[0-13]$ & 0.03 \\
\hline BCRL (\%) & $75(30)$ & $38(33)$ & $35(25)$ & \\
\hline Dominant arm, no (\%) & $126(50)$ & $57(49)$ & $69(50)$ & 0.89 \\
\hline Seroma, no (\%) & $68(27)$ & $40(34)$ & $28(20)$ & 0.01 \\
\hline History of erysipelas, no (\%) & $17(7)$ & $10(9)$ & $7(3)$ & 0.26 \\
\hline History of injury, no (\%) & $10(4)$ & $8(7)$ & $2(1)$ & 0.03 \\
\hline $\begin{array}{l}\text { Neo-adjuvant chemotherapy, no } \\
(\%)\end{array}$ & $31(12)$ & $15(13)$ & $16(12)$ & 0.75 \\
\hline \multicolumn{5}{|l|}{ Adjuvant therapy, no (\%) } \\
\hline Chemotherapy & $115(45)$ & $52(45)$ & $63(46)$ & 0.90 \\
\hline Trastuzumab & $38(15)$ & $16(14)$ & $22(16)$ & 0.63 \\
\hline Radiation therapy & $62(24)$ & $35(30)$ & $27(20)$ & 0.05 \\
\hline Hormone therapy & $139(55)$ & $69(59)$ & $70(51)$ & 0.16 \\
\hline
\end{tabular}

Abbreviations: SD; standard deviation, no; number, mo; months, FU; follow-up, BMI; body mass index, SLNB; sentinel lymph node biopsy, ALND; axillary lymph node dissection, LN's; lymph nodes 


\section{Characteristics of patients with BCRL}

A total of $73(29 \%)$ patients had subjective complaints of arm swelling and/or an inter-limb volume difference of $>200 \mathrm{ml}$ or undergoing treatment for arm lymphedema, of which 38 (33\%) were in the mastectomy group and $35(25 \%)$ in the reconstruction group. The patients in the breast reconstruction group were significantly younger $(p<0.001)$ and had significantly less lymph nodes removed $(p=0.05)$ compared to the patients in the mastectomy group. Reconstructive surgery was performed in the same surgical session in $49 \%$ and secondarily in $51 \%$ of the patients. Autologous reconstruction was done in $58 \%$ of the patients, $31 \%$ had a tissue expander/implant and $11 \%$ received a combination of an implant and a latissimus dorsi flap.

\section{Overall QOL scores: non-BCRL vs BCRL group}

Significantly lower scores were found in the BCRL group on all domains of the three QOL questionnaires, as compared to the non-BCRL group. Figures $1-4$ provide an overview of the mean scores arranged by type of surgery and BCRL status.

\section{QOL scores in the non-BCRL group: mastectomy vs reconstruction}

Patients with breast reconstruction scored significantly higher on the physical functioning domain $(p=0.004)$.

\section{QOL scores in the BCRL group: mastectomy vs reconstruction}

No statistically significant differences were found.

\section{QOL scores of reconstruction patients: non-BCRL vs BCRL group}

Patients in the BCRL group scored significantly lower on all EORTC domains, except for two: future perspective $(p=0.10)$ and breast symptoms $(p=0.15)$. The women in the $B C R L$ group also reported significantly more complaints on all domains of the Lymf-ICF questionnaire.

\section{Multivariate Analysis}

We further assessed the QOL domains in the group of women who had undergone breast reconstruction in a multiple linear regression, taking into account the presence of BCRL, total number of lymph nodes removed, radiation treatment and use of chemotherapy. After adjustment of these 
covariates $B C R L$ was significantly associated with a lower score on the following domains: physical function $(\beta=-7.46 ; p=0.009)$, role function $(\beta=-$ 15.75; $p=0.003)$, cognitive function $(\beta=-11.56 ; p=0.005)$ and body vision $(\beta=-$ $11.62 ; p=0.007)$. Furthermore, $B C R L$ was also associated with significantly higher scores on all domains of the Lymf-ICF questionnaire.

Figure 1-4. Median quality of life scores per domain shown by breast reconstruction and BCRL status.

Figure 1. QLQ-C30 scores

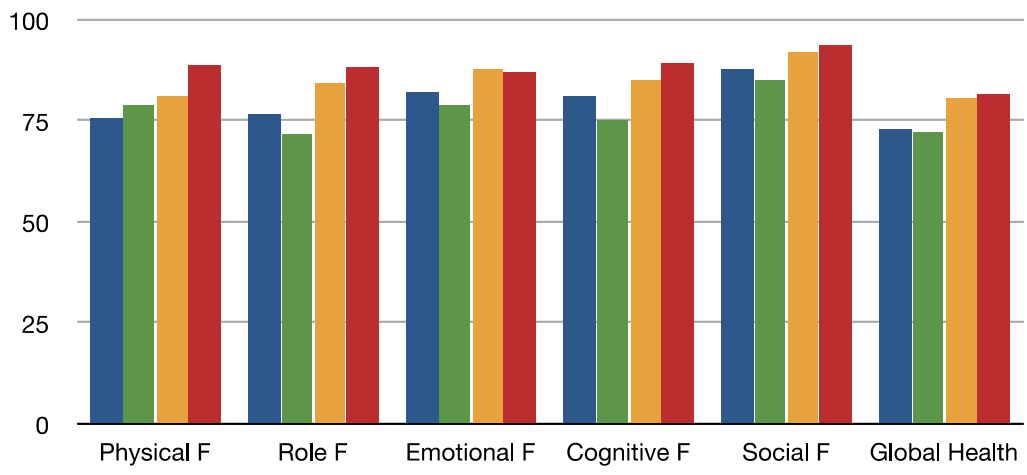

Figure 2. QLQ-Br23 scores

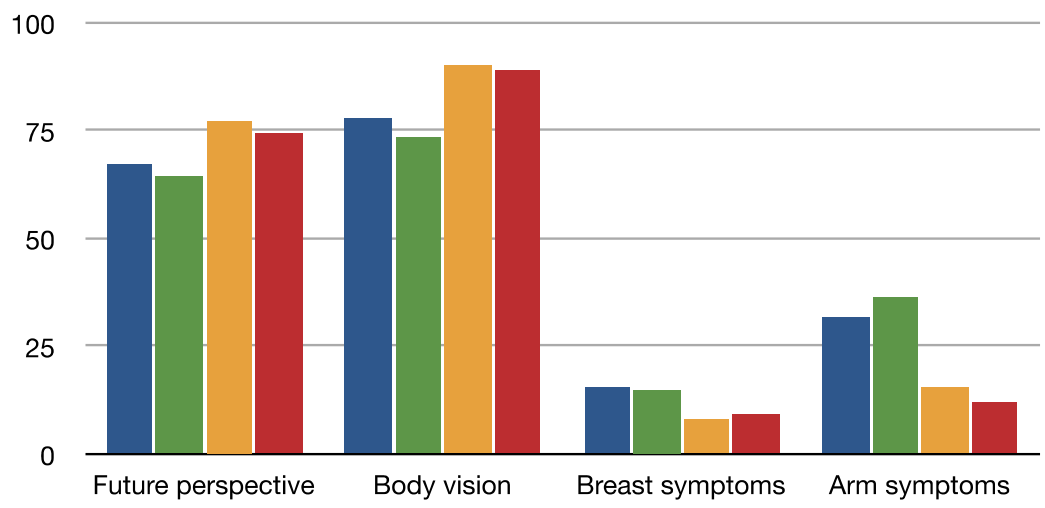


Figure 3. Lymph-ICF scores

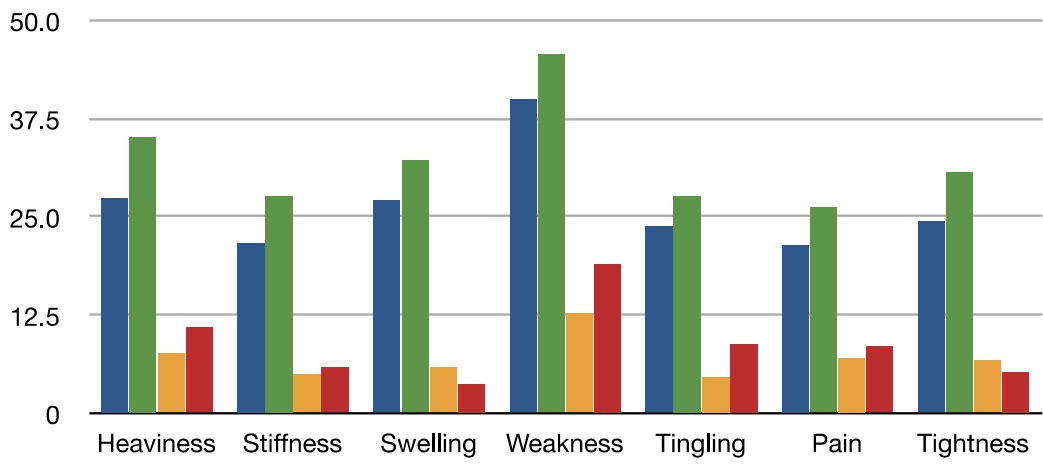

Figure 4. Lymph-ICF scores

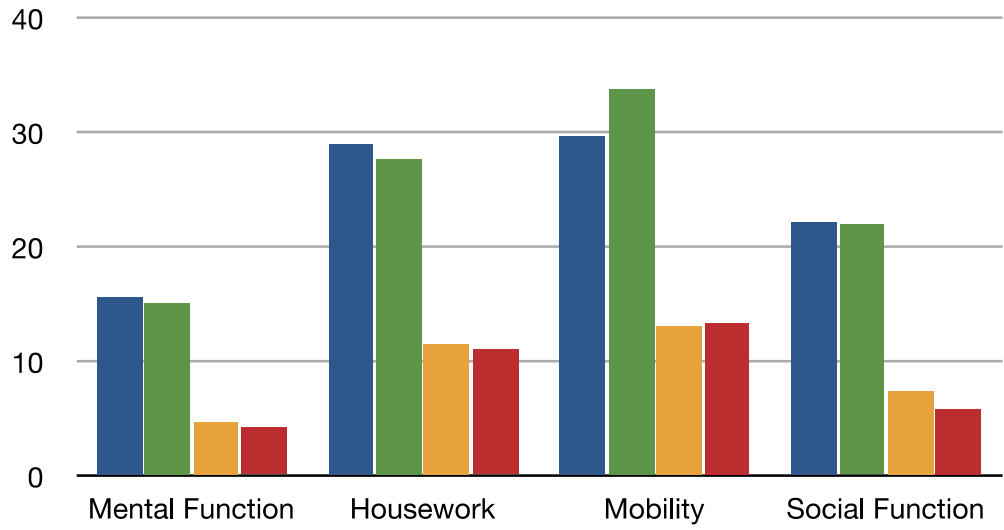

Blue bar: mastectomy patients with BCRL, Green bar: reconstruction patients with BCRL, Yellow bar: mastectomy patients without BCRL, Red bar: reconstruction patients without BCRL.

\section{Discussion}

In this cross-sectional study, we report on the impact of BCRL on the QOL of breast cancer survivors with and without breast reconstruction. We included women who underwent autologous-, implant- and a combination of implant and latissimus dorsi flap reconstruction in the same surgical session as the mastectomy or secondarily. Irrespective of having undergone breast reconstruction, our data suggests that BCRL has a negative effect on the QOL of breast cancer patients. This is an important observation, as in plastic surgery most surgical procedures are aimed at improving the health related quality of life. In other words, BCRL can undo 
the positive effect on the overall well-being of breast cancer survivors that is achieved with breast reconstruction. ${ }^{21-24}$ However, when we compared the QOL outcomes of the women in the non-BCRL group, those who underwent breast reconstruction only scored higher on the physical domain, as compared to the women who only underwent a mastectomy. The expected benefit of breast reconstruction on the psychological- and emotional well-being is not seen in this group. This may be related to the effect of the time that had elapsed since surgery, which was circa 52 months. A study by Metcalfe et al., in which the changes in psychosocial well-being of women who underwent breast reconstruction and mastectomy alone were monitored over a period of approximately 6 years, reported a significant improvement in QOL in both groups over time. ${ }^{25}$

\section{Quality of life questionnaires}

Despite the fact that the EORTC QLQ-C30 and the EORTC QLQ-BR23 were not specifically designed to be used among patients who have undergone reconstructive breast surgery, these were the most suitable QOL questionnaires available at the time this study was performed. These are valid and reliable questionnaires that can be used among breast cancer patients, and give good insight on the QOL of the research population. ${ }^{15,16}$ Moreover, we also used the disease-specific Lymf-ICF questionnaire which is a reliable and valid questionnaire that is used to assess impairments in function, activity limitations and participation restrictions of patients with arm lymphedema after breast cancer surgery. ${ }^{18}$ Currently, there are a few validated patient-reported QOL questionnaires available that can be used among breast reconstruction patients. The QLQ-BRR26, a new validated EORTC module specific for breast reconstructive patients, is developed as a supplement to the EORTC QLQ-C30 and the EORTC QLQ-BR23. This model also makes it possible to make a comparison of QOL among different breast reconstruction techniques. ${ }^{30}$ Furthermore, the BREAST-Q is another QOL questionnaire that can be used in breast augmentation, breast reduction and breast reconstructive patients. The questionnaire measures the surgery-related QOL and is specifically designed to measure the satisfaction among breast augmentation, breast reduction and breast reconstructive patients. A disadvantage of the BREAST-Q is that the questionnaire was not developed to be used among mastectomy patients ${ }^{31}$, which is why it was not used in this study. The Michigan Breast Reconstruction Outcome Study Satisfaction (MBROS-S) questionnaire and the Breast-Related Symptoms Questionnaire (BRSQ) are two other QOL 
questionnaires that can be used among breast reconstructive patients, but have limited validation for all breast reconstructive techniques. ${ }^{32}$

\section{Strengths and limitations}

One of the strengths of this study is the long mean follow-up time of more than 4 years, which excludes patients with acute lymphedema and physical complaints occurring directly post-operatively or related to adjuvant therapy, resulting in a study population of only chronic BCRL patients. Petrek et al. showed that in most patients the onset of BCRL will develop in the first 4 years after treatment, probably making this study population with a mean follow-up of more than 4 year a representative group. ${ }^{3}$ The measurement of $B C R L$ by using the use of the water displacement method, which is the gold standard for the measurement of BCRL, is another strength of this study. Furthermore, our study is the first to evaluate the QOL of breast cancer survivors after mastectomy alone and reconstructive breast surgery that have developed BCRL. However, several limitations of our study should also be mentioned. As a result of the cross-sectional design, measurements of baseline parameters immediately after surgery were not performed, making it impossible to measure the change in QOL. Shi et al reported the importance of a baseline measurement and showed that there is a significant improvement of QOL during the first years after surgery. ${ }^{24}$ Secondly, not all psychological and socio-demographic influences such as educational level, employment status, financial difficulties were incorporated into this study. The health related quality of life is a multidimensional entity. Disease related characteristics such as time since mastectomy, radiation, chemotherapy, hormone therapy and tumor stage are not the only important confounding factors. Lee et al. has reported on the relevance of socio-demographic characteristics as confounding factors for the QOL. ${ }^{33}$

\section{Future directions}

Due to the large impact of BCRL on the QOL of breast cancer survivors, a growing interest is shown for microlymphatic surgery as a potential treatment option for BCRL. ${ }^{33,34}$ In a systematic review we investigated the outcome of microlymphatic surgery, including lymphatic vessel transfer, composite tissue transfer and derivate surgery, on symptoms, limb circumference, limb volume and improvement of the lymphatic function. ${ }^{36}$ The available literature shows positive results with regards to limb volume/circumference reduction. Furthermore, few complications after 
microlymphatic surgery are reported. ${ }^{35}$ These findings underline the importance of future research to further assess the effectivity of microlymphatic surgery as a treatment option for BCRL.

\section{Conclusion}

In conclusion, this study implies that BCRL has a negative effect on the $\mathrm{QOL}$ of breast cancer survivors, potentially negating the positive effects on QOL reconstructive breast surgery has. It is therefore imperative for the quality of breast cancer survivorship that research is continued on the subject of curative BCRL treatment options, such a microlymphatic surgery. 


\section{References}

1. Berry DA, Inoue L, Shen Y, Venier J, Cohen D, Bondy M, et al. Modeling the impact of treatment and screening on U.S. breast cancer mortality: a Bayesian approach. Journal of the National Cancer Institute Monographs. 2006 (36):30-6.

2. Maddams J, Brewster D, Gavin A, Steward J, Elliott J, Utley M, et al. Cancer prevalence in the United Kingdom: estimates for 2008. British journal of cancer. 2009 Aug 4;101(3):541-7. PubMed PMID: 19568236.

3. Petrek JA, Heelan MC. Incidence of breast carcinoma-related lymphedema. Cancer. 1998 Dec 15;83(12 Suppl American):2776-81.

4. Kopec JA, Colangelo LH, Land SR, Julian TB, Brown AM, Anderson SJ, et al. Relationship between arm morbidity and patient-reported outcomes following surgery in women with node-negative NSABP protocol B-32. The journal of supportive oncology. 2013 Mar;11(1):22-30.

5. Oliveri JM, Day JM, Alfano CM, Herndon JE, 2nd, Katz ML, Bittoni MA, et al. Arm/hand swelling and perceived functioning among breast cancer survivors 12 years post-diagnosis: CALGB 79804. Journal of cancer survivorship : research and practice. 2008 Dec;2(4):233-42.

6. Chachaj A, Malyszczak K, Pyszel K, Lukas J, Tarkowski R, Pudelko M, et al. Physical and psychological impairments of women with upper limb lymphedema following breast cancer treatment. Psycho-oncology. 2010 Mar;19(3):299-305.

7. Ahmed RL, Prizment A, Lazovich D, Schmitz KH, Folsom AR. Lymphedema and quality of life in breast cancer survivors: the lowa Women's Health Study. Journal of clinical oncology : official journal of the American Society of Clinical Oncology. 2008 Dec 10;26(35):5689-96.

8. Pusic AL, Cemal Y, Albornoz C, Klassen A, Cano S, Sulimanoff I, et al. Quality of life among breast cancer patients with lymphedema: a systematic review of patient-reported outcome instruments and outcomes. Journal of cancer survivorship : research and practice. 2013 Mar;7(1):83-92.

9. Lee SH, Min YS, Park HY, Jung TD. Health-related quality of life in breast cancer patients with lymphedema who survived more than one year after surgery. Journal of breast cancer. 2012 Dec;15(4):449-53.

10. Beaulac SM, McNair LA, Scott TE, LaMorte WW, Kavanah MT. Lymphedema and quality of life in survivors of early-stage breast cancer. Archives of surgery. 2002 Nov;137(11):1253-7.

11. Lopez Penha TR, van Bodegraven J, Winkens B, Heuts EM, Voogd AC, von Meyenfeldt MF. The quality of life in long-term breast cancer survivors with breast cancer related lymphedema. Acta Chir Belg 2014;114: 239-244.

12. Dean $\mathrm{C}$, Chetty U, Forrest AP. Effects of immediate breast reconstruction on psychological morbidity after mastectomy. Lancet 1983;26:459-462.

13. Lopez Penha TR, Voogd AC, Heuts EM, ljsbrandy C, Hendrix NAM, von Meyenfeldt MF, van der Hulst RRWJ. Reduced risk of breast cancer-related lymphoedema after reconstructive breast surgery. Breast J 2014; 20(6): 671-3. 
14. Lette J. A simple and innovative device to measure arm volume at home for patients with lymphedema after breast cancer. Journal of clinical oncology : official journal of the American Society of Clinical Oncology. 2006 Dec 1;24(34):5434-40.

15. Sprangers MA, Groenvold M, Arraras JI, Franklin J, te Velde A, Muller M, et al. The European Organization for Research and Treatment of Cancer breast cancerspecific quality-of-life questionnaire module: first results from a three-country field study. Journal of clinical oncology : official journal of the American Society of Clinical Oncology. 1996 Oct;14(10):2756-68.

16. Aaronson NK, Ahmedzai S, Bergman B, Bullinger M, Cull A, Duez NJ, et al. The European Organization for Research and Treatment of Cancer QLQ-C30: a quality-of-life instrument for use in international clinical trials in oncology. Journal of the National Cancer Institute. 1993 Mar 3;85(5):365-76.

17. Sprangers MA, Cull A, Groenvold M, Bjordal K, Blazeby J, Aaronson NK. The European Organization for Research and Treatment of Cancer approach to developing questionnaire modules: an update and overview. EORTC Quality of Life Study Group. Quality of life research : an international journal of quality of life aspects of treatment, care and rehabilitation. 1998 May;7(4):291-300.

18. Devoogdt N, Van Kampen M, Geraerts I, Coremans T, Christiaens MR. Lymphoedema Functioning, Disability and Health Questionnaire (Lymph-ICF): Reliability and Validity. Phys Ther 2011; 91(6): 944-57.

19. Parker PA, Youssef A, Walker S, Basen-Engquist K, Cohen L, Gritz ER, et al. Short-term and long-term psychosocial adjustment and quality of life in women undergoing different surgical procedures for breast cancer. Annals of surgical oncology. 2007 Nov;14(11):3078-89.

20. Hartl K, Janni W, Kastner R, Sommer H, Strobl B, Rack B, et al. Impact of medical and demographic factors on long-term quality of life and body image of breast cancer patients. Annals of oncology : official journal of the European Society for Medical Oncology / ESMO. 2003 Jul;14(7):1064-71.

21. Jeevan R., Cromwell DA, Browne JP, Caddy CM, Pereira J, Sheppard C. Findings of a National comparative audit of mastectomy and breast reconstruction surgery in England. J Plast Reconstr Aesthet Surg 2014;67(10):1333-44.

22. Eltahir Y, Werners LL, Dreise MM, van Emmichoven IA, Jansen L, Werker PM. Quality-of-life outcomes between mastectomy alone and breast reconstruction: comparison of patient-reported Breast- $Q$ and other health-related quality of life measures. Plast Reconstr Surg 2013; 132(2):201e-209e.

23. Girotto JA, Schreiber J, Nahabedian MY. Breast reconstruction in the elderly: preserving excellent quality of life. Annals of plastic surgery. 2003 Jun;50(6):572-8.

24. Shi HY, Uen YH, Yen LC, Culbertson R, Juan CH, Hou MF. Two-year quality of life after breast cancer surgery: a comparison of three surgical procedures. European journal of surgical oncology : the journal of the European Society of Surgical Oncology and the British Association of Surgical Oncology. 2011 Aug;37(8):695702. PubMed PMID: 21664099.

25. Metcalfe KA, Zhong T, Narod SA, Quan ML, Holloway C, Hofer S, Bagher S, Semple J. A prospective study of mastectomy patients with and without delayed 
breast reconstruction: long-term psychosocial functioning in the breast cancer survivorship period. J Surg Oncol 2014; Ahead of EPUB.

26. Metcalfe KA, Semple J, Quan ML, Vadaparampil ST, Holloway C, Brown M, et al. Changes in psychosocial functioning 1 year after mastectomy alone, delayed breast reconstruction, or immediate breast reconstruction. Annals of surgical oncology. 2012 Jan;19(1):233-41.

27. Lee C, Sunu C, Pignone M. Patient-reported outcomes of breast reconstruction after mastectomy: a systematic review. Journal of the American College of Surgeons. 2009 Jul;209(1):123-33. PubMed PMID: 19651073.

28. Winters ZE, Benson JR, Pusic AL. A systematic review of the clinical evidence to guide treatment recommendations in breast reconstruction based on patientreported outcome measures and health-related quality of life. Annals of surgery. 2010 Dec;252(6):929-42.

29. Winters ZE, Belta V, Thomson HJ, Brandberg Y, Oberguggenberger A, LlewellynBennet R. Phase III development of the European organization for research and treatment of cancer quality of life questionnaire module for women undergoing breast reconstruction. Br J Surg 2014;101(4):371-82.

30. Pusic AL, Klassen AF, Scott AM, Klok JA, Cordeiro PG, Cano SJ. Development of a new patient-reported outcome measure for breast surgery: the BREAST-Q. Plastic and reconstructive surgery. 2009 Aug;124(2):345-53.

31. Pusic AL, Chen CM, Cano S, Klassen A, McCarthy C, Collins ED, et al. Measuring quality of life in cosmetic and reconstructive breast surgery: a systematic review of patient-reported outcomes instruments. Plastic and reconstructive surgery. 2007 Sep 15;120(4):823-37; discussion 38-9.

32. Lee ES, Lee MK, Kim SH, Ro JS, Kang HS, Kim SW, et al. Health-related quality of life in survivors with breast cancer 1 year after diagnosis compared with the general population: a prospective cohort study. Annals of surgery. 2011 Jan;253(1):101-8.

33. Becker C. Autologous Lymph Node Transfers. J Reconstr Microsurg. 2015 Sep 15. [Epub ahead of print].

34. Baumeister RG, Mayo W, Notohamiprodjo M, Wallmichrath J, Springer S, Frick A. Microsurgical Lymphatic Vessel Transplantation. J Reconstr Microsurg. 2015 Jul 10. [Epub ahead of print].

35. Penha TR, ljsbrandy C, van der Hulst RR. Microsurgical techniques for the treatment of breast cancer-related lymphedema: a systematic review. J Reconstructr Microsurg. 2013 Feb; 29(2): 99- 106. 


\title{
Chapter 7
}

Microsurgical techniques for the treatment of breast cancer related lymphedema: a systematic review

\author{
Tiara R Lopez Penha \\ Charlotte ljsbrandy \\ Nicole AM Hendrix \\ Adri C Voogd \\ Esther M Heuts \\ Maarten F von Meyenfeldt \\ René RWJ van der Hulst
}

Adapted from: J Reconstr Microsurg 2013 Feb;29(2):99-106 


\section{Abstract}

Background: Upper limb lymphedema is one of the most underestimated and debilitating complications of breast cancer treatment. The aim of this review is to summarize the recent literature for evidence of the effectiveness of lymphatic microsurgery for the treatment of breast cancer related lymphedema (BCRL).

Methods: A search was conducted for articles published from 2000 onwards. Only studies on secondary lymphedema after breast cancer treatment and those examining the effectiveness of microsurgery were included. The following data was extracted: surgical intervention type, population size, follow-up time, $B C R L$ classification, duration of BCRL, arm volume/circumference reduction, lymph-flow improvement, symptom relief, post-operative conservative therapy discontinuation and complications.

Results: No randomized clinical trials or comparative studies were available; ten case-series met inclusion criteria. Three surgical techniques were described: (composite) tissue transfer $(n=4)$, lymphatic vessel transfer $(n=2)$ and derivative microlymphatic surgery $(n=4)$. Limb volume/circumference reduction varied from $2 \%-50 \%$ over a follow-up time ranging from 1 to 132 months. Post-operative discontinuation rates of conservative therapy were only reported after composite tissue transfer, ranging from 33 to $100 \%$ after 3 to 24 months. Little to no complications were observed in all surgical techniques. Clear selection criteria for lymphatic surgery and lymphatic flow assessment were absent in most studies.

Conclusion: We identified the important methodological shortcomings of the available literature. Evidence acquired through comparative studies with uniform patient selection is lacking. Consistent positive findings with regards to volume/ circumference reduction and limited complications are reasons to further explore these techniques in methodologically superior studies. 


\section{Introduction}

Upper limb lymphedema is one of the most underestimated and debilitating complications of breast cancer treatment. Hitherto, lymphedema treatment options have mainly been based on the lifelong application of a combination of conservative techniques, such as compression garments/bandages and manual lymph drainage.$^{1-3}$ Conservative therapy is initially aimed at alleviating symptoms without curative intent; with such treatment, some patients may achieve sufficient limb volume reduction and symptom relief. In cases of inadequate disease management, lymphedema may progress: arm-swelling transforming from a predominantly fluid encompassing entity to fibrosis and fat. ${ }^{4,5}$ Lymphedema in its late chronic phase is irreversible and accompanied by more symptoms and physical impairments, consequently compromising the quality of survivorship. ${ }^{6-10}$ An alternative treatment option could be beneficial for patients that aren't responsive to standard conservative therapy. Lymphatic microsurgery could be such a treatment option, if treatment would be applied before lymphedema reaches its chronic, irreversible phase.

\section{Derivative (super) microlymphatic surgery}

Microlymphatic repair for lymph edematous limbs emerged with the development of reconstructive microsurgery in the late 1960's. The very first experimental studies reported, were in obstructive canine models. In these studies communications were created between the lymphatic and venous systems to divert static lymph fluid away from the obstruction site in a technique called lymphatic venous anastomoses. ${ }^{11}$ The canine studies reported low and inconsistent patency rates as the result of this intervention, triggering the further development of the derivative microlymphatic technique. Refinements were made in order to reduce the chances of venous back flow and consequently bypass stenosis. However, limitations in the available microsurgical technology hampered the long-term establishment of viable anastomoses, as the pressure gradient between the lymphatic- and venous systems were still too high. Until the beginning of this millennium there was little progression in lymphatic surgical techniques. In the contemporary clinical field of microvascular surgery anastomoses with vessels as small as $0.3 \mathrm{~mm}$ in diameter are possible, this also known as "super microsurgery". Because of these technical refinements it is now possible to create multiple bypasses between lymphatic vessels (ranging from $0.3 \mathrm{~mm}-0.5 \mathrm{~mm}$ ) and venular vessels $(0.5 \mathrm{~mm})$ found in the subdermal plane of a lymph edematous limb. Anastomosing smaller vessels of the two vascular systems is hypothesized to ensure better bypass patency due to the 
minor intra-vascular pressure differences. ${ }^{12}$ Over the years evidence has been reported of lymphatic repair being effective in patients with secondary lymphedema of both the upper and lower extremities using lymphatic venular anastomoses. $^{13-15}$

\section{Tissue Transfer}

Another technique to improve lymphatic drainage is the vascularized lymph node transfer with or without simultaneous free flap reconstruction. ${ }^{16}$ Experimental studies on lymph node transplantation in small animal studies have reported promising results of lymphatic function restoration, and with that, the facilitation of lymphedema resolution. ${ }^{17,18}$ Moreover, an alternative approach is achieved through the interposition of autologous tissue (i.e. lymph vessel), in which an attempt is made to restore flow within a damaged lymphatic system by bypassing the site of blockage. The transplanted lymph vessel(s) can function as a bridge connecting the afferent and efferent lymphatic vessels from the obstruction site. ${ }^{19}$

The recent movement towards the incorporation of evidence-based medicine into plastic surgery ${ }^{20}$ has stressed the importance of good quality research as the core of the clinical decision making process. The primary aim of this systematic review is to summarize the recent literature for evidence of the effectiveness of lymphatic microsurgery for the treatment of breast cancer related lymphedema (BCRL). Specifically, the effect of surgery on upper-limb volume/circumference reduction, symptom relief, lymph flow improvement and the discontinuation of compression therapy post-operatively will be evaluated.

\section{Methods}

\section{Literature search}

An electronic literature search was conducted in MEDLINE and PubMed for literature published from January 2000 onwards. Three independent investigators (TLP, NH, Cl) performed the search. The following search terms were used: Iymphedema, lymphoedema, microsurgery, surgical treatment, breast cancer, lymph node transfer, lymphovenous anastomoses, lymphaticovenular anastomoses and lymph vessel transplantation. The search was limited to English, Dutch, German and French literature, while we also hand-searched reference lists of the relevant articles found. Abstracts were 
scanned for relevance. Only the studies providing data of patients with secondary lymphedema after breast cancer treatment and those examining the effectiveness of microsurgical intervention were eligible for inclusion. Data from studies on primary lymphedema, lower extremity lymphedema and mixed groups of lower and upper extremity lymphedema were excluded. All articles were evaluated for duplicate reporting on the same patient population and if so removed.

\section{Data extraction}

The following data were extracted if available: surgical intervention type (lymph node transplantation, lymph vessel transplantation or derivative lymphatic surgery), size of the patient population, mean follow-up time, BCRL classification and stage, mean duration of BCRL before surgery, arm volume or circumference reduction, lymph flow improvement as quantified by lymphoscintigraphy, symptom relief (self-perceived pain, heaviness and erysipelas), discontinuation of post-operative conservative therapy (compression garments/bandages or manual lymphatic drainage) and complications (donor or recipient site morbidity).

\section{Quality assessment}

A detailed methodological quality assessment was conducted independently by three investigators (TLP, $\mathrm{Cl}, \mathrm{NH}$ ). The case series were assessed using an 8question checklist from The American Society of Plastic Surgeons (ASPS) for therapeutic studies. ${ }^{21}$ Each affirmative answer was a point. Thus, a total score of 8 was the maximum to be assigned per case series. The quality scores were compared and disagreements resolved by consensus.

\section{Data analysis}

The median and range of the methodological quality rating of all the studies combined, as well as the studies per surgical technique are provided. We compared the median quality ratings using the Mann-Whitney $U$ test. A p-value $<0.05$ was considered significant. Data-analysis was conducted using SPSS for Mac 17.0 (SPSS Inc. Chicago, Illinois). 


\section{Results}

There were no randomized clinical trials or comparative studies available, thus we were limited to the inclusion of case-series. A total of 19 case-series were identified. Nine ${ }^{22-30}$ were excluded as they described either lymphedema of only the lower extremity ${ }^{22-25}$, a mix of lower and upper extremity lymphedema ${ }^{26-29}$ or a mix of primary and secondary upper extremity lymphedema. ${ }^{30}$ The remaining 10 studies were included for assessment (Table 1). In these studies, three types of micro lymphatic surgery were described: composite tissue transfer, lymphatic vessel transfer and derivative surgery. The number of patients per case- series was small ranging from 6 - 24 women. However, one study reported evidence on 127 women. ${ }^{35}$ Follow-up time varied amongst the studies, ranging from 5 to 72 months in articles evaluating derivative lymphatic surgery and 6 to 132 months in that of (composite) tissue transfer. Different measures were used to assess treatment outcome. These included reduction of limb volume $^{35-39}$, circumference ${ }^{31,33,34,37,40}$ or symptomatology ${ }^{31,32,38-40}$ and

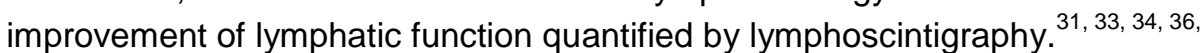
38-40

\section{Quality assessment}

The median methodological quality rating of the 10 studies was 4.5 [range 2-5] (Table 1). The studies on (composite) tissue transfer had a higher median quality score compared to that of derivative techniques, respectively 5 [2-5] VS 4 [range 3-5]. However, this difference was not statistically significant $p=0.567$.

\section{Microsurgical techniques}

We were unable to pool the results of the included studies due to a few restricting factors. Firstly, the outcomes of interest were reported in a variable manner in much of the studies. Secondly, the patient populations of the selected studies were of heterogeneous nature. We have therefore presented a schematic overview of the important data. 
Table 1. Methodological quality assessment of the case series reporting on lymphatic microsurgery for the treatment of BCRL.

\begin{tabular}{|c|c|c|c|c|c|c|c|c|c|}
\hline Ref & $\begin{array}{l}\text { Appropriate } \\
\text { selection }\end{array}$ & $\begin{array}{l}\text { Consecutive } \\
\text { cases }\end{array}$ & $\begin{array}{l}\text { Confounders } \\
\text { addressed }\end{array}$ & $\begin{array}{l}\text { Intervention } \\
\text { performed } \\
\text { similarly }\end{array}$ & $\begin{array}{l}\text { Procedures } \\
\text { performed by } 1 \\
\text { surgeon }\end{array}$ & $\begin{array}{l}\text { Valid \& } \\
\text { defined } \\
\text { criteria for }\end{array}$ & $\begin{array}{l}\text { FU time } \\
\text { sufficient to } \\
\text { detect } \\
\text { outcome }\end{array}$ & $\begin{array}{l}\text { No conflicts } \\
\text { of interest }\end{array}$ & $\begin{array}{l}\text { Total } \\
\text { score }\end{array}$ \\
\hline 31 & - & + & + & - & $?$ & + & + & + & 5 \\
\hline 32 & + & $?$ & + & + & $?$ & - & + & + & 5 \\
\hline 33 & + & $?$ & + & - & + & + & + & $?$ & 5 \\
\hline 34 & + & $?$ & + & + & $?$ & + & + & $?$ & 5 \\
\hline 35 & - & $?$ & - & + & $?$ & - & + & $?$ & 2 \\
\hline 36 & - & $?$ & - & + & $?$ & + & + & $?$ & 3 \\
\hline 37 & + & $?$ & - & + & $?$ & - & + & + & 4 \\
\hline 38 & + & $?$ & + & + & $?$ & - & + & + & 4 \\
\hline 39 & + & $?$ & + & + & + & + & + & $?$ & 5 \\
\hline 40 & - & $?$ & + & + & $?$ & - & + & $?$ & 3 \\
\hline
\end{tabular}

Abbreviations: Ref; reference, BCRL; breast cancer related lymphedema, FU; follow-up. 


\section{1. (Composite) tissue transfer}

A total of four retrospective case series $(n=52)$ on composite tissue transfer for the treatment of $B C R L$ were identified (Table 2.). Three $(n=39)$ described a similar operative technique: lymph nodes harvested at the inguinal site with the vascular structures and fat surrounding the superficial circumflex iliac vessels set in the axilla of the affected limb using the thoracodorsal vessels as recipient vessels. ${ }^{32-34}$ Of these three, Saaristo et al modified the technique by combining it with a DIEP/msTRAM free flap for simultaneous breast reconstruction. The technique described by Lin et al. differed from the other three in that the recipient site was the dorsal wrist of the affected arm instead of the axilla. Circumference reduction rate was provided by one study ${ }^{31}$, stating an average reduction of $51 \%$ at 4.7 years follow-up. As for symptom improvement, Becker et al. reported a reduction of pain in all 6 patients direct post-operatively and Lin et al. a reduction of the incidence of cellulitis in 11 of the 13 patients. Of the studies providing quantitative lymph flow assessment improvement was reported in all three. ${ }^{31,33,34}$ Three studies reported the discontinuation rate of post-operative compression therapy, ranging from $33-100 \% 3$ months to 2 years after surgery. ${ }^{32-34}$ No donor site morbidity was reported. Two studies $(n=139)$ were identified reporting on lymph vessel transplantation for the treatment of BCRL. The largest series $(n=127)$, a retrospective assessment by Baumeister et al. reported an average volume reduction of $22 \%$ at a follow-up of 31 months. ${ }^{35}$ The rate of post-operative discontinuation of compression therapy was not addressed. As for post-operative complications, one case of donor site edema was reported.

\section{Derivative (super) microsurgical techniques}

A total of four prospective case-series $(n=47)$, evaluating derivative (super) microsurgery for the treatment of BCRL, met the inclusion criteria (Table 3 ). Three of the four studies reported a volume or circumference decrease greater than $30 \%$ at a follow-up time ranging from 5 to 72 months. ${ }^{37,38,40}$ Results were less favorable in a study by Damstra et al, reporting a limb volume reduction of $2 \%$ with accompanying unchanged lymphatic flow, 12 months postoperatively. ${ }^{39}$ Three of the four studies showed improvement of symptomatic complaints post-operatively. ${ }^{38-40}$ Although only addressed by two studies, no post-operative complications were reported. ${ }^{38,40}$ Post-operative conservative therapy in the form of compression therapy and/or bandaging was continued indefinitely in all case-series. 


\section{Discussion}

In this review we summarized the available literature on lymphatic microsurgery for the treatment of BCRL. We were primarily interested in the efficacy of derivative lymphatic surgery and (composite) tissue transfer on upper-limb volume or circumference reduction, relief of symptoms related to BCRL, lymphatic function and the discontinuation of conservative therapy postoperatively. Data could only be acquired through a mix of pro- and retrospective case series, as randomized or comparative studies were not available. This resulted in level IV evidence. With respect to the methodological quality, the studies on composite tissue transfer rated best when compared to that of lymph vessel transfer and derivative surgery (Table 1). Two criteria were most often associated with a low methodological rating. The first is incomplete information on the patient selection procedure for surgery. As differentiating between early non-fibrotic lymphedema and chronic lymphedema is an important outcomedetermining factor recording of these lymphedema stages when selecting study patients is essential. Secondly, the post-surgical outcome assessment should not only include limb volume or circumference measurements, but should also be complemented with monitoring of lymphatic flow. Unfortunately, it was not possible to pool the results of the different studies included in this review, due to incomplete data documentation, but most importantly because of the large difference between the studies with respect to the criteria used for selecting patients for surgery. For example, only four studies stratified patients into lymphedema clinical stages before ensuing surgery, while the others did not take the pathophysiological nature of lymphedema into account, resulting in a heterogeneous patient population.

\section{Primary outcomes}

All but one study ${ }^{39}$ noted consistent reduction of upper-limb volume or circumference reduction from surgical intervention through derivative lymphatic surgery $^{37,38,40}$, lymph node transplantation ${ }^{31-34}$ or lymphatic vessel transfer. ${ }^{35,36}$ Damstra et al., reporting on results after lymphatic venous anastomosis, measured a disappointing mean volume difference of $2 \%$ after one year. There are, however, two aspects in the methodology of this study that might have affected the outcome. Firstly, a surgical procedure according to Degni-Cordeiro was applied. This is a rather outdated technique originating from the early 1980 ' ${ }^{41}$, a period in which derivative lymphatic surgery had proven low bypass patency due to the intravascular pressure gradient. Secondly, the selection 
criteria for the group of patients that would undergo derivative lymphatic surgery have affected the outcome of this study. It is stated by the authors that complete limb volume reduction was achieved in nearly half of the patient population when circumferential suction-assisted lipectomy was performed after the initial LVA operation. This suggests a chronic lymphedema stage. The natural progression of lymphedema sees to the change of limb swelling composition, from an at first predominantly fluid containing entity to the addition of fibrosis, fat and protein. So, even if the static lymph fluid is relieved, swelling still remains in the form of excess fat and fibrosis. ${ }^{42,43}$ Furthermore, chronic lymphedema also suggests a prolonged hypertensive state within the lymphatic system. This phenomenon causes irreversible damage to the lymph vessels i.e. degeneration of smooth muscle cells ${ }^{44,45}$, rendering the lymph vessels incapable of lymph fluid propulsion. Therefore failure is inevitable in the attempts of producing patent lymphatic venous bypasses.

Aside from limb volume or circumference reduction, surgery effectiveness can be determined by lymphatic function. Lymphoscintigraphy can visualize lymphatic flow, providing qualitative information on lymph transport in the affected limb. Only half the studies ${ }^{31,33,34,36,39}$ assessed in this review evaluated the effect of lymphatic microsurgery on the lymphatic function. This is a major methodological flaw, as the ultimate aim of every lymphatic surgery should be to repair the function of the damaged lymphatic system. Moreover, in derivative surgery it is important to monitor lymphatic-venular bypass patency. Until recently there were no means of doing so. The use of indocyanine green fluorescence lymphangiography appears promising in this respect. ${ }^{46,47}$

The effect of surgery on symptom relief was not a main focus for many of the studies in this review. A specific decrease in neuropathic pain and in cellulitis rates was reported in two small populations after lymph node transplantation. ${ }^{31,}$ ${ }^{32}$ As for the effect of derivative lymphatic surgery, a subjective relief of symptoms was noted in $50-100 \%$ of the patients in three studies. ${ }^{38-40}$ The discontinuation of post-operative conservative therapy was realized, although in variable rates, three to 24 months after surgery in the three studies evaluating inguinal lymph node transfer to the axilla of the lymph edematous arm. $^{32-34}$ As reported ${ }^{31,33}$, the results were better when the duration of lymphedema was the shortest before lymph node transfer suggesting that this surgery cannot only be used as an alternative treatment for conservative therapy-resistant BCRL, but also as a curative up-front approach for lymphedema. 
Table 2. Summary of studies on (composite) tissue transfer and derivative (super) micro lymphatic surgery for the treatment of BCRL

\begin{tabular}{|c|c|c|c|c|c|c|c|c|}
\hline Ref & Intervention & $\begin{array}{l}\text { Post-operative } \\
\text { conservative } \\
\text { treatment }\end{array}$ & $\mathbf{n}$ & $\begin{array}{l}\mathrm{FU} \text { in } \\
\mathrm{mo}\end{array}$ & $\begin{array}{l}\text { BCRL classification } \\
\text { \& stage }\end{array}$ & $\begin{array}{l}\text { Duration } \\
\text { of } B C R L\end{array}$ & Results & Complications \\
\hline 31 & $\begin{array}{l}\text { IFP \& nodes } \\
\text { set in wrist }\end{array}$ & Not mentioned & 13 & $\begin{array}{l}56 \\
{[6-96]}\end{array}$ & - & $\begin{array}{l}2.8 \text { years } \\
{[4-84 \mathrm{mo}]}\end{array}$ & $\begin{array}{l}C: 12 / 13 \text { had reduction, } \\
\text { mean of } 51 \%[0-71 \%] . \\
L: \text { in all flow improvement. } \\
S: 11 / 13 \text { had decrease } \\
\text { cellulitis incidence }\end{array}$ & $\begin{array}{l}\text { Wound infection } \\
(n=1) \text {, venous } \\
\text { congestion } \\
(n=1) \text {, no donor } \\
\text { site morbidity }\end{array}$ \\
\hline 32 & $\begin{array}{l}\text { IFP \& nodes } \\
\text { set in axilla }\end{array}$ & $\begin{array}{l}\text { No CG, MLD } \\
\text { discontinued after } \\
3 \text { mo }\end{array}$ & 6 & $\begin{array}{l}21 \\
{[13-38]}\end{array}$ & $\begin{array}{l}\text { No specification on } \\
\text { staging type: I }(n=4) \text {, II } \\
(n=2) \text {. }\end{array}$ & - & $\begin{array}{l}C / V \text { : lymphedema } \\
\text { resolved in } 5 / 6 \text { pts. } \\
S: 100 \% \text { reduction in pain } \\
\text { scale. }\end{array}$ & $\begin{array}{l}\text { No donor or } \\
\text { recipient site } \\
\text { morbidity }\end{array}$ \\
\hline 33 & $\begin{array}{l}\text { IFP \& nodes } \\
\text { set in axilla, } \\
2^{\text {nd }} \text { procedure } \\
(n=7) \text { IFP set } \\
\text { in elbow }\end{array}$ & $\begin{array}{l}\text { No CG, } 62.5 \% \\
\text { stopped MLD after } \\
12 \mathrm{mo}\end{array}$ & 24 & $\begin{array}{l}100 \\
{[60-132]}\end{array}$ & $\begin{array}{l}- \text { I }(n=6) \text { early edema, } \\
<2 \text { infectious } \\
\text { episodes, }<30 \% \\
\text { difference. } \\
\text { - II }(n=18) \text { edema }>1 \\
\text { year, }>2 \text { infectious } \\
\text { episodes, difference } \\
30-50 \%\end{array}$ & $\begin{array}{l}-\geq 1 \text { year } \\
\text { average of } \\
5.6 \text { years } \\
(n=18) \\
-<1 \text { year, } \\
\text { average } 5 \\
\text { months } \\
(n=6)\end{array}$ & $\begin{array}{l}C: 6>50 \% \text { reduction, } 6< \\
50 \% \text { reduction, } 10 \\
\text { returned to normal, } 2 \\
\text { unchanged. } \\
L: 5 / 16 \text { flow improvement. }\end{array}$ & $\begin{array}{l}\text { Lymphorrhea } \\
(\mathrm{n}=8)\end{array}$ \\
\hline 34 & $\begin{array}{l}\text { DIEP/msTRA } \\
\text { M \& IFP \& } \\
\text { nodes set in } \\
\text { axilla after } \\
\text { WLSE }\end{array}$ & $\begin{array}{l}33 \% \text { discontinued } \\
\text { MLD \& CG after 8- } \\
24 \text { mo }\end{array}$ & 9 & 6 & - & $\begin{array}{l}43 \text { months } \\
{[6-120]}\end{array}$ & $\begin{array}{l}C: 7 / 9 \text { had reduction } \\
L: 5 / 6 \text { had flow } \\
\text { improvement }\end{array}$ & $\begin{array}{l}\text { No donor site } \\
\text { morbidity }\end{array}$ \\
\hline 35 & $\begin{array}{l}\text { Lymphvessels } \\
\text { set in upper } \\
\text { arm/supraclavi } \\
\text { cular region }\end{array}$ & $\mathrm{CG}$ for $6 \mathrm{mo}$ & 127 & 31 & - & - & $V: 22 \%$ average reduction & $\begin{array}{l}\text { DVT }(n=1) \\
\text { donor site } \\
\text { edema }(n=1)\end{array}$ \\
\hline
\end{tabular}




\begin{tabular}{|c|c|c|c|c|c|c|c|c|}
\hline 36 & $\begin{array}{l}\text { Lymphvessels } \\
\text { set in upper } \\
\text { arm/supraclavi } \\
\text { cular region }\end{array}$ & CG for $6 \mathrm{mo}$ & 12 & 96 & - & - & $\begin{array}{l}V: \text { Reduction } 22-31 \% \\
L: 11 / 12 \text { significant flow } \\
\text { improvement }(p<0.01)\end{array}$ & - \\
\hline 37 & MLVI & $\mathrm{CT}$ for first $6 \mathrm{mo}$ & 9 & $\begin{array}{l}17 \\
{[15-22]}\end{array}$ & - & $\begin{array}{l}7.3 \text { years } \\
{[1-13]}\end{array}$ & $\begin{array}{l}\text { C: } 77.8 \% \text { had }>50 \% \\
\text { reduction }\end{array}$ & - \\
\hline 38 & LVA & $\begin{array}{l}\text { CT \& CG } \\
\text { continued } \\
\text { indefinitely }\end{array}$ & 20 & 12 & $\begin{array}{l}\text { Campisi classification: } \\
\text { stage II }(n=10) \& \text { III } \\
(n=10)\end{array}$ & $\begin{array}{l}4.8 \text { years } \\
{[1-17]}\end{array}$ & $\begin{array}{l}V: 65 \% \text { had reduction, } \\
\text { average } 35 \% \\
S: 80 \% \text { long term } \\
\text { improvement }\end{array}$ & NR \\
\hline 39 & LVA & $\begin{array}{l}\text { CG continued } \\
\text { indefinitely }\end{array}$ & 10 & 12 & $\begin{array}{l}\text { Campisi classification: } \\
\text { stage III }(n=10)\end{array}$ & $\begin{array}{l}5.3 \text { years } \\
{[3-14]}\end{array}$ & $\begin{array}{l}V: \text { average reduction of } \\
2 \% \\
\text { S: } 50 \% \text { improvement after } \\
6 \text { mo } \\
\text { L: no improvement }\end{array}$ & - \\
\hline 40 & MLVI & $\begin{array}{l}\text { CG continued } \\
\text { indefinitely }\end{array}$ & 18 & $\begin{array}{l}24 \\
{[12-72]}\end{array}$ & - & $\begin{array}{l}7.1 \text { years } \\
{[1-23]}\end{array}$ & $\begin{array}{l}\text { C: distal arm average } \\
\text { reduction } 54 \%[0-100 \%] \text {, } \\
\text { proximal arm average } \\
\text { reduction } 45 \% \text { [7.1-76.5\%] } \\
\text { S: } 100 \% \text { improvement }\end{array}$ & NR \\
\hline
\end{tabular}

Time of follow-up and duration of breast cancer related lymphedema presented as mean and range.

Abbreviations: IFP; inguinal fat pad, V, results measured by arm volume; C, results measured by arm circumference; L, results measured by lymphoscintigraphy; S, results measured by symptom assessment; CG, compression garments; CT, compression therapy; Pts, patients; MLVI, microsurgical lymphaticovenous implantation; LVA, lymphaticovenous anastomoses, NR; none reported, Mo; months, WLSE; wide local scar excision 
Even though we were limited to level IV evidence, a preference can be given to the inguinal lymph node transfer based on the reviewed literature. Not only was this the only technique that made the discontinuation of post-operative conservative therapy possible, it was also the technique described in better methodological quality studies compared to that of the other techniques. Furthermore, because this surgical procedure can be combined with autologous breast reconstruction it might be easier to incorporate it into current breast cancer management programs.

\section{Conclusion}

An overview is presented of the current evidence base for the effectiveness of lymphatic microsurgery for the treatment of BCRL. We have identified important methodological shortcomings of the available literature. Evidence acquired through comparative prospective studies with uniform patient selection is lacking. The consistent positive findings with regard to limb volume/ circumference reduction and limited to no complications reported after microlymphatic surgery are, however, reasons to further explore these techniques in methodologically superior studies, perhaps answering the question as to when is the most appropriate time in the disease process for lymphatic surgery. We believe that the true contribution of micro lymphatic surgery for the treatment of BCRL will only be elucidated through protocolized treatment initiation by experienced micro surgeons. In our institution we are currently in the process of setting up a prospective study: an integrated care program in which breast cancer patients are prospectively screened for lymphedema and are structurally treated with conservative therapy followed by lymph node transplantation or derivative surgery in conservative treatmentresistant cases. 


\section{References}

1. Kligman L, Wong RK, Johnston M, Laetsch NS. The treatment of lymphedema related to breast cancer: a systematic review and evidence summary. Support Care Cancer 2004; 12(6): 421-31.

2. Moseley AL, Carati CJ, Piller NB. A systematic review of common conservative therapies for arm lymphoedema secondary to breast cancer treatment. Ann Onco 2007; 18(4): 639-46.

3. McNeely ML, Peddle CJ, Yurick JL, Dayes IS, Mackey JR. Conservative and dietary interventions for cancer-related lymphedema: a systematic review and meta-analysis. Cancer 2011; 117(6): 1136-48.

4. The diagnosis and treatment of peripheral lymphedema. 2009 Concensus Document of the International Society of Lymphology. Lymphology 2009; 42(2): 51-60.

5. Ji RC. Lymphatic endothelial cells, lymphedematous lymphangiogenesis, and molecular control of edema formation. Lymphat Res Biol 2008; 6(3-4): 123-37.

6. Rietman JS, Dijkstra PU, Debreczeni R, Geertzen JH, Robinson DP, De Vries J. Impairments, disabilities and health related quality of life after treatment for breast cancer: a follow-up study 2.7 years after surgery. Disabil Rehabil 2004; 26(2): 78-84.

7. Morgan PA, Franks PJ, Moffatt CJ. Health-related quality of life with lymphoedema: a review of the literature. Int Wound J 2005; 2(1): 47-62.

8. Ahmed RL, Prizment A, Lazovich D, Schmitz KH, Folsom AR. Lymphedema and quality of life in breast cancer survivors: the lowa Women's Health Study. J Clin Oncol 2008; 26(35): 5689-96.

9. Oliveri JM, Day JM, Alfano CM, Herndon JE, 2nd, Katz ML, Bittoni MA, et al. Arm/hand swelling and perceived functioning among breast cancer survivors 12 years post-diagnosis: CALGB 79804. J Cancer Surviv 2008; 2(4): 233-42.

10. Nesvold IL, Reinertsen KV, Fossa SD, Dahl AA. The relation between arm/shoulder problems and quality of life in breast cancer survivors: a cross-sectional and longitudinal study. J Cancer Surviv 2011; 5(1): 62-72.

11. O'Brien BM. Replantation and reconstructive microvascular surgery. Part II. Ann R Coll Surg Engl 1976; 58(3): 171-82.

12. Nagase T, Gonda K, Inoue K, Higashino T, Fukuda N, Gorai K, et al. Treatment of lymphedema with lymphaticovenular anastomoses. Int J Clin Oncol 2005; 10(5): 304-10.

13. Koshima I, Kawada S, Moriguchi T, Kajiwara Y. Ultrastructural observations of lymphatic vessels in lymphedema in human extremities. Plast Reconstr Surg 1996; 97(2): 397-405; discussion 6-7.

14. O'Brien BM, Mellow CG, Khazanchi RK, Dvir E, Kumar V, Pederson WC. Long-term results after microlymphaticovenous anastomoses for the treatment of obstructive lymphedema. Plast Reconstr Surg 1990; 85(4): 562-72.

15. Campisi C, Boccardo F. Role of microsurgery in the management of lymphoedema. Int Angiol 1999; 18(1): 47-51.

16. Massey MF, Spiegel AJ, Levine JL, Craigie JE, Kline RM, Khoobehi K, et al. Perforator flaps: recent experience, current trends, and future directions based on 3974 microsurgical breast reconstructions. Plast Reconstr Surg 2009; 124(3):737-51.

17. Blum KS, Hadamitzky C, Gratz KF, Pabst R. Effects of autotransplanted lymph node fragments on the lymphatic system in the pig model. Breast Cancer Res Treat 2010; 120(1): 59-66.

18. Tobbia D, Semple J, Baker A, Dumont D, Johnston M. Experimental assessment of autologous lymph node transplantation as treatment of postsurgical lymphedema. Plast Reconstr Surg 2009; 124(3): 777-86.

19. Baumeister RG, Siuda S. Treatment of lymphedemas by microsurgical lymphatic grafting: what is proved? Plast Reconstr Surg 1990; 85(1): 64-74; discussion 5-6.

20. Rohrich RJ, Eaves FF, 3rd. So you want to be an evidence-based plastic surgeon? A lifelong journey. Plast Reconstr Surg 2011; 127(1): 467-72. 
21. Sullivan D, Chung KC, Eaves FF, 3rd, Rohrich RJ. The level of evidence pyramid: indicating levels of evidence in Plastic and Reconstructive Surgery articles. Plast Reconstr Surg 2011; 128(1): 3114.

22. Maegawa J, Mikami T, Yamamoto Y, Satake T, Kobayashi S. Types of lymphoscintigraphy and indications for lymphaticovenous anastomosis. Microsurgery 2010; 30(6): 437- 42.

23. Demirtas $Y$, Ozturk N, Yapici O, Topalan M. Supermicrosurgical lymphaticovenular anastomosis and lymphaticovenous implantation for treatment of unilateral lower extremity lymphedema. Microsurgery 2009; 29(8): 609-18.

24. Matsubara S, Sakuda H, Nakaema M, Kuniyoshi Y. Long-term results of microscopic lymphatic vessel-isolated vein anastomosis for secondary lymphedema of the lower extremities. Surg Today 2006; 36(10): 859-64.

25. Koshima I, Nanba Y, Tsutsui T, Takahashi Y, Itoh S. Long-term follow-up after lymphaticovenular anastomosis for lymphedema in the leg. J Reconstr Microsurg 2003; 19(4): 209-15.

26. Narushima M, Mihara M, Yamamoto Y, lida T, Koshima I, Mundinger GS. The intravascular stenting method for treatment of extremity lymphedema with multiconfiguration lymphaticovenous anastomoses. Plast Reconstr Surg 2010; 125(3): 935-43.

27. Lee BB, Laredo J, Neville R. Reconstructive surgery for chronic lymphedema: a viable option, but. Vascular 2011;19(4): 195-205.

28. Campisi C, Bellini C, Accogli S, Bonioli E, Boccardo F. Microsurgery for lymphedema: clinical research and long-term results. Microsurgery 2010; 30(4): 256-60.

29. Auba C, Marre D, Rodriguez-Losada G, Hontanilla B. Lymphaticovenular anastomoses for lymphedema treatment: 18 months postoperative outcomes. Microsurgery 2012; 32(4): 261-8.

30. Koshima I, Inagawa K, Urushibara K, Moriguchi T. Supermicrosurgical lymphaticovenular anastomosis for the treatment of lymphedema in the upper extremities. J Reconstr Microsurg 2000; 16(6): 437-42.

31. Lin $\mathrm{CH}$, Ali R, Chen SC, Wallace C, Chang YC, Chen HC, et al. Vascularized groin lymph node transfer using the wrist as a recipient site for management of postmastectomy upper extremity lymphedema. Plast Reconstr Surg 2009; 123(4): 1265-75.

32. Becker C, Pham DN, Assouad J, Badia A, Foucault C, Riquet M. Postmastectomy neuropathic pain: results of microsurgical lymph nodes transplantation. Breast 2008; 17(5): 472-6.

33. Becker C, Assouad J, Riquet M, Hidden G. Postmastectomy lymphedema: long-term results following microsurgical lymph node transplantation. Ann Surg 2006; 243(3): 313-5.

34. Saaristo AM, Niemi TS, Viitanen TP, Tervala TV, Hartiala P, Suominen EA. Microvascular Breast Reconstruction and Lymph Node Transfer for Postmastectomy Lymphedema Patients. Ann Surg 2012; 255(3): 468-73.

35. Baumeister RG, Frick A. [The microsurgical lymph vessel transplantation]. Handchir Mikrochir Plast Chir 2003; 35(4): 202-9.

36. Weiss M, Baumeister RG, Hahn K. Post-therapeutic lymphedema: scintigraphy before and after autologous lymph vessel transplantation: 8 years of long-term follow-up. Clin Nucl Med 2002; 27(11): 788-92.

37. Furukawa H, Osawa M, Saito A, Hayashi T, Funayama E, Oyama A, et al. Microsurgical lymphaticovenous implantation targeting dermal lymphatic backflow using indocyanine green fluorescence lymphography in the treatment of postmastectomy lymphedema. Plast Reconstr Surg 2011; 127(5): 1804-11.

38. Chang DW. Lymphaticovenular bypass for lymphedema management in breast cancer patients: a prospective study. Plast Reconstr Surg 2010; 126(3): 752-8.

39. Damstra RJ, Voesten HG, van Schelven WD, van der Lei B. Lymphatic venous anastomosis (LVA) for treatment of secondary arm lymphedema. A prospective study of 11 LVA procedures in 10 
patients with breast cancer related lymphedema and a critical review of the literature. Breast Cancer Res Treat 2009; 113(2): 199-206.

40. Yamamoto Y, Horiuchi K, Sasaki S, Sekido M, Furukawa H, Oyama A, et al. Follow-up study of upper limb lymphedema patients treated by microsurgical lymphaticovenous implantation (MLVI) combined with compression therapy. Microsurgery 2003; 23(1): 21-6.

41. Degni M. New microsurgical technique of lymphatico-venous anastomosis for the treatment of lymphedema. Lymphology 1981; 14(2): 61-3.

42. Brorson H. From lymph to fat: complete reduction of lymphoedema. Phlebology 2010; 25 Suppl 1:52-63.

43. Brorson $\mathrm{H}$, Svensson $\mathrm{H}$. Liposuction combined with controlled compression therapy reduces arm lymphedema more effectively than controlled compression therapy alone. Plast Reconstr Surg 1998; 102(4):1058-67; discussion 68.

44. Koshima I, Kawada S, Moriguchi T, Kajiwara Y. Ultrastructural observations of lymphatic vessels in lymphedema in human extremities. Plast Reconstr Surg 1996; 97(2): 397-405; discussion 6-7.

45. Nagase T, Gonda K, Inoue K, Higashino T, Fukuda N, Gorai K, et al. Treatment of lymphedema with lymphaticovenular anastomoses. Int J Clin Oncol 2005; 10(5): 304-10.

46. Maegawa J, Yabuki Y, Tomoeda H, Hosono M, Yasumura K. Outcomes of lymphaticovenous sideto-end anastomosis in peripheral lymphedema. J Vasc Surg 2012; 55(3): 753-60.

47. Mukenge SM, Catena M, Negrini D, Ratti F, Moriondo A, Briganti A, et al. Assessment and followup of patency after lymphovenous microsurgery for treatment of secondary lymphedema in external male genital organs. Eur Urol 2011; 60(5): 1114-9. 
Microsurgical techniques for lymphedema treatment 


\section{Chapter 8}

\section{The changing role of axillary treatment in breast cancer: Who will remain at risk for developing arm morbidity in the future?}

Tiara R Lopez Penha*

Lori $M$ van Roozendaal*

Marjolijn L Smidt

Liesbeth J Boersma

Adri C Voogd

Maarten $\mathrm{F}$ von Meyenfeldt

Esther M Heuts

* Both authors contributed equally to this manuscript

Adapted from: The Breast 2015.Oct;24(5):543-7 


\begin{abstract}
Introduction: Primary aim is to give an overview of changes in axillary staging and treatment of breast cancer patients. Secondly, we aim to identify patients with a high arm/shoulder morbidity risk, and describe a strategy to improve early detection and treatment.
\end{abstract}

Methods: Recent and initiated studies on axillary staging and treatment were evaluated and clustered for clinically node negative and clinically node positive breast cancer patients, together with studies on pathology, detection and (surgical) prevention and treatment of lymphedema.

Results: For clinically node negative patients, the indication for axillary lymph node dissection in sentinel node positive patients is fading. On the contrary, clinically node positive patients are routinely subjected to an axillary lymph node dissection, in combination with other therapies associated with an increased lymphedema risk, such as mastectomy, adjuvant radiation- and (taxane-based) chemotherapy. Techniques for prevention, early detection and (surgical) treatment of lymphedema are being developed.

Conclusion: Axillary staging and treatment in breast cancer patients with a clinically node negative status will become less invasive, thereby reducing the incidence of morbidity. Nevertheless, in patients with a clinically node positive status, aggressive treatment will still be required for oncologic control. For these patients, a surveillance program should be implemented in order to apply (curative) surgical treatment for lymphedema. 


\section{Introduction}

Breast cancer treatment is in the process of moving towards an era of more conservative axillary treatment. Studies have shown that in selected patient populations, less extensive axillary surgery does not increase the regional recurrence rate, nor does it decrease overall survival. ${ }^{1-3}$ The main advantage of a conservative approach towards axillary surgery is the reduction in treatmentrelated morbidity. Of all, lymphedema has the highest incidence amongst axillary treatment related morbidities in breast cancer and is perceived as disabling. Swelling of the affected arm, symptoms of heaviness, paresthesia and decreased range of motion contribute negatively to the quality of life. ${ }^{4,5}$ Studies have revealed several patient- and treatment related risk factors for breast cancer related lymphedema (BCRL), with most evidence pointing towards the axillary lymph node dissection (ALND) as an important risk factor. Other risk factors include greater number of dissected lymph nodes, mastectomy, high body mass index, adjuvant radiation therapy, and taxanebased chemotherapy. ${ }^{4,6}$

For a long time, ALND was considered standard treatment for all breast cancer patients. Fifteen years ago, the sentinel lymph node biopsy (SLNB) replaced the ALND in patients with a clinically node negative status, resulting in significantly lower axillary morbidity rates, without compromising regional recurrence rates and overall survival. ${ }^{7,8}$ Completion ALND was up until shortly considered the standard treatment in patients with a positive sentinel lymph node (SLN). Currently, there is a decline in the indication for completion ALND in patients with SLN metastases, and the clinical relevance of the SLNB in certain patient groups is being debated.

The primary aim of this paper is to give an overview of current and expected future changes in axillary staging and treatment, and to estimate the impact of these changes on the incidence of arm/shoulder morbidity, and of BCRL in particular. Secondly, we aim to identify the group of patients still high at risk for $B C R L$ and to describe a strategy to improve early detection and treatment. 


\section{The changing role of axillary staging and treatment}

\section{Clinically node negative breast cancer patients}

The standard preoperative lymph node staging consists of physical examination of the axilla, and according to the ESMO breast cancer guideline, combined with an axillary ultrasound. ${ }^{9}$ If negative, a patient is considered clinically node negative, an SLNB is performed, and until recently, followed standardly by a completion ALND in patients with a positive SLN. The reported BCRL rate after completion ALND is $20 \%$, and $6 \%$ after SLNB-only. ${ }^{4}$ Several randomized trials have been performed with the aim to investigate whether completion ALND in patients with metastatic SLNs could be replaced by less invasive treatment or even omitted. In the AMAROS trial, clinically T1-2NO breast cancer patients with SLN metastases were randomized to completion ALND or axillary and periclavicular radiation therapy. ${ }^{3}$ This trial has demonstrated that axillary and periclavicular radiation therapy provided a five-year regional recurrence rate of $1.03 \%$ that is comparable to $0.54 \%$ in the completion ALND group. Most patients were treated with breast conserving therapy (82\%) and received adjuvant systemic therapy (90\%). At five years, the BCRL rate following axillary radiation therapy was significantly lower than following completion ALND based on clinical signs ( 11 vs. $23 \%$; $p<0.0001$ ), as well as based on an arm circumference increase of $\geq 10 \%$ ( $6 \%$ vs. $13 \%$; $p=0.0009$ ). The higher $B C R L$ rate in the completion ALND-arm might partly be explained by the fact that $6 \%$ of these patients underwent axillary and periclavicular radiation therapy as well, compared to $2 \%$ of patients in the radiation therapy-arm that received both therapies. ${ }^{3}$ In this subgroup of patients, the BCRL rate was $58 \%$. Further, it is uncertain whether the stated advantage for axillary and periclavicular radiation therapy will persist over time, as side effects of radiation therapy evolve over a more prolonged time course than surgical side effects. ${ }^{10}$

In the ACOSOG Z0011 trial, clinically T1-2N0 patients with 1-2 macrometastatic SLNs treated with breast conserving therapy were randomized to completion ALND or no completion ALND. ${ }^{2}$ Results revealed a regional recurrence rate of $0.9 \%$ at five years after treatment for patients in whom the completion ALND was omitted compared to $0.5 \%$ in the completion ALND group, while it was estimated that $27 \%$ of the patients had residual nodal disease. ${ }^{2}$ Furthermore, overall survival was not compromised by not performing a completion ALND in this patient population. However, adjuvant systemic treatment was administered to $96 \%$ of the patients. Side effects such as seroma, paresthesia or 
lymphedema, were reported in $70 \%$ of patients in the completion ALND-arm, and in $25 \%$ after SLNB alone in the first year after randomization $(p \leq 0.001) .{ }^{11}$

The IBCSG 23-01 trial also randomized clinically T1-2N0 patients to completion ALND or no completion ALND, though only in case of a micrometastasis in the SLN. ${ }^{1}$ Breast conserving treatment was performed in $91 \%$ of the patients, mastectomy in $9 \%$ and adjuvant systemic treatment was administered to $96 \%$ of the patients. The ALND-specimen of patients in the control arm contained additional lymph node metastases in $11 \%$ of the cases, but again, the regional recurrence rate after omitting the completion ALND was low (1.1\%) and comparable to the completion ALND group (0.2\%).

The AMAROS, ACOSOG Z0011 and IBCSG 23-01 trial were underpowered, as events occurred less common than anticipated. ${ }^{1-3}$ Nevertheless, these trials suggest that for clinically node negative breast cancer patients, a completion ALND is no longer indicated in case of 1-2 macrometastatic SLNs when treated with breast conserving therapy and adjuvant systemic treatment, ${ }^{2}$ and neither in the case of a micrometastastic SLN when treated with mastectomy and adjuvant systemic treatment. ${ }^{1}$ Furthermore, axillary- with or without periclavicular radiation therapy instead of a completion ALND might be beneficial in terms of morbidity risk for mastectomy patients with a macrometasis in the SLN. ${ }^{3}$ Thus, the incidence of BCRL in the clinically node negative patient group is likely to decrease in the coming years due to omitting completion ALND in the majority of patients with SLN metastases. The incidence is expected to decrease even further in the future when results of several ongoing randomized trials become clear. One of these trials is the Dutch BOOG 2013-07 trial that randomizes clinically T1-2N0 breast cancer patients with macrometastatic SLNs treated with mastectomy, to completion axillary treatment or no further axillary treatment. ${ }^{12}$ Several other independent randomized controlled trials are investigating the safety of omitting the SLNB in clinically T1-2N0 breast cancer patients with negative axillary ultrasound findings who are treated with breast conserving therapy: the Dutch BOOG 2013-08, the Italian SOUND, and the British SNIPE trial. ${ }^{13-15}$ The hypothesis that the SLNB could be safely omitted in this patient population derives from the fact that residual lymph node metastases in $11-27 \%$ of patients in the ACOSOG Z0011 and IBCSG 23-01 trials in whom completion ALND was omitted, did not result in a worse regional recurrence- and overall survival rate. ${ }^{1,2}$ Despite the developments of minimizing or even no longer performing invasive staging and treatment of the axilla, we should remain mindful that patients with a clinically node negative status could still develop BCRL with the risk ranging from 6 to 
$20 \%{ }^{4}$ As described earlier, type of breast surgery, a high body mass index, and adjuvant therapy could influence this risk. ${ }^{4,6}$

\section{Clinically node positive breast cancer patients}

Breast cancer patients with preoperatively biopsy-proven nodal metastases or with palpable lymph nodes that are highly suspicious for malignancy, are considered clinically node positive. ${ }^{16}$ In most of these patients an ALND should be performed according to ASCO and ESMO guidelines. ${ }^{9,17}$ These patients are consequently at a high risk for developing severe BCRL, especially since a clinically node positive status is associated with a larger primary tumor, more often requiring a mastectomy, adjuvant chemotherapy and radiation therapy.Adjuvant chemotherapy is frequently indicated in patients with nodal metastases and in patients without nodal metastases but with poor prognostic factors based on primary tumor characteristics, such as tumor grade and diameter. Nowadays, chemotherapy schedules containing taxanes are standard of care. Several studies have shown that taxanes are associated with generalized edema during treatment that can persist and increase the risk of BCRL. ${ }^{18-20}$ The indication for adjuvant radiation therapy of the chest wall, axilla and periclavicular region is based on the risk of disease relapse and type of breast surgery, but in case of a pathological node negative or $\mathrm{N} 1$ status, there is no consensus amongst European and North-American guidelines. Varying risk factors are used in the guidelines to indicate the need for adjuvant chest wall irradiation in mastectomy patients, such as large tumor size, a grade 3 tumor, angio-invasive growth and age below 40 years. Independent from the type of breast surgery, adjuvant periclavicular radiation therapy (combined with breast/chest wall) is recommended in patients with $\geq 4$ lymph node metastases. A prospective study concluded that patients treated with radiation therapy of the breast/chest wall, axilla and periclavicular region have, after only two years of follow-up, a risk of BCRL ranging from $21 \%$ to $25 \%$ when combined with ALND. ${ }^{21}$ Remarkably, the one-year BCRL rate after completion ALND and axillary and periclavicular radiation therapy was much higher in the AMAROS trial, to note $59 \%$ and after five years $58 \% .^{3}$ This large difference in BCRL rate between these studies might partly be ascribed to different BCRL definitions and measurement methods. In the AMAROS trial, an increase in arm circumference of at least $10 \%$, or any recorded sign of lymphedema was defined as BCRL, ${ }^{3}$ while Warren et al. only used standardized arm volume measurements to define BCRL as an arm volume increase of at least $10 \% .{ }^{21}$ 
Furthermore, a difference in the lateral border of the axillary radiation field could also play a role. In the AMAROS trial, the axilla was irradiated with a broad anteroposterior field, and a smaller, laterally-localized, posteroanterior radiation field. In the study of Warren et al., it seems that periclavicular nodes were irradiated with a much smaller anteroposterior field, with sometimes an additional medially-localized posteroanterior field to treat axillary level 3 . This corresponds with a study of Graham et al., who found that there was no increased risk of lymphedema if the lateral border of the supraclavicular field did not extend laterally from the coracoid process. ${ }^{22}$ BCRL due to radiation therapy is thought to develop by increasing fibrosis over the years, resulting in progressive obstruction and infiltration of lymphatic structures. The risk of BCRL is obviously further increased when lymph nodes and vessels are removed at surgery.

So, patients with a clinically node positive status and a large tumor size who are subjected to ALND, combined with mastectomy and radiation therapy of the chest wall, axilla and periclavicular region, and adjuvant chemotherapy should be considered as patients with a high risk for developing BCRL. Especially the combination of ALND and axillary radiation therapy seems to increase the risk of $B C R L$, but no randomized data are available on this specific issue. For these women, it is imperative that clinicians anticipate the development of severe arm morbidity and treat accordingly in order to maintain an acceptable quality of life. Although this "high-risk" group of women might be small in numbers when comparing to the women who will benefit from less extensive axillary treatment, arm lymphedema is a chronic disease that in most cases calls for lifelong treatment, loss of quality of life and potentially resulting in a substantial economic burden. ${ }^{23}$

\section{Pathology and early diagnosis of BCRL}

Little is known about the exact pathophysiology of lymphedema and the time it takes for disease progression to take place, but what is clear is that progression is driven by hydrostatic and osmotic changes in the lymphatic system and accelerated by inflammation and infection. ${ }^{24,25}$ This leads to irreversible structural changes, such as interstitial fibrosis or atrophy of smooth muscle cells within the lymphatic walls, rendering the lymph vessels incapable of lymph fluid propulsion. ${ }^{26}$ Nevertheless, early diagnosis and treatment initiation has proven to be more effective at reducing limb-volume. ${ }^{27}$ The aforementioned points 
substantiate the move from the current so-called impairment (symptom)-based model, in which the patient is the initiative taker, towards a surveillance-based model for diagnosing and treating upper-limb morbidities. ${ }^{28}$ For BCRL this entails pre-operative distribution of precautionary information and limb-volume assessment. Even though there are no results of randomized trials available yet, the efficacy of such a surveillance model has been assessed in a prospective population-based study. ${ }^{29}$ Pre- and postoperative upper-limb volume assessment allows the start of early lymphedema treatment, presumably resulting in more effective treatment and less cases of chronic lymphedema. Implementation of a breast cancer related arm morbidity surveillance program into standard care could reduce the burden and should find its base in appropriate clinical investigations.

\section{Surgical interventions for lymphedema prevention and treatment}

Axillary surgery is the biggest predictor for the development of lymphedema. In the hopes of limiting lymphatic damage in the upper-extremity, axillary reverse mapping (ARM) has been proposed as a technique to further refine axillary surgery. ${ }^{30,31}$ By mapping out the afferent lymphatic system of the upperextremity using blue dye, a radioisotope, or indocyanine green as a tracer agent in conjunction with standard SLNB/ALND procedures, the lymph nodes draining the breast can be selected are removed. In theory, the ARM-procedure facilitates preservation of the lymphatic system draining the upper-extremity, thus reducing the risk of BCRL. An anatomical study assessing the relationship between the breast and the upper-extremity lymphatic drainage, reported a close relationship of the two systems with shared connections in $24 \%$ of the cases. ${ }^{32}$ This phenomenon is seen in clinical studies in which crossover of SLNB/ALND and ARM-nodes are reported, rightfully raising doubts on the oncological safety of the ARM technique. ${ }^{33}$ Moreover, the efficacy of sparing ARM-nodes for reducing the incidence of BCRL has yet to be confirmed in longterm follow-up studies. ${ }^{34,35}$ As previously stated, achieving oncological radicality with preservation of the ARM-nodes is debatable. With that in mind Boccardo et al. developed the Lymphatic Microsurgical Preventative Healing Approach (LYMPHA) to be performed in conjunction with the ARM-procedure. In cases where crossover of SLNB/ALND and ARM-nodes are present in the axillary dissection plain, lymphatic venous anastomosis are made after dissection in order to restore the upper-extremity lymphatic drainage system. After a 4-year 
follow-up, the Boccardo group reported a lymphedema incidence rate of $4 \%$ $(3 / 74) .{ }^{36}$ Although it concerns only a small study, these results are quite promising, when compared with the incidence of BCRL after ALND and SLNB, $20 \%$ and $6 \%$ respectively. ${ }^{4}$

For a long time, treatment of BCRL consisted of symptom control and maintenance with manual lymphatic drainage and compression garments. The Dutch breast cancer guideline suggests compression stockings for three months in case of a 5-10\% limb-volume increase. The addition of compression therapy as part of complete decongestive therapy could induce significant limbvolume reduction. ${ }^{37}$ When maximum limb-volume reduction is achieved, compression stockings should be worn to retain achieved results. These treatment strategies are without curative intent, which for most patients means lifelong treatment and a constant reminder of the breast cancer period. Published evidence for restoring normal lymphatic function in the damaged limb through microsurgery has triggered the idea that a curative approach to BCRL is possible. The most promising is the vascularized autologous lymph node transfer with or without simultaneous free flap reconstruction. ${ }^{38}$ Once again, if lymphatic surgery could indeed repair the flow of a damaged lymphatic system after breast cancer treatment, surgery would need to be done when lymphatic vessels are still viable, with the aim of eliminating the need for life-long conservative treatment and making BCRL a disease less prevalent.

\section{Conclusion}

In conclusion, axillary staging and treatment in breast cancer patients with a clinically node negative status is becoming increasingly less invasive, thereby reducing the incidence of lymphedema of the arm, and increasing quality of life. Nevertheless, in some patients with a clinically node positive status, aggressive treatment will still be required for optimal oncologic control. For these patients, a surveillance program should be implemented in order to apply surgical treatments that are being developed to curatively treat lymphedema at an early stage. 


\section{References}

1. Galimberti V, Cole BF, Zurrida S, et al. Axillary dissection versus no axillary dissection in patients with sentinel-node micrometastases (IBCSG 23-01): a phase 3 randomised controlled trial. The lancet oncology. Apr 2013;14(4):297305.

2. Giuliano AE, Hunt KK, Ballman KV, et al. Axillary dissection vs no axillary dissection in women with invasive breast cancer and sentinel node metastasis: a randomized clinical trial. JAMA : the journal of the American Medical Association. Feb 9 2011;305(6):569-575.

3. Donker M, van Tienhoven G, Straver ME, et al. Radiotherapy or surgery of the axilla after a positive sentinel node in breast cancer (EORTC 10981-22023 AMAROS): a randomised, multicentre, open-label, phase 3 non-inferiority trial. The lancet oncology. 2014;15(12):1303-1310.

4. DiSipio T, Rye S, Newman B, Hayes S. Incidence of unilateral arm lymphoedema after breast cancer: a systematic review and meta-analysis. The lancet oncology. May 2013;14(6):500-515.

5. Peintinger F, Reitsamer R, Stranzl H, Ralph G. Comparison of quality of life and arm complaints after axillary lymph node dissection vs sentinel lymph node biopsy in breast cancer patients. British journal of cancer. Aug 18 2003;89(4):648-652.

6. Bevilacqua JL, Kattan MW, Changhong Y, et al. Nomograms for predicting the risk of arm lymphedema after axillary dissection in breast cancer. Annals of surgical oncology. Aug 2012;19(8):2580-2589.

7. Kootstra JJ, Dijkstra PU, Rietman H, et al. A longitudinal study of shoulder and arm morbidity in breast cancer survivors 7 years after sentinel lymph node biopsy or axillary lymph node dissection. Breast cancer research and treatment. May 2013;139(1):125-134.

8. Krag DN, Anderson SJ, Julian TB, et al. Sentinel-lymph-node resection compared with conventional axillary-lymph-node dissection in clinically nodenegative patients with breast cancer: overall survival findings from the NSABP B-32 randomised phase 3 trial. The lancet oncology. Oct 2010;11(10):927-933.

9. Senkus E, Kyriakides S, Penault-Llorca F, et al. Primary breast cancer: ESMO Clinical Practice Guidelines for diagnosis, treatment and follow-up. Annals of oncology : official journal of the European Society for Medical Oncology / ESMO. Oct 2013;24 Suppl 6:vi7-23.

10. Bentzen SM, Dische S. Morbidity related to axillary irradiation in the treatment of breast cancer. Acta oncologica. 2000;39(3):337-347.

11. Lucci A, McCall LM, Beitsch PD, et al. Surgical complications associated with sentinel lymph node dissection (SLND) plus axillary lymph node dissection compared with SLND alone in the American College of Surgeons Oncology Group Trial Z0011. J Clin Oncol. Aug 20 2007;25(24):3657-3663. 
12. van Roozendaal LM, de Wilt JHW, Smidt ML. The Z11 design for breast cancer patients undergoing a mastectomy. San Antonio Breast Cancer Symposium; 2012.

13. van Roozendaal LM, de Wilt JHW, Smidt ML. Clinically node negative breast cancer patients undergoing breast conserving therapy: follow-up versus sentinel lymph node biopsy. San Antonio Breast Cancer Symposium; 2012.

14. Gentilini O, Veronesi U. Abandoning sentinel lymph node biopsy in early breast cancer? A new trial in progress at the European Institute of Oncology of Milan (SOUND: Sentinel node vs Observation after axillary UltraSouND). Breast. Oct 2012;21(5):678-681.

15. Nadeem RM. The feasibility of SNIPE trial; sentinel lymph node biopsy vs. noSLNB In patients with early breast cancer. Cancer Res. 2013;73(24 Suppl).

16. Edge S, Byrd DR, Compton CC, Fritz AG, Greene FL, Trotti A. Breast. AJCC Cancer Staging Manual. 7th ed: New York, NY: Springer; 2010:347-376.

17. Lyman GH, Temin S, Edge SB, et al. Sentinel lymph node biopsy for patients with early-stage breast cancer: American Society of Clinical Oncology clinical practice guideline update. J Clin Oncol. May 1 2014;32(13):1365-1383.

18. Ohsumi S, Shimozuma K, Ohashi Y, et al. Subjective and objective assessment of edema during adjuvant chemotherapy for breast cancer using taxanecontaining regimens in a randomized controlled trial: The National Surgical Adjuvant Study of Breast Cancer 02. Oncology. 2012;82(3):131-138.

19. Qin YY, Li H, Guo XJ, et al. Adjuvant chemotherapy, with or without taxanes, in early or operable breast cancer: a meta-analysis of 19 randomized trials with 30698 patients. PloS one. 2011;6(11):e26946.

20. Lee MJ, Beith J, Ward L, Kilbreath S. Lymphedema Following Taxane-Based Chemotherapy in Women with Early Breast Cancer. Lymphatic research and biology. Nov 202014.

21. Warren LE, Miller CL, Horick N, et al. The impact of radiation therapy on the risk of lymphedema after treatment for breast cancer: a prospective cohort study. International journal of radiation oncology, biology, physics. Mar 1 2014;88(3):565-571.

22. Graham P, Jagavkar R, Browne L, Millar E. Supraclavicular radiotherapy must be limited laterally by the coracoid to avoid significant adjuvant breast nodal radiotherapy lymphoedema risk. Australasian radiology. Dec 2006;50(6):578582.

23. Shih YC, Xu Y, Cormier JN, et al. Incidence, treatment costs, and complications of lymphedema after breast cancer among women of working age: a 2-year follow-up study. J Clin Oncol. Apr 20 2009;27(12):2007-2014.

24. Mortimer PS. The pathophysiology of lymphedema. Cancer. Dec 15 1998;83(12 Suppl American):2798-2802.

25. Nagase T, Gonda K, Inoue K, et al. Treatment of lymphedema with lymphaticovenular anastomoses. International journal of clinical oncology. Oct 2005;10(5):304-310. 
26. Koshima I, Kawada S, Moriguchi T, Kajiwara Y. Ultrastructural observations of lymphatic vessels in lymphedema in human extremities. Plastic and reconstructive surgery. Feb 1996;97(2):397-405; discussion 406-397.

27. International Society of $L$. The diagnosis and treatment of peripheral lymphedema: 2013 Consensus Document of the International Society of Lymphology. Lymphology. Mar 2013;46(1):1-11.

28. Stout NL, Binkley JM, Schmitz KH, et al. A prospective surveillance model for rehabilitation for women with breast cancer. Cancer. Apr 15 2012;118(8 Suppl):2191-2200.

29. Hayes SC, Johansson K, Stout NL, et al. Upper-body morbidity after breast cancer: incidence and evidence for evaluation, prevention, and management within a prospective surveillance model of care. Cancer. Apr 15 2012;118(8 Suppl):2237-2249.

30. Nos C, Kaufmann G, Clough KB, et al. Combined axillary reverse mapping (ARM) technique for breast cancer patients requiring axillary dissection. Annals of surgical oncology. Sep 2008;15(9):2550-2555.

31. Thompson M, Korourian S, Henry-Tillman R, et al. Axillary reverse mapping (ARM): a new concept to identify and enhance lymphatic preservation. Annals of surgical oncology. Jun 2007;14(6):1890-1895.

32. Pavlista D, Eliska O. Relationship between the lymphatic drainage of the breast and the upper extremity: a postmortem study. Annals of surgical oncology. Oct 2012;19(11):3410-3415.

33. Gobardhan PD, Wijsman JH, van Dalen T, et al. ARM: axillary reverse mapping - the need for selection of patients. European journal of surgical oncology : the journal of the European Society of Surgical Oncology and the British Association of Surgical Oncology. Aug 2012;38(8):657-661.

34. Boneti C, Badgwell B, Robertson Y, Korourian S, Adkins L, Klimberg V. Axillary reverse mapping (ARM): initial results of phase II trial in preventing lymphedema after lymphadenectomy. Minerva ginecologica. Oct 2012;64(5):421-430.

35. Klompenhouwer EG, Gobardhan PD, Beek MA, Voogd AC, Luiten EJ. The clinical relevance of axillary reverse mapping (ARM): study protocol for a randomized controlled trial. Trials. 2013;14:111.

36. Boccardo F, Casabona F, Decian F, et al. Lymphatic Microsurgical Preventing Healing Approach (LYMPHA) for primary surgical prevention of breast cancerrelated lymphedema: Over 4 years follow-up. Microsurgery. Mar 262014.

37. McNeely ML, Magee DJ, Lees AW, Bagnall KM, Haykowsky M, Hanson J. The addition of manual lymph drainage to compression therapy for breast cancer related lymphedema: a randomized controlled trial. Breast cancer research and treatment. Jul 2004;86(2):95-106.

38. Lopez Penha TR, ljsbrandy C, Hendrix NA, et al. Microsurgical techniques for the treatment of breast cancer-related lymphedema: a systematic review. Journal of reconstructive microsurgery. Feb 2013;29(2):99-106. 


\section{Chapter 9}

General discussion 
General discussion 


\section{General discussion}

Upper-limb lymphedema is one of the most debilitating chronic morbidities that can develop as a result of breast cancer treatment. Yet, there is little interest for this treatment-related complication amongst clinicians. Thankfully, the increase in focus on the quality of breast cancer survivorship has stimulated research on this topic. It is the opinion of the authors that both the detection of breast cancer related lymphedema (BCRL) and its treatment warrant improvement. This belief formed the driving force behind the initiation of the studies described in this thesis. In this thesis we focus on several important aspects of BCRL, such as the problems associated with its diagnosis, its effect on quality of life, and the possible role of reconstructive (breast) surgery in the pathophysiology and treatment.

\section{Diagnosing Lymphedema}

The research presented in this thesis is based on two separate cohorts of breast cancer survivors and on two overviews of recent literature. The women in the study cohorts were not prospectively assessed pre- and post-operatively after breast cancer surgery for the presence of BCRL, but the post-operative contralateral limb volume was used as a control for diagnosing BCRL. This outcome was combined with patient reports of self-perceived complaints known to be associated with BCRL. It is our opinion that with this method the patients with clinically relevant BCRL were identified, which ultimately is the target group for treatment. We understand that the lack of consensus regarding the diagnosis of BCRL is an important limitation in the research base of BCRL. An observation made when assessing the available BCRL literature is that it seems as if each researcher has adopted his/her preferred mode of lymphedema measurement as rule of law, as there are many available methods for measuring lymphedema. The consequence of this is described in Chapter 2, in which we demonstrate varying BCRL prevalence rates in one patient cohort when using four different modes of measurement. With this we underline the necessity for a consensus on the diagnostic criteria for BCRL. Furthermore, it is true that lymphedema assessment provides some challenges. This is in part due to differences in intra-observer reliability of the measurement techniques, the dynamic nature of the pathophysiology of lymphedema and also due to the discrepancy sometimes seen between patient perception and limb volume measurement. Volumetry, either being the classic water displacement method or the optoelectronic volumeter (Perometer), is considered the most reliable method for the assessment of lymphedema. ${ }^{1}$ The optoelectronic volumeter is 
gaining interest as the new gold standard for lymphedema assessment; Deltombe et al. have shown a slightly better intra-observer reliability for the Perometer when comparing it to the water displacement method. ${ }^{2}$ Moreover, the usage of infrared light instead of water, results in a convenient and faster limb volume assessment. These points make the Perometer an attractive substitute for the water displacement device. However, the advantage of the water displacement method is that it is more cost-effective and the most applied method and readily available device in Dutch institutions. Also, there is sufficient evidence reporting comparable (high reliability) results with that of the Perometer. ${ }^{3-5}$ Our research group has assessed three-dimensional imaging as a novel approach for limb volume measurements. In this study the validity and reliability of the 3D camera was assessed by measuring arm volume in healthy volunteers and by using water volumetry as the gold standard. ${ }^{6} 3 \mathrm{D}$ measurements appeared to be as reliable as water volumetry, with a high intraand inter rater reliability of both 0.99.6 But, as in case with the Perometer, and unlike the water displacement technique, the hand is not incorporated into the volume measurements by $3 \mathrm{D}$ imaging. Not having the hand included in the 3D limb volume measurement does not necessarily have to be problematic, as it can be combined with a simple circumference measurement of the dorsum of the hand. 3D imaging is yet to be validated in patients with lymphedema.

In the clinical evaluation of lymphedema the focus should not only be put on volume changes. Although volume is important and is the most objective current clinical measure, using only volume may overlook a few important points, such as: tissue texture changes and the symptoms that patients experience. Firstly, the latent stage of lymphedema preceding the increase in volume can go unnoticed if one only focuses on volume changes. ${ }^{7}$ Ideally, to objectively determine the stage, lymphedema assessment should also take place on a histological level. In Chapter 4 the possible role of the Cutometer device for testing and monitoring biomechanical changes in the lymphadematous skin was evaluated. The results of this study show a significantly lower elasticity of the skin in upper-limb lymphedema. In healthy women no difference was found in the skin elasticity of both arms. This finding is supported by the theory that there is an increase in volume of the subcutaneous tissue in BCRL that affects the skin by increasing its tension at rest. ${ }^{15}$ It is hypothesized that the proportional changes within the tissue result in modification of the intermolecular bridging and thickening of the collagen bundle. ${ }^{16}$ The clinical use of the Cutometer as a diagnostic or follow-up tool warrants further investigation in a prospective setting with a larger population. A tool currently being used in the assessment of the early stages of BCRL when 
swelling predominately consists of extracellular lymph fluid ${ }^{8-14}$ is the bioelectrical impedance spectroscopy (BIS), as it can accurately differentiate extracellular fluid from tissue. Secondly, because there is poor agreement between patient perception and objective measures ${ }^{17-20}$, patient perceptions should be investigated for their relationship with the pathophysiology of BCRL. The discrepancy between complaints and symptoms could for example be explained by sensory changes in the treated limb due to neurological damage caused by (even limited) axillary surgery or radiation treatment. ${ }^{20}$ Thus, questions that remain to be answered are: how do we differentiate sensory neuropathy as a consequence of surgery/radiation from that of numbness and tingling experienced by patients with lymphedema? Furthermore, does the inflammatory process activated by tissue injury as seen in $\mathrm{BCRL}^{21,22}$ also cause dysfunction of the sensory nerves located in the epidermis? Currently, there are no studies that explore the symptoms caused by sensory nerve dysfunction in the context of the pathophysiology of BCRL.

\section{Burden of disease}

One of the most important risk factors for the development of BCRL is the axillary lymph node dissection (ALND). ${ }^{23-26}$ For a long time, ALND was considered standard treatment for all breast cancer patients. Around 15 years ago, the sentinel lymph node biopsy (SLNB) replaced the ALND in patients with a clinically node negative status, resulting in lower axillary morbidity rates, without compromising regional recurrence rates and overall survival. ${ }^{27-29}$ However, BCRL rates after SLNB are not negligible. One of the largest RCT's comparing morbidity rates between SLNB and ALND reported a BCRL incidence rate of $7 \%$ after three years in patients having undergone SLNB. ${ }^{30}$ Furthermore, a review of SLNB procedure specific BCRL incidence rates by Shah et al. reported a range of $3 \%-23 \% .{ }^{31}$ In Chapter 3 the long-term healthrelated quality of life (HRQOL) of breast cancer patients with $B C R L$ surviving more than 5 years after diagnosis, was assessed using the EORTC QLQ-C30 and QLQ-BR23 in the SLNB-era. Half of the women in this cohort underwent a SLNB (76/145). Of these 76 women, five were diagnosed with BCRL, which equals to a $6.6 \%$ rate in the SLNB patients. After adjustment for BMI and age, the women with BCRL scored lower on the social functioning scale when compared to the women without BCRL. Moreover, the presented cohort as a whole scored lower on a majority of the functioning scales, compared to scores in the general Dutch population. However, it was only the BCRL group that 
scored significantly lower on role- and social functioning. A prospective study comparing the long-term HRQOL of patients undergoing SLNB alone versus ALND observed that women reporting arm lymphedema themselves, both in the presence of or without objectively measured lymphedema, scored lower on all HRQOL domains. ${ }^{17}$ Thus, clinicians should be perceptive of and receptive to subjective reports of symptoms which might be related to lymphedema. This is a further plea for investigating the relationship between patient perceptions and the pathophysiology of BCRL.

In plastic surgery most surgical procedures are aimed at improving HRQOL. There is evidence that reconstructive breast surgery has a positive effect on the overall wellbeing of breast cancer survivors. ${ }^{32-36}$ However, it is of interest to know if this positive effect is also present in patients with BCRL after breast reconstruction. In a cross-sectional study in chapter 5 , we reported on the impact of BCRL on the HRQOL of breast cancer survivors with and without breast reconstruction. We included women who underwent autologous reconstruction, an implant-based reconstruction and a combination of an implant and latissimus dorsi flap reconstruction in the same surgical session as the mastectomy, or secondarily. Irrespective of having undergone breast reconstruction, our data suggest that $B C R L$ has a negative effect on the $Q O L$ of breast cancer patients. Thus, it goes without saying that BCRL has a negative impact on the HRQOL of breast cancer survivors. However, some believe that $\mathrm{BCRL}$ will be a problem of the past as breast cancer treatment is in the process of moving towards an era of increasingly conservative axillary treatment. Many patients have already benefited from the introduction of the SLNB and many more patients with clinically node negative breast cancer are likely to benefit from developments aimed at further reducing axillary treatment. Results of Z0011 trial suggest that a completion ALND is no longer indicated in case of 12 macrometastatic sentinel lymph nodes (SLN) when the patient is treated with breast conserving therapy and adjuvant systemic treatment ${ }^{37}$, and neither in the case of a micrometastastic SLN when the patient is treated with mastectomy and adjuvant systemic treatment. ${ }^{38}$ Furthermore, axillary radiotherapy with or without periclavicular irradiation, instead of a completion ALND was reported to be beneficial in terms of the morbidity risk for mastectomy patients with a macrometasis in the SLN ${ }^{39}$ However, it is uncertain whether the stated advantage for axillary and periclavicular radiation therapy will persist over time, as side effects of radiation therapy tend to evolve over a more prolonged time course than surgical side effects. ${ }^{40}$ Furthermore, patients with a clinically negative axillary status are still at risk of developing BCRL, with percentages ranging from 6 to $20 \% .{ }^{26}$ The type of breast surgery, a high body mass index, 
and use of radiotherapy and adjuvant systemic therapy can influence this risk. ${ }^{26,41}$ A further specific subgroup which will remain at a significant risk of developing BCRL are the patients with clinically positive axillary lymph nodes. These patients usually present with large tumors, more often requiring a mastectomy, adjuvant hormonal treatment and/or chemotherapy ${ }^{42-44}$ and radiation therapy ${ }^{45-47}$ of the chest wall, axilla and periclavicular region. Especially the combination of ALND and axillary radiation therapy is known to increase the risk of BCRL. ${ }^{46}$ For these women, it is imperative that clinicians anticipate the development of severe arm morbidity and treat accordingly in order to maintain an acceptable quality of life. Thus, we must move away from the current so-called impairment (symptom)-based model, in which the patient is the initiative taker, towards a surveillance-based model for diagnosing and treating BCRL. ${ }^{48}$ This should entail pre-operative distribution of precautionary information and pre- and postoperative limb-volume and symptom assessment. $^{49-52}$ The Implementation of a BCRL surveillance program into standard care could reduce the burden and should find its base in appropriate clinical investigations.

\section{Reconstructive surgery and lymphedema}

Reconstructive breast surgery is now clearly established in the arsenal of breast cancer management. Currently, autologous and implant based reconstructions are widely performed either in the same (oncologic) surgical session or secondarily. The wide application of reconstructive breast surgery has raised the question whether these procedures might have an effect in the development of BCRL. Current literature provides some evidence for a protective effect of breast reconstruction on the development of BCRL. ${ }^{53-56}$ Our findings in Chapter 5 are in line with the current body of evidence; after multivariable analysis breast reconstruction was associated with a lower risk of having BCRL. Although, there are also studies that have reported no effect of reconstructive breast surgery on the incidence of BCRL. ${ }^{57,58}$ Moreover, it is most unlikely that a randomized study will ever be performed with the aim to determine the effect of reconstructive breast surgery on the risk of developing BCRL. 
Studies on reconstructive surgery in the context of a potential curative treatment option for $B C R L$ is of interest, especially for patients who are not responsive to standard conservative therapy. A variety of techniques is described in the literature, such as derivative microsurgery in the form of lymphatic venular anastomose $\mathrm{s}^{59-64}$ and composite tissue transfers containing vascular structures and lymph nodes ${ }^{65-70}$ with varying outcomes on limb volume/circumference. Evidence acquired through comparative prospective studies with uniform patient selection is lacking. The consistent positive findings with regard to limb volume/ circumference reduction and limited to no complications reported after microlymphatic surgery are, however, reasons to further explore these techniques in methodologically superior studies, perhaps answering the question as to when is the most appropriate time in the disease process for lymphatic surgery. We believe that the true contribution of micro lymphatic surgery for the treatment of BCRL will only be elucidated through protocolized treatment by experienced micro surgeons.

\section{Concluding Remarks}

In this thesis we focused on lymphedema of the arm. However, experience gained through conducting the studies presented in this thesis has taught us that swelling of the trunk, breast and axilla is also considered problematic by those who experience it. Means of objectively measuring and monitoring lymphedema in these anatomical locations is technically challenging. Hopefully in the future, as our knowledge grows on the exact etiology and pathophysiology of BCRL we will be able to provide a solution for this problem. Perhaps the Cutometer device will find its place, after further confirmation of the before described results (chapter 4) in larger clinical studies, in the diagnosis of lymphedema of the trunk, breast and axilla.

With regards to the management and treatment of BCRL, a structured approach is lacking in the national breast cancer standard of care. In most hospitals patients have to take the initiative themselves to seek help of a lymph therapist, as the treating physician often pays little attention to post-breast cancer treatment arm morbidities. Saying this, an integrative BCRL surveillance program that combines pre- and post-operative limb measurements and patient education on lymphedema symptoms should be implemented in standard breast cancer care to assist in the early identification ${ }^{49-52}$ and treatment of lymphedema, especially for high-risk patients. Pre-operative limb measurements are especially important to allow the identification of early 
symptoms and of small post-operative changes in limb volume..$^{71,72}$ Furthermore, the effectivity of lymphatic microsurgery to prevent or treat BCRL warrants further investigation in a randomized controlled trial (RCT) comparing it to the current gold standard of conservative therapy. With this, we will also be able to retrospectively formulate clinical criteria to select patients who will benefit mostly from new treatment strategies, including lymphatic microsurgery.

Implementing a multidisciplinary BCRL screening program into standard of care and setting up a RCT are costly and not possible without the help of external funding. Unfortunately, the opinion that BCRL is and will remain a relevant problem amongst breast cancer survivors is not shared amongst the majority of those in charge of distributing national grant funding for research. It is the goal of the authors to further pursue research on the topic of BCRL and ultimately obtain enough evidence to enthuse these non-believers. 


\section{References}

1. Auvert JF, Vayssairat M. Volumetrics: an indispensable complementary test in lymphology. Rev Med Interne 2002; 23 Suppl 3: 388s-90s.

2. Deltombe T, Jamart J, Recloux S, Legrand C, Vandenbroeck N, Theys S et al. Reliability and limits of agreement of circumferential, water displacement, and optoelectronic volumetry in the measurement of upper limb lymphedema. Lymphology. 2007 Mar;40(1):26-34.

3. Tierney S, Aslam M, Rennie K, Grace P. Infrared optoelectronic volumetry, the ideal way to measure limb volume. Eur J Vasc Endovasc Surg 1996; 12(4): 412-7.

4. Lee MJ, Boland RA, Czerniec S, Kilbreath SL. Reliability and concurrent validity of the perometer for measuring hand volume in women with and without lymphedema. Lymphat Res Biol 2011; 9(1): 13-8.

5. Man IO, Markland KL, Morrissey MC. The validity and reliability of the Perometer in evaluating human knee volume. Clin Physiol Funct Imaging 2004; 24(6): 352-8.

6. Erends M, van der Aa T, Piatkowski de Gryzmala A, van der Hulst R. Validity and Reliability of three dimensional imaging for measuring the volume of the arm. Lymphat Res Biol 2014;12(4):275-81)

7. Johnson KC, Kennedy AG, Henry SM. Clinical measurements of lymphedema. Lymphatic research and biology. 2014;12(4):216-21.

8. Jaffrin MY, Morel H. Body fluid volumes measurements by impedance: A review of bioimpedance spectroscopy (BIS) and bioimpedance analysis (BIA) methods. Med Eng Phys 2008; 30(10): 1257-69.

9. Cornish B. Bioimpedance analysis: scientific background. Lymphat Res Biol 2006; 4(1): 47-50.

10. Warren AG, Janz BA, Slavin SA, Borud LJ. The use of bioimpedance analysis to evaluate lymphedema. Ann Plast Surg 2007; 58(5): 541-3.

11. Ward LC, Czerniec S, Kilbreath SL. Quantitative bioimpedance spectroscopy for the assessment of lymphoedema. Breast Cancer Res Treat 2009; 117(3): 541-7.

12. Ward LC, Dylke E, Czerniec S, Isenring E, Kilbreath SL. Confirmation of the reference impedance ratios used for assessment of breast cancer-related lymphedema by bioelectrical impedance spectroscopy. Lymphat Res Biol 2011; 9(1): 47-51.

13. Cornish BH, Chapman M, Thomas BJ, Ward LC, Bunce IH, Hirst C. Early diagnosis of lymphedema in postsurgery breast cancer patients. Ann N Y Acad Sci 2000; 904:571-5.

14. Cornish BH, Ward LC, Thomas BJ, Bunce IH. Quantification of lymphoedema using multifrequency bioimpedance. Appl Radiat Isot 1998; 49(5-6): 651-2.

15. Sakorafas GH, Peros G, Cataliotti L, Vlastos G. Lymphedema following axillary lymph node dissection for breast cancer. Surgical oncology. 2006;15(3):153-65.

16. Manschot JF, Brakkee AJ. The measurement and modelling of the mechanical properties of human skin in vivo--II. The model. Journal of biomechanics. 1986;19(7):517-21.

17. Sackey H, Johansson H, Sandelin K, Liljegren G, MacLean G, Frisell J et al. Selfperceived, but not objective lymphoedema is associated with decreased long-term healthrelated quality of life after breast cancer surgery. Eur J Surg Oncol. 2015 Apr;41(4):57784.

18. Voogd AC, Ververs JMMA, Vingerhoets AJJM, Roumen RMH, Coebergh JWW, Crommelin MA. Lymphoedema and reduced shoulder function as indicators of quality of life after axillary lymph node dissection for invasive breast cancer. BJS 2003; 90: 76-81.

19. McLaughlin SA, et al. Prevalence of lymphedema in women with breast cancer 5 years after sentinel lymph node biopsy or axillary dissection: Patient perceptions and precautionary behaviors. J Clin Oncol 2008; 26:5220-26.

20. Goldberg JI, Riedel ER, Morrow M, van Zee KJ. Morbidity of sentinel node biopsy: relationship between number of excised lymph nodes and patient perceptions of lymphedema. Ann Surg Oncol 2011; 18(10):2866-72.

21. Ji RC. Lymphatic endothelial cells, lymphedematous lymphangiogenesis, and molecular control of edema formation. Lymphat Res Biol 2008;6(3-4):123-37.

22. Ghanta S, Cuzzone DA, Torrisi JS, Albano NJ, Joseph WJ, Savetsky IL et al. Regulation of inflammation and fibrosis by macrophages in lymphedema. Am J Physiol Heart Circ Physiol 2015;308(9):1065-77.

23. Tsai RJ, Dennis LK, Lynch CF, Snetselaar LG, Zamba GK, Scott-Conner C. The risk of 
developing arm lymphedema among breast cancer survivors: a meta-analysis of treatment factors. Ann Surg Oncol.2009;16(7):1959-72.

24. Ugur S, Arıcı C, Yaprak M, Mescı A, Arıcı GA, Dolay K et al. Risk factors of breast cancer-related lymphedema. Lymphat Res Biol. 2013 Jun;11(2):72-5.

25. Coriddi M, Khansa I, Stephens J, Miller M, Boehmler J, Tiwari P. Analysis of factors contributing to severity of breast cancer-related lymphedema. Ann Plast Surg. 2015 Jan;74(1):22-5.

26. DiSipio T, Rye S, Newman B, Hayes S. Incidence of unilateral arm lymphoedema after breast cancer: a systematic review and meta-analysis. Lancet Oncol. 2013 May;14(6):500-15.

27. Krag DN, Weaver DL, Alex JC, Fairbank JT. Surgical resection and radiolocalization of the sentinel lymph node in breast cancer using a gamma probe. Surg Oncol 1993; 2:335399.

28. Kootstra JJ, Dijkstra PU, Rietman H, et al. A longitudinal study of shoulder and arm morbidity in breast cancer survivors 7 years after sentinel lymph node biopsy or axillary lymph node dissection. Breast cancer research and treatment. May 2013;139(1):125-134.

29. Krag DN, Anderson SJ, Julian TB, et al. Sentinel-lymph-node resection compared with conventional axillary-lymph-node dissection in clinically node-negative patients with breast cancer: overall survival findings from the NSABP B-32 randomised phase 3 trial. The lancet oncology. Oct 2010;11(10):927-933.

30. Ashikaga T, Krag DN, Land SR, Julian TB, Anderson SJ, Brown AM et al. Morbidity results from the NSABP B-32 trial comparing sentinel lymph node dissection versus axillary dissection. J Surg Oncol.2010;102(2):111-8.

31. Shah C, Arthur D, Riutta J, Whitworth P, Vicini FA, Breast -Cancer related lymphedema: A review of procedure specific incidence rates, clinical assessment aids, treatment paradigms, and risk reduction. Breast J 2012; 18(4): 357-61.

32. Jeevan R., Cromwell DA, Browne JP, Caddy CM, Pereira J, Sheppard C. Findings of a National comparative audit of mastectomy and breast reconstruction surgery in England. J Plast Reconstr Aesthet Surg 2014;67(10):1333-44.

33. Eltahir Y, Werners LL, Dreise MM, van Emmichoven IA, Jansen L, Werker PM. Quality-oflife outcomes between mastectomy alone and breast reconstruction: comparison of patient-reported Breast-Q and other health-related quality of life measures. Plast Reconstr Surg 2013; 132(2):201e-209e.

34. Girotto JA, Schreiber J, Nahabedian MY. Breast reconstruction in the elderly: preserving excellent quality of life. Annals of plastic surgery. 2003 Jun;50(6):572-8.

35. Shi HY, Uen YH, Yen LC, Culbertson R, Juan CH, Hou MF. Two-year quality of life after breast cancer surgery: a comparison of three surgical procedures. European journal of surgical oncology : the journal of the European Society of Surgical Oncology and the British Association of Surgical Oncology. 2011 Aug;37(8):695-702.

36. Dean C, Chetty U, Forrest AP. Effects of immediate breast reconstruction on psychological morbidity after mastectomy. Lancet 1983;26:459-462.

37. Giuliano AE, Hunt KK, Ballman KV, et al. Axillary dissection vs no axillary dissection in women with invasive breast cancer and sentinel node metastasis: a randomized clinical trial. JAMA : the journal of the American Medical Association. Feb 9 2011;305(6):569575.

38. Galimberti V, Cole BF, Zurrida S, et al. Axillary dissection versus no axillary dissection in patients with sentinel-node micrometastases (IBCSG 23-01): a phase 3 randomised controlled trial. The lancet oncology. Apr 2013;14(4):297-305.

39. Donker M, van Tienhoven G, Straver ME, et al. Radiotherapy or surgery of the axilla after a positive sentinel node in breast cancer (EORTC 10981-22023 AMAROS): a randomised, multicentre, open-label, phase 3 non-inferiority trial. The lancet oncology. 2014;15(12):1303-1310.

40. Bentzen SM, Dische S. Morbidity related to axillary irradiation in the treatment of breast cancer. Acta oncologica. 2000;39(3):337-347.

41. Bevilacqua JL, Kattan MW, Changhong Y, Koifman S, Mattos IE, Koifman RJ et al. Nomograms for predicting the risk of arm lymphedema after axillary dissection in breast cancer. Annals of surgical oncology. Aug 2012;19(8):2580-2589. 
42. Ohsumi S, Shimozuma K, Ohashi Y, Takeuchi A, Suemasu K, Kuranami M et al. Subjective and objective assessment of edema during adjuvant chemotherapy for breast cancer using taxane-containing regimens in a randomized controlled trial: The National Surgical Adjuvant Study of Breast Cancer 02. Oncology. 2012;82(3):131-138.

43. Qin YY, Li H, Guo XJ, Ye XF, Wei X, Zhou YH, Zhang XJ et al. Adjuvant chemotherapy, with or without taxanes, in early or operable breast cancer: a meta-analysis of 19 randomized trials with 30698 patients. PloS one. 2011;6(11):e26946.

44. Lee MJ, Beith J, Ward L, Kilbreath S. Lymphedema Following Taxane-Based Chemotherapy in Women with Early Breast Cancer. Lymphatic research and biology. Nov 202014.

45. Graham P, Jagavkar R, Browne L, Millar E. Supraclavicular radiotherapy must be limited laterally by the coracoid to avoid significant adjuvant breast nodal radiotherapy lymphoedema risk. Australasian radiology. Dec 2006;50(6):578-582.

46. Warren LE, Miller CL, Horick N, Skolny MN, Jammallo LS, Sadek BT et al. The impact of radiation therapy on the risk of lymphedema after treatment for breast cancer: a prospective cohort study. International journal of radiation oncology, biology, physics. Mar 1 2014;88(3):565-571.

47. Donker M, van Tienhoven G, Straver ME, Meijnen P, vd Velde CJ, Mansel RE et al. Radiotherapy or surgery of the axilla after a positive sentinel node in breast cancer (EORTC 10981-22023 AMAROS): a randomised, multicentre, open-label, phase 3 noninferiority trial. The lancet oncology. 2014;15(12):1303-1310.

48. Stout NL, Binkley JM, Schmitz KH, et al. A prospective surveillance model for rehabilitation for women with breast cancer. Cancer. Apr 15 2012;118(8 Suppl):21912200.

49. Blaney JM, McCollum G, Lorimer J, Bradley J, Kennedy R, Rankin JP. Prospective surveillance of breast cancer-related lymphedema in the first-year post-surgery: feasibility and comparison of screening measures. Support Care Cancer 2015;23:1549-1559.

50. Ostby PL, Armer JM, Dale PS, van Loo PJ, Wilbanks CL, Stewart BR. Surveillance recommendations in reducing risk of and optimally managing breast cancer-related lymphedema. J. Pers. Med. 2014;4:424-447.

51. Hayes S, Johansson K, Stout NL, Prosnitz R, Armer JM, Gabram S et al. Upper-body morbidity after breast cancer: Incidence and evidence for evaluation, prevention and management within a prospective surveillance model of care. Cancer 2012;118(8):22372249.

52. Brunelle C, Skolny M, Ferguson C, Swaroop M, O'Toole J, Taghian AG. Establishing and sustaining a prospective screening program for breast cancer-related lymphedema at the Massachusetts General Hopsital: lessons learned. J Pers Med 2015;5:153-164.

53. Miller CL, Colwell AS, Horick N, Skolny MN, Jammallo LS, O'Toole JA et al. Immediate Implant Reconstruction Is Associated With a Reduced Risk of Lymphedema Compared to Mastectomy Alone: A Prospective Cohort Study. Ann Surg 2015 Epub ahead of print.

54. Card A, Crosby MA, Liu J, Lindstrom WA, Lucci A, Chang DW. Reduced incidence of breast cancer- related lymphedema following mastectomy and breast reconstruction versus mastectomy alone. Plast Reconstr Surg 2012;130(6):1169-78. .

55. Lee KT, Mun GH, Lim SY, Pyon JK, Oh KS, Bang SI. The impact of immediate breast reconstruction on post-mastectomy lymphedema in patients undergoing modified radical mastectomy. Breast 2013; 22(1):53-7.

56. Chang DW, Kim S. Breast reconstruction and lymphedema. Plast Reconstr Surg 2010; 125(1): 19-23.

57. Avraham T, Daluvoy SV, Riedel ER, Cordeiro PG, Van Zee KJ, Mehrara BJ. Tissue expander breast reconstruction is not associated with an increased risk of lymphedema. Ann Surg Oncol 2010; 17(11): 2926-32.

58. Crosby MA, Card A, Lindstrom WA, Chang DW. Immediate breast reconstruction and lymphedema incidence. Plast Reconstrc Surg 2012; 129(5): 789e-95e.

59. Torrisi JS, Joseph WJ, Ghanta S, Cuzzone DA, Albano NJ, Savetsky IL et al. Lymphaticovenous bypass decreases pathologic skin changes in upper extremity breast cancer-related lymphedema. Lymphatic research and biology 2015;13(1):46-53.

60. Mihara M, Hara H, Hayashi Y, Lida T, Araki J, Yamamoto T et al. Upper-limb lymphedema treated aesthetically with lymphaticovenous anastomosis using indocyanine 
green lymphography and noncontact vein visualization. J Reconstr Microsurg 2012;28:327-332.

61. Furukawa H, Osawa M, Saito A, Hayashi T, Funayama E, Oyama A, et al. Microsurgical lymphaticovenous implantation targeting dermal lymphatic backflow using indocyanine green fluorescence lymphography in the treatment of postmastectomy lymphedema. Plast Reconstr Surg 2011; 127(5): 1804-11.

62. Chang DW. Lymphaticovenular bypass for lymphedema management in breast cancer patients: a prospective study. Plast Reconstr Surg 2010; 126(3): 752-8.

63. Damstra RJ, Voesten HG, van Schelven WD, van der Lei B. Lymphatic venous anastomosis (LVA) for treatment of secondary arm lymphedema. A prospective study of 11 LVA procedures in 10 patients with breast cancer related lymphedema and a critical review of the literature. Breast Cancer Res Treat 2009; 113(2): 199-206.

64. Yamamoto Y, Horiuchi K, Sasaki S, Sekido M, Furukawa H, Oyama A, et al. Follow-up study of upper limb lymphedema patients treated by microsurgical lymphaticovenous implantation (MLVI) combined with compression therapy. Microsurgery 2003; 23(1): 21-6.

65. Lin $\mathrm{CH}$, Ali R, Chen SC, Wallace $\mathrm{C}$, Chang YC, Chen HC, et al. Vascularized groin lymph node transfer using the wrist as a recipient site for management of postmastectomy upper extremity lymphedema. Plast Reconstr Surg 2009; 123(4): 1265-75.

66. Becker C, Pham DN, Assouad J, Badia A, Foucault C, Riquet M. Postmastectomy neuropathic pain: results of microsurgical lymph nodes transplantation. Breast 2008; 17(5): 472-6.

67. Becker C, Assouad J, Riquet M, Hidden G. Postmastectomy lymphedema: long-term results following microsurgical lymph node transplantation. Ann Surg 2006; 243(3): 313-5.

68. Saaristo AM, Niemi TS, Viitanen TP, Tervala TV, Hartiala P, Suominen EA. Microvascular Breast Reconstruction and Lymph Node Transfer for Postmastectomy Lymphedema Patients. Ann Surg 2012; 255(3): 468-73.

69. Baumeister RG, Frick A. [The microsurgical lymph vessel transplantation]. Handchir Mikrochir Plast Chir 2003; 35(4): 202-9.

70. Weiss M, Baumeister RG, Hahn K. Post-therapeutic lymphedema: scintigraphy before and after autologous lymph vessel transplantation: 8 years of long-term follow-up. Clin Nucl Med 2002; 27(11): 788-92.

71. Springer BA, Levy E, McGarvey C, Pfalzer LA, Stout NL, Gerber LH, Soballe PW, Danoff J. Pre-operative assessment enables early diagnosis and recovery of shoulder function in patients with breast cancer. Breast Cancer Res Treat 2010. 120:135-147.

72. Stout Gergich NL, Pfalzer LA, McGarvey C, Springer B, Gerber LH, Soballe P. Preoperative assessment enables the early diagnosis and successful treatment of lymphedema. Cancer. 2008 Jun 15;112(12):2809-19. 
General discussion 
Summary 
Summary

141 


\section{Summary}

In chapter 1, an introduction on breast cancer related lymphedema (BCRL) is provided as well as the outline of the thesis. Focus is placed on certain important aspects of BCRL, such as issues associated with its diagnosis, its effect on the quality of life, and the possible role reconstructive (breast) surgery plays in its treatment and pathophysiology. The aim of this thesis was to gain better insight on the above-mentioned aspects in order to substantiate the need for improvement of lymphedema management amongst breast cancer survivors.

Chapter 2 describes the long-term prevalence of BCRL using four different commonly used measuring methods in a cohort of breast cancer survivors five years after oncological surgery. The prevalence varied significantly depending on the method used for lymphedema assessment. This data underlines the necessity for consensus on the diagnostic criteria for BCRL.

In chapter 3 data are presented that show that the health related quality of life (HRQOL) of long-term breast cancer survivors with BCRL is significantly lower compared to breast cancer survivors without BCRL and also significantly lower compared to normative data representing the Dutch speaking population in the Netherlands within the same age category. The women in the study cohort were all treated in the sentinel lymph node biopsy (SLNB) era. These results demonstrate the clinical relevance of BCRL as a morbidity of the upper-limb, despite of the less invasive axillary surgery performed in the SLNB-era.

Ultra-structural research has given insight on the progressive nature of BCRL: tissue injury induces the accumulation of inflammatory cells, which ultimately leads to fibrosis and degeneration of smooth muscle cells in the lymphedematous tissue. The above-described pathogenesis process implicates a role of biomechanical skin changes within the development of BCRL. In chapter 4 the biomechanical skin changes of patients with BCRL are presented using a Cutometer ${ }^{\circledR}$ for assessing skin-elasticity and visco-elasticity, and the Corneometer $\AA^{\circledR}$ for the assessment of skin-hydration. Data of this study give evidence of a reduced elasticity of the skin of the affected limb in BCRL, suggesting the use of the Cutometer ${ }^{\circledR}$ device in the diagnostic evaluation of BCRL in which a continued decrement in the skin elasticity may be an indication of further progression of lymphedema.

Breast reconstruction is an important component of rehabilitation after ablative breast surgery. These procedures do not only provide good aesthetic results, 
but have also been demonstrated beneficial with regards to quality of life and body image without interfering with cancer management. The wide application of reconstructive breast surgery has raised the question whether it should be considered as a risk factor or protective factor for the development of. Chapter 5 investigated whether women who underwent breast reconstruction, as part of their breast cancer treatment, were less likely to develop BCRL.130 women who underwent unilateral mastectomy and axillary lymph node dissection (ALND) with or without immediate or delayed breast reconstruction between January 2006 and December 2010 were included in this study. After multivariable adjustment breast reconstruction was associated with a significantly lower $B C R L$ risk, this being of interest for the surgical decision making process.

In chapter 6 data are presented that show that the HRQOL of breast cancer survivors who have undergone breast reconstruction and have BCRL is significantly impaired, negating the positive effects reconstructive breast surgery might have on the HRQOL.

Chapter 7 presents a systematic review that was undertaken to give an overview on currently available literature on the effectiveness of lymphatic microsurgery for the treatment of BCRL. In this review it was concluded that composite tissue transfer and derivative microlymphatic surgery may be a promising treatment option that provides limb volume/circumference reduction. This systematic review identified the important methodological shortcomings of the available literature.

In chapter 8 an overview of the changes in axillary staging and its implications on the development of arm morbidity for the future is given. It was concluded that clinically node negative breast cancer patients would have a reduced risk due to less invasive axillary staging and treatment. Nevertheless, in patients with a clinically node positive status, aggressive treatment will still be required for oncologic control. These patients should be considered at high risk for developing BCRL.

Finally, chapter 9 provides the general discussion with conclusions following from this thesis. 
Summary (in Dutch) 
Summary (in Dutch) 


\section{Samenvatting}

In hoofdstuk 1 wordt de opzet van het proefschrift beschreven en een introductie over "breast cancer related lymphedema (BCRL)", oftewel lymfoedeem van de arm na behandeling van borstkanker, gegeven. Enkele belangrijke aspecten van de pathofysiologie en de behandeling van $B C R L$ worden besproken, zoals problemen omtrent de diagnose, het effect op de kwaliteit van leven en de mogelijke rol van reconstructieve (borst-)chirurgie. Het doel van dit proefschrift was om een beter inzicht te verkrijgen in bovengenoemde aspecten en zodoende een verbetering van de zorg van borstkanker patiënten te waarborgen.

In hoofdstuk 2 wordt de prevalentie van BCRL, vijf jaar na de behandeling voor borstkanker, beschreven. In een cohort van 145 borstkankerpatiënten, werd de aanwezigheid van lymfoedeem gemeten met behulp van vier verschillende meetmethodes: volumetrie, omtrek meting, som van arm omtrek metingen en subjectieve klachten patroon. De prevalentie van BCRL varieerde significant, afhankelijk van de methode die werd gebruikt om het lymfoedeem te bepalen. De gepresenteerde data benadrukken het gebrek en de behoefte aan een consensus omtrent diagnostische criteria voor BCRL.

In hoofdstuk 3 wordt aangetoond dat de kwaliteit van leven, oftewel de quality of life (QOL) van borstkanker patiënten mét BCRL significant lager is dan die van overlevenden zónder $B C R L$ en tevens significant lager is dan de $Q O L$ van vrouwen in de algemene Nederlandse populatie in dezelfde leeftijdscategorie. De vrouwen in het studiecohort zijn allemaal in het sentinel lymfklier biopsie (SNB) tijdperk behandeld en hebben dientengevolge minder uitgebreide okselchirurgie ondergaan. Ondanks de beperkte okselchirurgie, bevestigen deze resultaten dat, de morbiditeit van BCRL in het SNB tijdperk substantieel is.

De ontwikkeling van lymfoedeem en de progressieve aard van de aandoening wordt gekenmerkt door een aantal opeenvolgende pathofysiologische processen. Het proces wordt geïnitieerd doordat weefselschade activatie van inflammatoire cellen veroorzaakt, wat uiteindelijk fibrosering en vervolgens degeneratie van gladde spiercellen en oedemateuze huid veroorzaakt. Het hierboven beschreven proces impliceert het optreden van biomechanische huidveranderingen in de pathogenese van BCRL. In hoofdstuk 4 worden deze biomechanische huidveranderingen van patiënten met $B C R L$ gepresenteerd met behulp van de Cutometer ${ }^{\circledR}$ voor bepaling van huidelasticiteit en visco- 
elasticiteit en de Corneometer ${ }^{\circledR}$ voor bepaling van de hydratie van de huid. Data van deze studie hebben aangetoond dat er een significant verminderde huidelasticiteit aanwezig is in de aangedane arm bij patiënten met BCRL. Dit impliceert het gebruik van de Cutometer ${ }^{\circledR}$ als een diagnosticum bij de evaluatie van $B C R L$, waarbij een progressieve vermindering van de huidelasticiteit mogelijk duidt op het ontstaan of progressie van het lymfoedeem.

Tijdens of na de behandeling van borstkanker kiezen steeds meer vrouwen voor een borstreconstructie, waardoor de reconstructieve chirurgie een belangrijk onderdeel van de borstkankerbehandeling is geworden. Deze ingrepen zorgen niet alleen voor een verbeterde esthetiek, maar blijken ook een gunstig effect te hebben op de QOL en het lichaamsbeeld van deze patiënten, zonder hierbij te interfereren met de oncologische behandeling. De brede toepassing van reconstructieve borstchirurgie heeft geleid tot de vraag of er een associatie is tussen borstreconstructie en de ontwikkeling van BCRL. In hoofdstuk $\mathbf{5}$ is de invloed van borstreconstructie als onderdeel van borstkankerbehandeling op het ontwikkelen van BCRL onderzocht. Honderddertig vrouwen die een unilaterale mastectomie met een okselklierdissectie (OKD) hebben ondergaan, met of zonder reconstructieve borstchirurgie, tussen januari 2006 en december 2010 werden geïncludeerd in deze studie. Multivariate analyse toonde een protectieve associatie tussen borstreconstructie en BCRL. Deze interessante bevinding is van belang voor de chirurgische besluitvorming en verdient verder onderzoek.

In hoofdstuk 6 wordt aangetoond dat de QOL van borstkankeroverlevenden die reconstructieve borstchirurgie hebben ondergaan en daarbij BCRL hebben ontwikkeld significant verminderd is ten opzicht van borstkankeroverlevenden zonder $B C R L$ na reconstructieve borstchirurgie. Deze data impliceren dat $B C R L$ het mogelijke positieve effect van borstreconstructie op de $Q O L$ teniet doet.

Hoofdstuk 7 is een systematische review welke de huidige literatuur omtrent de effectiviteit van lymfatische microchirurgie als behandeling voor BCRL behelst. Deze review concludeert dat gemengde weefseltransplantaties, welke dus onder andere lymfeklieren bevatten, alsook lymfe-veneuze anastomoseringen mogelijke behandelingsopties zijn die voor volumelomtrekreductie zorgen van ledematen aangedaan door BCRL. Tevens identificeert deze review de belangrijke tekortkomingen van de huidige literatuur en dientengevolge de behoefte aan research op dit gebied. 
In hoofdstuk 8 wordt een overzicht gegeven van de huidige veranderingen die plaatsvinden in de borstkankerbehandeling met betrekking tot de oksel. Er is momenteel een trend naar minder invasieve okselchirurgie ter stadiering en behandeling van borstkanker patiënten. Diverse studies naar de oncologische veiligheid en de verwachte gevolgen van minder invasieve okselchirurgie op de ontwikkeling van $B C R L$ zijn opgezet en de resultaten zullen over enkele jaren bekend zijn . In hoofdstuk 8 wordt geconcludeerd dat het risico op BCRL zal afnemen bij borstkankerpatiënten die klinisch geen axillaire metastasen hebben. Toch zullen vrouwen met positieve axillaire lymfeklieren een agressieve behandeling moeten ondergaan met het oog op behoud van oncologische controle. Deze patiëntengroep moet beschouwd worden als een hoog risicogroep op het ontwikkelen van BCRL.

Hoofdstuk 9, tenslotte, bevat de algemene discussie met de uit deze thesis voortvloeiende conclusies. 
Summary (in Dutch) 
Valorization 
Valorization

151 


\section{Introduction}

Approximately one in eight women in the Netherlands will develop breast cancer during her lifetime. Fortunately, due to the implementation of population based screening programs, advancements in treatment options and increased awareness, a large proportion of these women will go on to survive the initial treatment phase. The fact that more women are successfully being treated for breast cancer has caused a shift of attention towards the period after active cancer treatment, also known as the period of survivorship. Survivorship refers to the end of active cancer therapy, a period in which late effects of cancer treatment are prevalent. In saying this, the management of the late effects of breast cancer treatment is imperative for maintaining an acceptable long-term quality of life. In the scope of upper-arm morbidities as part of the late effects of breast cancer treatment, lymphedema has the highest incidence and is perceived as disabling. Swelling of the affected arm, symptoms of heaviness, paresthesia and decreased range of motion contribute negatively to the quality of life. Between $6 \%$ - $43 \%$ of breast cancer survivors develop breast cancer related lymphedema (BCRL). Studies have revealed several patient- and treatment related risk factors for BCRL, with most evidence pointing towards the axillary lymph node dissection (ALND) as an important risk factor.

In this chapter the focus is put on the economic and societal benefits of the knowledge acquired through the studies gathered in this thesis.

\section{Relevance of scientific results}

This thesis addressed several important aspects of BCRL, such as the problems associated with its diagnosis, its effect on quality of life, and the possible role of reconstructive (breast) surgery in the pathophysiology and treatment.

Most importantly, we were able to conclude that $B C R L$ is and will remain a relevant problem amongst breast cancer survivors. Currently, axillary staging and treatment in breast cancer patients with a clinically node negative status is becoming increasingly less invasive, thereby reducing the incidence of lymphedema of the arm. Nevertheless, in patients with a clinically node positive status, aggressive treatment will still be required for optimal oncologic control. Although this "high-risk" group of women might be small in numbers when 
comparing to the women who will benefit from less extensive axillary treatment, $B C R L$ is a chronic disease that in most cases calls for life long treatment, decrease in quality of life and potentially resulting in a economic burden. Therefore, we advice implementing a BCRL surveillance program into standard breast cancer care in order to facilitate early lymphedema treatment.

With regards to the treatment of $B C R L$, a structured approach is lacking in the national breast cancer standard of care. In most hospitals patients have to take the initiative themselves to seek help of a lymph therapist, as the treating physician often pays little attention to post-breast cancer treatment arm morbidities. Saying this, an integrative BCRL surveillance program that combines pre- and post operative limb measurements and patient education on lymphedema symptoms should be implemented in standard breast cancer care to assist in the early identification and treatment of lymphedema, especially for high-risk patients. Pre-operative limb measurements are especially important to allow the identification of early symptoms and of small post-operative changes in limb volume. Furthermore, the effectivity of lymphatic microsurgery to prevent or treat BCRL warrants further investigation in a randomized controlled trial (RCT) comparing it to the current gold standard of conservative therapy. With this, we will also be able to retrospectively formulate clinical criteria to select patients who will benefit mostly from new treatment strategies, including lymphatic microsurgery.

\section{Target population}

The results of this thesis are relevant for investigators in the medical field with special interest in breast cancer, morbidities related to breast cancer, lymphedema and quality of life. In addition, this thesis is of interest to (surgical) oncologists, plastic surgeons, lymphedema therapists, dedicated nurses and lymphedema-patient platforms.

\section{Knowledge utilization and innovation}

As previously mentioned, a multidisciplinary BCRL screening program should be implemented in breast cancer standard of care. This will especially be important for "high-risk" patients. Through this approach of secondary prevention of BCRL we will not only be able to treat lymphedema more 
effectively but also learn more about its pathophysiology. The idea of moving away from the current so-called impairment (symptom)-based model, in which the patient is the initiative taker, towards a surveillance-based model is an innovative concept in Dutch breast cancer care. In the US a few hospitals have already adopted this approach as standard of care with evidence of being potentially cost saving compared to the traditional treatment of BCRL.

The place of lymphatic microsurgery in the treatment of BCRL is yet to be established in comparative prospective studies with a uniform patient group. This is ultimately one of the most important goals of our research group. 
Valorization

155 
Appendix

Scientific output

Acknowledgements (in Dutch)

About the author 


\section{Scientific output}

TR Lopez Penha, B Botter, EM Heuts, AC Voogd, MF von Meyenfeldt, RRWJ van der Hulst. Quality of life in patients with breast cancer related lymphedema and reconstructive breast surgery. Journal Reconstr Microsurg (submitted)

RC Killaars, TR Lopez Penha, EM Heuts, AA Piatkowski de Grzymala, RRWJ van der Hulst. Biomechanical properties of the skin in breast cancer patients with upper-limb lymphedema compared to healthy individuals. Lymphat Res Biol 2015. Sep;13 (3):215-21.

TR Lopez Penha*, LM van Roozendaal ${ }^{*}$, ML Smidt, LJ Boersma, MF von Meyenfeldt, AC Voogd, EM Heuts. The changing role of axillary treatment in breast cancer: Who will remain at risk for developing arm morbidity in the future? The Breast 2015. Oct;24(5):543-7.

TR Lopez Penha, AC Voogd, EM Heuts, C ljsbrandy, NAM Hendrix, MF von Meyenfeldt, RRWJ van der Hulst. Reduced risk of breast cancer-related lymphoedema after reconstructive breast surgery. Breast J 2014. Nov-Dec; 20(6):671-673.

TR Lopez Penha, J van Bodegraven, B Winkens, EM Heuts, AC Voogd, MF von Meyenfeldt. The impact of breast cancer-related lymphedema on the quality of life of long-term breast cancer survivors. Acta Chirg Belg 2014; 114(4):239-44

DRJ van Mierlo, TR Lopez Penha, RJ Schipper, MH Martens, J Serroyen, MBI Lobbes, EM Heuts, S Tuinder, ML Smidt. Skin-sparing mastectomy followed by immediate breast reconstruction in breast cancer patients is oncologically safe. The Breast 2013; 22(6): 1166-70

TR Lopez Penha, C IJsbrandy, NAM Hendrix, EM Heuts, AC Voogd, MF von Meyenfeldt, RRWJ van der Hulst. Microsurgical techniques for the treatment of breast cancer related lymphedema: a systematic review. J Reconstr Microsurg 2013; 29(2):99-106

TR Lopez Penha, NAM Hendrix, C IJsbrandy, EM Heuts, AC Voogd, RRWJ van der Hulst. De invloed van borstreconstructies op het ontwikkelen van lymfoedeem. Nederlands Tijdschrift voor Plastische Chirurgie. 2012;3(4):171-2.

TR Lopez Penha, JJG Slangen, EM Heuts, AC Voogd, MF von Meyenfeldt. Prevalence of Lymphedema more than five years after treatment. Eur J Surg Oncol 2011; 37(12): 1059-6

* Shared first 


\section{Dankwoord}

Allereerst wil ik de afdeling Heelkunde en Plastische chirurgie van het Maastricht Universitair Medisch Centrum (MUMC+) bedanken voor het mogelijk maken van dit promotietraject. Ook dank aan de patiënten die de tijd genomen hebben om naar het ziekenhuis te komen voor het laten uitvoeren van de metingen. Tevens de mammacare verpleegkundigen in het MUMC+, Orbis Medisch Centrum (thans Zuyderland Medisch Centrum) te Sittard en Viecuri Medisch Centrum te Venlo voor hun hulp.

Daarnaast, wil ik een aantal mensen in het bijzonder bedanken voor hun bijdrage:

Prof. dr. von Meyenfeldt, mijn promotor: Maarten, bedankt voor de kans om aan dit onderzoekstraject te beginnen. De mogelijkheden die hierdoor zijn ontstaan, zijn grotendeels aan jou te danken. Ondanks jouw drukke agenda heb je altijd tijd gemaakt voor overleg en om mijn stukken te lezen.

Prof. dr. van der Hulst, mijn tweede promotor en opleider: René, ook jou wil ik persoonlijk bedanken dat je me gesteund hebt tijdens dit promotietraject. Ook ben ik ontzettend dankbaar dat je me hebt aangenomen als agnio en vervolgens als opleidingsassistent in 2013, hierdoor heb ik de kans gekregen om te laten zien dat mijn hart bij de Plastische Chirurgie ligt.

Dr. Heuts, mijn co-promotor: Esther ook zonder jou zou dit niet mogelijk zijn geweest. Ik heb altijd mijn verhaal bij jou kwijt gekund, bedankt voor jouw steun op wetenschappelijk en persoonlijk gebied.

Dr. Voogd, mijn tweede co- promotor: Adri, je kritische blik op alle aan geleverde stukken heb ik ontzettend gewaardeerd. Ik vond het ontzettend fijn om met je samen te werken.

Prof. dr. Smeets, bedankt voor het aanvaarden van de rol van voorzitter van de beoordelingscommissie van mijn proefschrift. Naast de voorzitter wil ik ook de andere leden van de beoordelingscommissie bedanken: prof dr. Roukema, prof. dr. Tjan-Heijnen, prof. dr. Ulrich en dr. Veraart, bedankt voor het kritisch lezen en becommentariëren van het proefschrift. 
Jules, ook veel dank aan jou. Jij hebt de voorwerk op dit gebied gedaan, waardoor ik tijdens mijn semi-arts stage het stokje van je kon overnemen. We hebben nog gelachen tijdens het congres-tripje in Barcelona! Veel succes met je carrière in de Radiologie.

Een woord van dank aan de studenten die mij geholpen hebben met de metingen en met het denkproces tijdens dit promotie traject: Charlot, Nicole, Jolanda, Bente, Renee en Jop, hartstikke bedankt!

Graag wil ik ook het secretariaat Plastische Chirurgie en Heelkunde, in het bijzonder Sabeth, bedanken.

Omdat promoveren meer is dan het bedrijven van wetenschappelijk onderzoek, en ook bestaat uit vele koffiepauzes, je op vrijdag middag om 17:00 uur (okay soms zelfs om 16:00 uur als het allemaal een beetje tegen zit) als eerste melden in de kroeg en gezellige lab/onderzoeks- uitjes, wil ik een aantal collega's die een bijdrage hebben geleverd aan wat soms aanvoelde als een verlenging van mijn studenten tijd specifiek bedanken:

Mijn roomies van 5.580: Mechteld, de originele roomie. Je hebt je werkethos mee genomen uit Baltimore, je bent zeker een bron van inspiratie geweest gedurende de tijd dat we een werkruimte gedeeld hebben. In de jaren die volgden zijn we vriendinnen en zelfs gym-buddies geworden. Op naar meerdere gezellige avonden bij Cafe Sjiek $\odot$. Givan, hoe jij het hebt kunnen volhouden tussen ons meiden vraag ik me nog steeds af. Heel veel succes in regio Amsterdam, ze boffen om jou als collega te hebben. Kim $\vee$ W, de sportieveling tussen ons. Ik heb de eer gehad naast jouw te staan als paranimf tijdens de verdediging van jou proefschrift. Lori, bedankt dat je mijn paranimf wilde zijn! Ik vond het fijn om met jou samen te werken. We moeten maar snel een mammacongres uitzoeken om samen heen te gaan! En niet te vergeten, de regelmatige binnenvaller van de MDL en later mede-Spartan, Mark $\vee A$.

De collega's van uns 50: Edgar, Irene-Fleur, Robert-Jan, Rutger, de "vaatboys": Rob, Mark, Yee-Lai en Fabio. In het verre Oxford gebouw: Freek. Collega's van het lab: Liliane, Kim v M, Nina, Kostan, Bas, Mo, Kaatje, Dirk, Inca en Charlotte (later nog collega bij de chirurgie in Venlo en carpool-buddy). Simon, oftewel mijn "geweten" tijdens de laatste loodjes van het afronden van mijn proefschrift. Ik heb een goede vriend overgehouden aan onze tijd als collega's! 
Ook wil ik al mijn collega's van de Heelkunde en Plastische Chirurgie in het VieCuri en MUMC+ bedanken.

Mijn vrienden die ieder op hun eigen manier mij hebben gesteund gedurende dit traject:

The Maastricht's Toughest Crew; wat heb ik een leuke tijd met jullie gehad. Herinneringen, sommige trauma's - London, 4 graden, zeiknat en onderkoeld- , die ik nooit zal vergeten. In de modder ben ik vaak genoeg mezelf tegen gekomen en verbaasd hoeveel het menselijk lichaam eigenlijk kan hebben.

Melanie en Marcel jullie hebben mij het thuisgevoel oftewel het eiland gevoel gegeven in Maastricht. Daarvoor zal ik jullie altijd dankbaar zijn.

Mijn vrienden uit St. Maarten. Hoewel we elkaar sporadisch zien en spreken, de vriendschappen die wij hebben zijn voor het leven.

Patricia, mijn "partner in crime" en beste vriendin, $15+$ jaar heb ik op jou kunnen steunen en vertrouwen gedurende de mooie en minder leuke momenten in het leven. Vanaf ons $12^{\mathrm{e}}$ in de tuin vals-zingend " if you like piña coladas...." naar vandaag, sta je weer naast me, als mijn paranimf. Ik ben ontzettend trots op jou en bewonder jouw positieve kijk op het leven.

Tot slot, Pa, Ma, Ivar en David, mijn allergrootste "support system". Ik zal nooit de juiste woorden op papier kunnen samen stellen om jullie te bedanken. Zonder jullie onvoorwaardelijke steun zou dit niet mogelijk zijn geweest.

Het is eindelijk af! 


\section{About the author}

Tiara Rebecca Lopez Penha was born the youngest of three siblings on March $11^{\text {th }} 1986$ in St.Maarten, Netherlands Antilles. In June of 2004 she graduated from the Milton Peters College with a VWO diploma. Subsequently, she moved to the Netherlands to pursue her secondary education at the Maastricht University.

She received her medical degree at the Maastricht University in September 2010. During her final year at university she did a research internship on the subject of Breast Cancer-related lymphedema under the guidance of Prof.dr. M.F. von Meyenfeldt, of which would lay the basis for the current dissertation.

Tiara started her career in September 2010 at the Surgical department of the Maastricht UMC as a resident not in training and shortly thereafter (February 2011- January 2013) as a PhD-student.

In February 2013 she was employed as a resident not in training at the Plastic, Reconstructive and Hand Surgery department of the Maastricht UMC.

As of July 2013 she is a Plastic Surgery resident in training at the Maastricht UMC under the supervision of Prof.dr. R.R.W.J. van der Hulst. 
165 